\title{
III Diretrizes Brasileiras Sobre Dislipidemias e Diretriz de Prevenção da Aterosclerose do Departamento de Aterosclerose da Sociedade Brasileira de Cardiologia
}

Data final de elaboração da versão: 23 de agosto de 2001

Coordenador geral - RaulD. Santos

Comissãode Redação e de Divulgação

Sérgio D. Giannini (SP)

Raul D. Santos (SP)

Francisco H. Fonseca (SP)

EmílioH.Moriguchi(RS)

Coordenadores

I-Metabolismolipídico

Raul C. Maranhão (SP)

II - Aterogênese

Protásio Lemos da Luz (SP)

III-Determinações laboratoriais José Carlos Lima (BA)

IV - Classificação das dislipidemias Wilson Salgado Filho (SP)

V -Lípides e aterosclerose: aspectos epidemiológicos, clínicos e preventivos Álvaro Avezum(SP) e Bruce Duncan (RS)

VI-Estratificação de risco e metas lipídicas para a prevenção da aterosclerose Andréia A. Loures-Vale (MG)

VII-Mudançadoestilode vida

José Ernesto dos Santos (SP)

VIII-Tratamentomedicamentoso das dislipidemias MarceloC. Bertolami (SP)

IX - Dislipidemias em grupos especiais André A. Faludi (SP)

X-Genética e dislipidemias

Francisco H. Fonseca (SP) 


\title{
Participantes
}

Abel Pereira (SP), Abrahão Afiúne Neto (GO), Agnaldo David de Souza (BA), Alváro Avezum (SP), André A. Faludi (SP), Andrei C. Spósito (SP), Andréia A. Loures-Vale (MG), Ana Maria Lottenberg (SP), Antonio Carlos P. Chagas (SP), Antônio de Pádua Mansur (SP), Armênio Guimarães (BA), Bruce Duncan (RS), Bruno Caramelli (SP), Cleonice Carvalho Coelho Mota (MG), Carisi Polanczyk (RS), Carlos Scherr (RJ), Dikran Armaganijan (SP), Dante M. Giorgi (SP), Éder Quintão(SP), Edgar P. de Mello (PE), Edna Nakandakare (SP), Egle Oppi (SP), Eliane Cotta de Faria (SP), Eloisa Janovich (SP), Emílio Moriguchi (RS), Francisco H. Fonseca (SP), Geraldo Picheth (PR), Giuseppe Dioguardi (SP), Guido Rosito (RS), Hermes Toros Xavier (SP), Ieda L. Lopes (SP), Ivana da Cruz (RS), Jaqueline S. Issa (SP), Jayme Diament (SP), José Antônio F. Ramires (SP), José Carlos Basques (MG), José Carlos Lima (BA), José Carlos Nicolau
(SP), José Eduardo Krieger (SP), José Ernesto dos Santos (SP), José Jayme Galvão (SP), José Mendes Aldrighi (SP), José Paulo Novazzi (SP), Leonor Pinto de Almeida (SP), Liliana Paula Bricarello(SP), Lísia Rabelo(BA), Luciana Uint (SP), Luiz Antônio Machado César (SP), Luis Carlos Bodanese (RS), Luiz Introcaso(DF), Maria Cristina Izar(SP), Maria Eliane C. Magalhães (RJ), Maria Helena Catelli(MG), Mariléia Scartezini (PR), Marcelo C. Bertolami (SP), Marcus V.B. Malachias (MG), Michel Batlouni (SP), Nabil Ghorayeb (SP), Nadine Clausell (RS), Neusa A. Forti (SP), Olavo Garcia F. Silva (PR), Otávio C. E. Gebara (SP), Otávio R. Coelho(SP), Protásio Lemos da Luz (SP), RaulC. Maranhão (SP), RaulD. Santos (SP), Ricardo Stein (SC), Rosana Perim Costa (SP), Sérgio D. Giannini (SP), Sérgio Kaiser (RJ), Sílvia Ihara (SP), Tania Martinez (SP), Thales de Carvalho (SC), Wilson Salgado Filho (SP).

Fontes de Financiamento: Laboratórios Bayer, Biolab, Merck, Sharpe \& Dohme, Novartis, Pfizer, Sankyo Pharma e Sanofi.

\begin{abstract}
Participaram da elaboração deste documento representantes das seguintes sociedades brasileiras: Cardiologia, Análises Clínicas, Patologia Clínica (Medicina Laboratorial),

Endocrinologia, Pediatria, Hipertensão, Nutrologia, Geriatria e Gerontologia, Nefrologia e Ginecologia e Obstetrícia.
\end{abstract}

Descrição do Método de Coleta de Evidências: Levantamento bibliográfico no MEDLINEe INDEX MEDICUS Latino Americano, Consulta às Diretrizes Européias 1998 e Americanas 2001 e a Documentos de Consenso sobre Excesso de Peso e Tabagismo. 


\section{Prefácio}

A doença aterosclerótica é a principal causa de mortalidade no Brasil. Essa doença é multifatorial e a sua prevenção passa pela identificação e controle, não só das dislipidemias, mas do conjunto dos fatores de risco. Este documento é uma evolução do II Consenso Brasileiro de Dislipidemias, pois, além de versar sobre o controle dos lípides, abrange uma avaliação global do risco do indivíduo desenvolver aterosclerose, assim como do tratamento do tabagismo, do exercício físico e do uso de fármacos adjuvantes para a prevenção das manifestações clínicas da aterosclerose. Além disso, foi feita uma extensa revisão sobre os novos marcadores de risco coronariano orientando à luz da literatura vigente no segundo semestre de 2001, a utilização ou não desses testes. Este documento contém também um capítulo sobre como interpretar estudos clínicos, apresenta o resumo dos principais estudos sobre o controle do colesterol e prevenção da aterosclerose e sua custo-eficácia.

A elaboração do documento passou por três fases durante nove meses de trabalho: uma reunião com os participantes, divisão de grupos de trabalho sob supervisão de coordenadores de grupo, entrega dos trabalhos pelos coordenadores, reavaliação com os mesmos e finalmente avaliação da comissão de redação. Publicaremos três versões do documento: uma resumida, uma extensa e um livro sobre prevenção de aterosclerose. A diretriz passará por atualização constante e documentos acessórios poderão ser divulgados a critério da comissão de redação.

Gostaria de agradecer o empenho de todos na elaboração da diretriz e contar com os colegas na fase principal do trabalho que será a implementação das diretrizes na prática clínica.

RaulD. Santos

Vice Presidente do Departamento de Aterosclerose da SBC 2000-2001

Coordenador das III Diretrizes Brasileiras Sobre Dislipidemias - Diretriz de Prevenção da Aterosclerose 


\section{Resumo das III Diretrizes Brasileiras sobre Dislipidemias e Diretriz de Prevenção da Aterosclerose do Departamento de Aterosclerose da Sociedade Brasileira de Cardiologia}

As recomendações deste documento seguem os seguintes critérios de evidência adotados pela Sociedade Brasileira de Cardiologia:

\section{Graus de Recomendações}

A) Conclusiva e/ou unanimemente recomendado (sempre usar): conduta terapêutica conclusivamente útil e segura; eficácia e segurança comprovadas (quase sempre se requer níveis de evidência excelentes 1 ou 2).

B) Recomendado como aceitável, mas com ressalvas (deve-se geralmente indicar): conduta aceitável e segura, grande potencial de utilidade, mas ainda sem comprovação conclusiva (evidência menos sólida).

C) Recomendação indefinida (é inteiramente a critério individual, usar ou não): conduta para a qual não há evidência segura, nem favorável, nem desfavorável, quanto à eficácia e segurança (pode ser conduta terapêutica tradicionalmente utilizada, sem comprovação científica).

D) Conduta terapêutica não recomendada, embora possa, em alguns contextos de excepcionalidade ser adotada (opção muito fraca, geralmente não indicar): evidência minimamente sugestiva de eficácia e segurança, embora se divise algum potencial de utilidade em algumas circunstâncias.

E) Conclusiva e/ou unanimemente não-recomendado (nunca usar): (Comissão de Cardiologia Baseada em Evidências da Sociedade Brasileira de Cardiologia e Associação Médica Brasileira-no prelo).

\section{Níveis de Evidência}

Nível 1 - Evidência baseada em múltiplos estudos randomizados, controlados, amplos, concordantes e com poder estatístico adequado; preferencialmente com revisão sistemática conclusiva.

Nível 2 - Evidência baseada em poucos estudos randomizados, controlados, concordantes, de médio porte ou metanálise de vários estudos dessa natureza, pequenos (equivalendo a estudo de moderado porte).

Nível 3 - $\geq 1$ estudo randomizado, controlado, de ótima qualidade.

Nível 4 - $\geq 1$ estudo de coorte de alta qualidade

Nível 5 - $\geq 1$ estudo de caso-controle de alta qualidade

Nível 6 - $\geq 1$ série de casos de alta qualidade - inclui registros.

Nível 7 - Evidência apenas baseada em: extrapolações de resultados coletados para outros propósitos (testar outras hipóteses); conjecturas racionais, experimentos com animais, ou baseados em modelos mecanísticos de fisiopatologia; conduta antiga, adotada em prática comum; opiniões sem referência a estudos anteriores.

(Comissão de Cardiologia Baseada em Evidências da Sociedade Brasileira de Cardiologia e Associação Médica Brasileira-no prelo).

Nota: as recomendações emitidas neste documento de forma geral refletem as evidências de efetividade das intervenções. Portanto, não incorpora, de forma sistemática, análises de custo-efetividade. Desta forma, este documento não deve ser encarado como um guia global absoluto para serviços preventivos em nível de saúde pública.

\section{I - Classificação das dislipidemias}

\section{A) Classificação laboratorial:}

Hipercolesterolemia isolada (aumento do colesterol total-CT e ou LDL-colesterol LDL-C)

Hipertrigliceridemia isolada (aumento dos triglicérides-TG)

Hiperlipidemia mista (aumento do CTe dos TG)

Diminuição isolada do HDL-colesterol (HDL-C) ou associada a aumento dos TG ou LDL-C.

\begin{tabular}{|lll|}
\hline \multicolumn{2}{|c|}{$\begin{array}{c}\text { Valores de referencia dos lípides para indivíduos } \\
\text { idade }\end{array}$} & $\mathbf{2 0}$ anos de \\
\hline Lípides & Valores & Categoria \\
\hline CT & $<200$ & \\
& $200-239$ & Ótimo \\
& $\geq 240$ & Limítrofe \\
& $<100$ & Alto \\
LDL-C & $100-129$ & Ótimo \\
& $130-159$ & Desejável \\
& $160-189$ & Limítrofe \\
& $\geq 190$ & Alto \\
& $<40$ & Muito alto \\
HDL-C & $>60$ & \\
& $<150$ & Baixo \\
TG & $150-200$ & Alto \\
& $200-499$ & Ótimo \\
& $\geq 500$ & Limítrofe \\
& & Alto \\
& & Muito alto \\
\hline
\end{tabular}




\section{B) Classificação etiológica}

Dislipidemias primárias - origem genética

Dislipidemias secundárias - Causadas por outras doenças ou uso de medicamentos: hipotireoidismo, diabetes melito (DM), síndrome nefrótica, insuficiênciarenal crônica, obesidade, alcoolismo, icterícia obstrutiva, uso de doses altas de diuréticos, betabloqueadores, corticosteróides, anabolizantes.

\section{II - Avaliação laboratorial das dislipidemias}

Operfillipídicoédefinidopelas determinaçõesdoCT,HDLC, TGe, quandopossível, doLDL-C* apósjejum de 12ha $14 \mathrm{~h}$.

* Fórmula de Friedewald:LDL-C =CT-HDL-C-TG/5 (válida se TG <400mg/dL).

O perfil lipídico deverá ser realizado em indivíduos com um estado metabólico estável, dieta habitual e peso devem ser mantidos por pelo menos duas semanas antes da realização do exame. Levar em consideração que após qualquer doença ou cirurgia em geral, o perfil lipídico do paciente poderá estar temporariamente comprometido. Recomenda-se, portanto, aguardar pelo menos oito semanas para a determinação dos lípides sangüíneos. Nenhuma atividade física vigorosa deve ser realizada nas $24 \mathrm{~h}$ que antecedem o exame.

Realizar as dosagens seriadas sempre que possível no mesmo laboratório para tentar minimizar o efeito da variabilidade analítica. Evitar a ingesta de álcool nas $72 \mathrm{~h}$ que antecederem a coleta do sangue.

Grau de recomendação: $B$. Nível de evidência: 4.

\section{Dosagem da homocisteína, $\operatorname{Lp}(\mathrm{a})$ e fatores he- mostáticos}

Nãoé recomendada a determinação rotienira da homocisteína, Lp(a), fibrinogênio e outros fatores hemostáticos.

Grau de recomendação: $C$. Nível de evidência: 3.

\section{Proteína C reativa dealtasensibilidade(PCR-as)}

\section{Recomendação}

A proteína C reativa de alta sensibilidade (PCR-as) poderá ser determinada no auxílio da estratificação do risco de aterosclerose clínica. Indivíduos acima do 3o percentil de distribuição encontram-se sob risco relativo maior de eventos do que os nos percentis 1 e 2 . Nesses indivíduos deve ser considerada mudança agressiva do estilo de vida e controle dos fatores de risco presentes.

Grau de recomendação: $B$. Nível de evidência: 2.

\section{III - Estratificação de risco e metas lipídicas de tratamento para a aterosclerose}

\section{Estratificação de risco}

O LDL-C é fator causal e independente de ateroscle- rose sobre o qual devemos agir para diminuir a morbi-mortalidade A prevenção deve ser baseada no risco absoluto de eventos coronarianos. Todos os indivíduos devem ser submetidos à mudança do estilo de vida (MEV) - dieta, exercício, abstenção do fumo, perda de peso.

Fatores de risco para aterosclerose que modificam as metas de LDL-C:

Fumo

Hipertensão arterial sistêmica (PA $\geq 140 / 90 \mathrm{mmHg}$ )

HDL-C* $<40 \mathrm{mg} / \mathrm{dL}$

Diabetes melito (diabéticos são considerados como portadores de aterosclerose)

Idade ( $\geq 45$ anos para homens e $\geq 55$ anos para mulheres)

História familiar precoce de aterosclerose (parentes de primeiro grau $<55$ anos para homens e $<65$ anos para mulheres)

*HDL-C >60mg/dL são considerados um fator protetor devendo ser descontado um fator de risco da soma.

A) Baixo risco: Risco absoluto de eventos < que $10 \%$ em 10 anos. Indivíduos com 1 FR (excetuando DM) além do colesterol (LDL-C >160mg/dL). Não é necessário o uso de escores de risco.

Recomendação: Meta LDL-C <130mg/dL, entretanto, tolera-se LDL-C até $160 \mathrm{mg} / \mathrm{dL}$.

Perfil desejado: $C T<200 \mathrm{mg} / \mathrm{dL}, \mathrm{HDL}-\mathrm{C}>40 \mathrm{mg} / \mathrm{dLe}$ $T G<150 \mathrm{mg} / \mathrm{dL}$.

Grau de recomendação: B. Nível de evidência: 2.

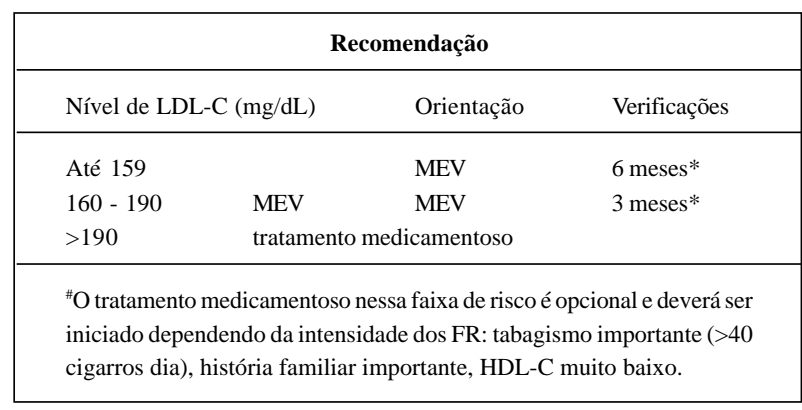

B) Médio risco: risco de evento $>10 \%$ porém menor do que $20 \%$ em 10 anos.

Indivíduos com 2 FR (excetuando DM) além do colesterol ( $L D L-C>160 m g / d L)$.

Recomendação: Meta LDL < 130mg/dL

Grau de recomendação para o $L D L-C: A$.

Nivel de evidência: 1.

Perfil desejado: $C T<200 \mathrm{mg} / \mathrm{dL}, \mathrm{HDL}-\mathrm{C}>40 \mathrm{mg} / \mathrm{dL}$ $e T G<150 \mathrm{mg} / \mathrm{dL}$.

Grau de recomendação para os TG e HDL-C: B.

Nível de evidência: 2.

O cálculo do risco absoluto de eventos poderá ser fei- 


\begin{tabular}{|lll|}
\hline \multicolumn{3}{|c|}{ Recomendação } \\
\hline Nível de LDL-C (mg/dL) & Orientação & verificações \\
\hline $\begin{array}{l}\text { Até } 160 \\
>160\end{array}$ & $\begin{array}{l}\text { MEV } \\
\text { tratamento medicamentoso }\end{array}$ \\
\hline
\end{tabular}

to pelo uso do escore de risco de Framingham (ERF) que avalia o risco de eventos coronarianos em 10 anos.

C) Alto risco: risco de evento $\geq 20 \%$ em 10 anos ou $>20 \%$ extrapolando-se a idade para os 60 anos de vida.

Indivíduos com > de $2 \mathrm{FR}$ (excetuando DM) além do colesterol (LDL-C $>160 \mathrm{mg} / \mathrm{dL}$ ), principalmente homens com idade acima dos 55 anos e outros FR associados, diabéticos e portadores de doença aterosclerótica coronariana ou não (aneurisma de aorta, insuficiência vascular periférica ou doença cerebrovascular sintomática). Portadores de síndromes genéticas, como a hipercolesterolemia familiare a hiperlipidemia familiar combinada, também se encontram nesse grupo. O cálculo do risco absoluto de eventos poderá ser feito pelo uso do escore de risco de Framingham. OERF dá uma idéia do risco de eventos coronarianos em diabéticos, entretanto, não é recomendado para se estabelecer a meta lipídica, já que a mesma nesses indivíduos é LDL-C $<100 \mathrm{mg} /$ dL. Da mesma forma, o ERF nãoé indicado para os indivíduos portadores de manifestações clínicas da aterosclerose ou dislipidemias de origem genética.

\section{Recomendação: prevenção primária de alto riscoe}

prevenção secundária - meta: $\mathrm{LDL}<100 \mathrm{mg} / \mathrm{dl}$

Grau de recomendação para o LDL-C: $A$.

Nível de evidência: 1.

Perfil desejado: $C T<200 \mathrm{mg} / \mathrm{dL}, \mathrm{HDL}-\mathrm{C}>40 \mathrm{mg} / \mathrm{dL}$ (HDL-C $>45 \mathrm{mg} / \mathrm{dL}$ em diabéticos) e $T G<150 \mathrm{mg} / \mathrm{dL}$.

Recomendação para o CT: A. Nível de evidência: 2 . Grau de recomendação para o HDL-C e TG: B. Nível de evidência: 2.

\begin{tabular}{|c|c|c|}
\hline \multicolumn{3}{|c|}{ Recomendação } \\
\hline Nível de LDL-C (mg/dL) & Orientação & Verificações \\
\hline $100-129^{\#}$ & MEV & 3 meses \\
\hline tratame & \multicolumn{2}{|c|}{ tratamento medicamentoso imediato } \\
\hline \multicolumn{3}{|c|}{$\begin{array}{l}\text { "Recomendação: LDL-C entre } 100 \text { e } 129 \mathrm{mg} / \mathrm{dL} \text {, nesses casos, não é } \\
\text { obrigatório o início do tratamento medicamentoso imediato já nesses } \\
\text { níveis. Se após três meses as metas não forem atingidas, recomenda-se } \\
\text { iniciar o tratamento medicamentoso. }\end{array}$} \\
\hline
\end{tabular}

\section{Uso de escores de risco de Framingham como ferramenta de auxílio na estratificação do risco de eventos clínicos coronarianos}

O ERF calcula o risco absoluto de eventos coronaria- nos (morte, IAM e angina de peito) em 10 anos. São atribuídos pontos para idade, pressão arterial sistólica (PAS) e diastólica (PAD), CT, HDL-C, fumo (qualquer cigarro no últi-

\begin{tabular}{|ccc|}
\hline & Passo 1 & \\
\hline Idade & Homens & Mulheres \\
\hline $30-34$ & -1 & -9 \\
$35-39$ & 0 & -4 \\
$40-44$ & 1 & 0 \\
$45-49$ & 2 & 3 \\
$50-54$ & 3 & 6 \\
$55-59$ & 4 & 7 \\
$60-64$ & 5 & 8 \\
$65-69$ & 6 & 8 \\
$70-74$ & 7 & 8 \\
\hline
\end{tabular}

\begin{tabular}{|lcc|}
\hline & Passo 2 & \\
\hline Colesterol Total & Homens & Mulheres \\
\hline$<160$ & -3 & -2 \\
$160-199$ & 0 & 0 \\
$200-239$ & 1 & 1 \\
$240-279$ & 2 & 1 \\
$\geq 280$ & 3 & 3 \\
\hline
\end{tabular}

\begin{tabular}{|lcc|}
\hline & Passo 3 & \\
\hline HDL-C & Homens & Mulheres \\
\hline$<35$ & 2 & 5 \\
$35-44$ & 1 & 2 \\
$45-49$ & 0 & 1 \\
$50-59$ & 0 & 0 \\
$\geq 60$ & -1 & -3 \\
\hline
\end{tabular}

\begin{tabular}{|lccc|}
\hline \multicolumn{4}{|c|}{ Passo 4 } \\
\hline PAS & PAD & Homens & Mulheres \\
\hline$<120$ & $<80$ & 0 & -3 \\
$120-129$ & $80-84$ & 0 & 0 \\
$130-139$ & $85-89$ & 1 & 0 \\
$140-159$ & $90-99$ & 2 & 2 \\
$\geq 160$ & $\geq 100$ & 3 & 3 \\
\hline Quando os valores da PAS e PAD discordarem usar o mais alto. \\
\hline
\end{tabular}

\begin{tabular}{|lcc|}
\hline \multicolumn{1}{|c|}{ Passos 5 e 6 } \\
\hline Diabetes & Homens & Mulheres \\
\hline Sim & 2 & 4 \\
Não & 0 & 0 \\
Fumo & & 2 \\
Sim & 2 & 0 \\
Não & 0 & \\
\hline
\end{tabular}


Arq Bras Cardiol

volume 77, (suplemento III), 2001

\begin{tabular}{|c|}
\hline Passo 7 somar os pontos \\
\hline Idade + CT + HDL-C + PAS ou PAD + DM + Fumo $=$ total de pontos \\
\hline
\end{tabular}

\begin{tabular}{|llll|}
\hline \multicolumn{4}{c}{ Passo 8 veja o risco absoluto nas tabelas } \\
\hline Homens & Homens Risco de & Mulheres & Mulheres Risco de \\
Pontos & DAC em 10 anos \% & Pontos & DACem 10 anos \% \\
\hline$<-1$ & 2 & $\leq-2$ & 1 \\
0 & 3 & -1 & 2 \\
1 & 3 & 0 & 2 \\
2 & 4 & 1 & 2 \\
3 & 5 & 2 & 3 \\
4 & 7 & 3 & 3 \\
5 & 8 & 4 & 4 \\
6 & 10 & 5 & 4 \\
7 & 13 & 6 & 5 \\
8 & 16 & 7 & 6 \\
9 & 20 & 8 & 7 \\
10 & 25 & 9 & 8 \\
11 & 31 & 10 & 10 \\
12 & 37 & 11 & 11 \\
13 & 45 & 12 & 13 \\
$\geq 14$ & 53 & 13 & 15 \\
& & 15 & 20 \\
& & 16 & 24 \\
& & 17 & $\geq 27$ \\
\hline
\end{tabular}

mo mês) e presença ou não de DM. Após o cálculo dos pontos deve-se consultar a tabela anexa para ambos os sexos.

\section{Excesso de peso, obesidade e síndrome plurimetabólica}

O excesso de peso (índice de massa corpórea - IMC >$\left.25 \mathrm{~kg} / \mathrm{m}^{2}\right)$, principalmente acúmulo de gordura na região abdominal, está associado a um maior risco de doença aterosclerótica. A medida da circunferência da cintura permite-nos identificar portadores de obesidade androgênica. Risco muito aumentado: medida de cintura $>88 \mathrm{~cm}$ mulheres e $>102 \mathrm{~cm}$ nos homens.

\section{Recomendação:}

Nesses indivíduos, enfatizamos que a MEV que levem à perda de peso, tais como exercício, dieta e, em casos específicos, farmacoterapia é de extrema importância

Grau de recomendação: $B$. Nível de evidência: 2 .

\section{IV - Mudanças do estilo de vida (MEV)}

\section{A) Tratamento dietético}

Para a hipercolesterolemia recomenda-se dieta pobre em colesterol e gorduras saturadas. Para a hipertrigliceridemia, os que apresentam quilomicronemia, devem reduzir a ingestão de gordura total da dieta. Na hipertrigliceridemia secundária à obesidade ou diabetes, recomenda-se, respectivamente, dieta hipocalórica, restrição de carboidratos e
Diretrizes de Dislipidemias e Prevenção da Aterosclerose

compensação do DM. Abstenção do consumo de álcool é recomendada em todos os casos de dislipidemias.

Grau de recomendação: A. Nível de evidência: 2 .

\section{Antioxidantes eálcool}

Não se recomenda o uso destes alimentos para o tratamento das dislipidemias nem para a prevenção da aterosclerose.

Grau de recomendação: $D$.

Nível de evidência: 1 para suplementação com os antioxidantes e 4 para o álcool.

\section{B) Exercício físico}

Devem seradotadas, com frequiência de três a seis vezes por semana, sessões deemmédia, 40min de atividade físicaaeróbia. A zonaalvodoexercícioaeróbio deveficarnafaixade $60 \%$ a $80 \%$ da frequiência cardíaca máxima, observada em teste ergométrico, realizado na vigência dos medicamentos de uso corrente.

Grau de recomendação: B. Nível de evidência: 2 .

\section{C) Tabagismo}

O tabagismo deve ser combatido de forma agressiva. $\mathrm{O}$ tratamento do tabagismo passa por duas etapas: abordagem cognitivo comportamental e farmacoterapia.

Grau de recomendação: A. Nível de evidência: 2.

\section{V - Tratamento medicamentoso das dislipi- demias}

\section{A) Vastatinas ou estatinas ou inibidores da HMG-CoA redutase}

São os medicamentos de escolha para se reduziroLDL$\mathrm{C}$ em adultos. Assim, para o tratamento adequado devem ser atingidas as metas de LDL-C propostas, utilizando-se as doses necessárias (lovastatina $20 \mathrm{mg}-80 \mathrm{mg}$, sinvastatina $10 \mathrm{mg}-80 \mathrm{mg}$, pravastatina $20 \mathrm{mg}-40 \mathrm{mg}$, fluvastatina $10 \mathrm{mg}$ $80 \mathrm{mg}$, atorvastatina $10 \mathrm{mg}-80 \mathrm{mg}$, cerivastatina $0,2 \mathrm{mg}-0,8 \mathrm{mg}$ retirada do mercado em agosto de 2001 para avaliação de segurança). Uma vez estabelecido o tratamento este deverá ser seguido por tempo indeterminado. As vastatinas devem ser suspensas caso haja aumento das aminotransferases $>3$ vezes os valores normais, ou se houver dor muscular ou aumento da creatinoquinase $>10$ vezes o valor normal.

Grau de recomendação: A. Nível de evidência: 1 .

\section{B) Resinas de troca}

A colestiramina nas doses $16 \mathrm{~g}-24 \mathrm{~g} /$ dia reduz o LDL-C (15\%-30\%) e o risco de eventos coronarianos. É fármaco de escolha em crianças e como adjuvante às vastatinas. Não deve ser usada na hipertrigliceridemia.

Grau de recomendação: $A$. Nível de evidência: 2 . 


\section{C) Fibratos}

São indicados no tratamento da hipertrigliceridemia endógena quando houver falha das MEV ou quando esta for muito elevada $(>500 \mathrm{mg} / \mathrm{dL}$ ). Doses dos fibratos (genfibrosila $600 \mathrm{mg}-1200 \mathrm{mg}$, bezafibrato $600 \mathrm{mg} / \mathrm{dia}$ e $400 \mathrm{mg}$ da forma de subtração lenta, etofibrato $500 \mathrm{mg} / \mathrm{dia}$, fenofibrato micronisado- $200 \mathrm{mg} / \mathrm{dia}$, fenofibrato $250 \mathrm{mg} / \mathrm{dia}$, ciprofibrato $100 \mathrm{mg} / \mathrm{dia}$ ). Têm papel na prevenção da aterosclerose clínica em indivíduos com as características dos estudos de Helsinki e VA-HIT.

Grau de Recomendação: A. Nível de evidência: 2.

\section{D) Ácido nicotínico}

$\mathrm{Na}$ forma tradicional, utiliza-se a dose de $2 \mathrm{~g}$ a $6 \mathrm{~g} / \mathrm{dia}$ ajustadas conforme o efeito ou a tolerância. $\mathrm{O}$ acipimox dose $250 \mathrm{mg}$ até 3 vezes ao dia.

Grau de recomendação: $B$. Nível de evidência: 2.

\section{E) Ômega-3}

Os ômega-3 reduzem os TG. A dose mínima recomendada é de $4 \mathrm{~g} /$ dia.

Grau de recomendação: $B$. Nível de evidência: 2 .

\section{F) Ácido acetil salicílico (AAS)}

O AAS nas doses acima de 100mg/dia deve ser prescrito para indivíduos que se encontrem sob alto risco de eventos cardiovasculares sem contra-indicação. Indivíduos hipertensos devem ter a pressão controlada.

Grau de recomendação: A. Nível de evidência: 1 .

\section{G) Inibidores da enzima de conversão (IECA)}

Os IECA devem ser prescritos para indivíduos em prevenção secundária principalmente os que apresentem disfunção ventricular esquerda ou para diabéticos que apresentem algum outro FR associado ou nefropatia.

Grau de recomendação: $B$. Nível de evidência: 1 .

\section{H) Betabloqueadores (BB)}

Os $B B$ devem ser prescritos para indivíduos que sofreram IAM principalmente os que apresentam disfunção ventricular

Grau de recomendação: $A$. Nível de evidência: 1.

\section{VI - Dislipidemias em grupos especiais}

\section{A) Síndromes isquêmicas agudas (SIA)}

O perfil lipídico deverá ser determinado em todos os portadores de SIA preferencialmente nas primeiras $24 \mathrm{~h}$ após o evento. Após esse período o LDL-C diminui. As vastatinas estão indicadas para os indivíduos no IAM ou angina instável se o LDL-C $\geq 130 \mathrm{mg} / \mathrm{dL}$. Para os com LDL-C $100 \mathrm{mg} / \mathrm{dL}-129 \mathrm{mg} / \mathrm{dL}$ o uso fica a critério do médico e se LDL-C <100mg/dL não há indicação nesse momento. O LDL-C deverá ser reavaliado 2 meses após o evento agudo e seguidas as recomendações da prevenção secundária.

Grau de recomendação: $B$. Nível de evidência: 2 .

\section{B) Idosos ( $>70$ anos)}

Nessa faixa etária, deve ser dada especial atenção ao afastamento de causas secundárias de dislipidemias. $O s$ estudos de prevenção secundária com vastatinas mostram alta eficácia nessa faixa etária.

Grau de recomendação: $B$. Nível de evidência: 2.

\section{C) Mulheres no período climatérico pós-menopausal}

Embora os estrogênios melhorem o perfil lipídico não há indicação da terapia de reposição hormonal para a prevenção da aterosclerose.

Grau de recomendação C na prevenção primária.

Nível de evidência: 4.

Grau de recomendação D na prevenção secundária. Nível de evidência: 2.

\section{D) Mulheres 20-45 anos e homens 20-35 anos}

A MEV devem ser enfatizadas em adultos jovens com LDL $\geq 130$. Entretanto, deve se considerar terapia hipolipemiante para indivíduos com LDL-C entre 160mg/dL-189mg/ $\mathrm{dL}$, principalmente em fumantes. Aqueles com LDL-C $>190 \mathrm{mg} / \mathrm{dL}$ devem receber terapia hipolipemiante como os adultos mais velhos.

Grau de recomendação: $B$. Nível de evidência: 2 . 


\section{I - Metabolismo Lipídico}

\section{Aspectos gerais}

As espécies moleculares de lípides presentes no plasma, mais importantes do ponto de vista fisiológico e clínico, são os ácidos graxos, os triglicérides, referidos também como triacilgliceróis, os fosfolípides e o colesterol. Os ácidos graxos podem ser saturados (sem duplas ligações entre seus átomos de carbono), mono ou poliinsaturados com uma ou mais duplas ligações na sua cadeia. Nos animais, os resíduos de ácidos graxos predominantes são os que têm cadeia com 16 e com 18 átomos de carbono - o palmítico e o esteárico, que são saturados, o oléico e o linoléico, que são insaturados. Os triglicérides são a forma de armazenamento energético mais importante no organismo, constituindo depósitos no tecido adiposo e muscular. Os fosfolípides têm, entre outras, a função primordial de formar a bicamada que é a estrutura básica das membranas celulares. O colesterol é precursor dos hormônios esteróides, dos ácidos biliares, da vitamina $\mathrm{D}$, além de ter importantes funções nas membranas celulares, influenciando na sua fluidez e no estado de ativação de enzimas ligadas a membranas.

\section{Lipoproteínas, estrutura e função}

As lipoproteínas são responsáveis pelo transporte dos lípides no plasma e são compostas por lípides e proteínas, as chamadas apolipoproteínas (“apo"). As apolipoproteínas têm diversas funções no metabolismo das lipoproteínas como: montagem da partícula (apo B100 e B48), meio ligante a receptores de membrana que as captam para o interior da célula (apo B100 e E) ou co-fatores enzimáticos (apos CII, CIII e AI). Existem quatro grandes classes de lipoproteínas: as maiores e menos densas ricas em triglicérides, os quilomícrons, de origem intestinal, e as lipoproteínas de densidade muito baixa ou VLDL de origem hepática (tab. I). As lipoproteínas de densidade baixa, as LDL, e as lipoproteínas de densidade alta, as HDL são ricas em colesterol. Existe ainda uma quinta classe, as lipoproteínas de densi- dade intermediária, as IDL. Uma outra lipoproteína de interesse clínico é a lipoproteína (a) [Lp(a)].

Os quilomícrons são os responsáveis pelo transporte dos lípides da dieta (via exógena $)^{1}$. O transporte de lípides de origem hepática ocorre por meio da VLDL e LDL, que caracteristicamente contém apoB-100 (via endógena). Os triglicérides das VLDL, assim como os dos quilomícrons, são hidrolizados pela lipase de lipoproteína (referida mais comumente, em anglicismo, como lipase lipoprotéica) ${ }^{2}$. Os ácidos graxos são liberados para os tecidos e metabolizados. Os quilomícrons se transformam em remanescentes que são removidos pelo fígado por receptores específicos, sendo que o mais aparente é o receptor da $\mathrm{LDL}^{1}$. Uma parte das VLDL se transforma em LDL após a perda de componentes de superfície lipídicos e protéicos. As VLDL trocam triglicérides por ésteres de colesterol com as HDL e LDL por intermédio da proteína de transferência de colesterol esterificado (CETP) ${ }^{3}$. Tanto as VLDL como as LDL serão removidas no fígado por intermédio de ligação com receptores específicos ${ }^{4}$. Dentre eles, o receptor da LDL também denominado receptor B,Eé o mais importante. A expressão desses receptores é a principal responsável pelo nível de colesterol no sangue e depende da atividade da enzima HMG-CoA redutase (hidróxi-metil-glutaril CoA redutase) que é a enzima limitante da síntese do colesterol hepático ${ }^{5}$. As partículas de HDL ${ }^{6}$ são formadas no plasma e compartimento extravascular. A apo A-I e a apo AII representam o principal conteúdo protéico da HDL. O colesterol livre da HDL é esterificado pela ação da lecitina colesterol acil transferase (LCAT). A HDL carrega o colesterol até o fígado onde este será eliminado no chamado transporte reverso do colesterol.

\section{Subfrações de lipoproteínas}

As grandes classes de lipoproteínas - como as VLDL, as LDL e as HDL - não são compostas de partículas homogêneas. Apresentam subclasses distintas de partículas que diferem em tamanho, densidade e composição química. Tais

\begin{tabular}{|c|c|c|c|c|c|c|c|c|}
\hline \multirow[t]{2}{*}{ Lipoproteínas } & \multirow[t]{2}{*}{$\begin{array}{c}\text { Densidades } \\
(\mathrm{g} / \mathrm{dL})\end{array}$} & \multirow[t]{2}{*}{$\begin{array}{l}\text { Diâmetro } \\
\text { (A) }\end{array}$} & \multicolumn{5}{|c|}{$\begin{array}{c}\text { Composição } \\
(\%)\end{array}$} & \multirow[t]{2}{*}{ Apolipoproteínas } \\
\hline & & & $\mathrm{CE}$ & $\mathrm{CL}$ & TG & FL & PR & \\
\hline Quilomícrons & $<0,95$ & $800-5.000$ & 5 & 2 & 84 & 7 & 2 & B-48; E; C A-I; A-II; A-IV \\
\hline VLDL & $<1,006$ & $300-800$ & 12 & 7 & 55 & 18 & 8 & B-100; E; C \\
\hline IDL & $1,006-1,019$ & $250-350$ & 23 & 8 & 32 & 21 & 16 & B-100; E; C \\
\hline LDL & $1,019-1,063$ & $180-280$ & 38 & 10 & 9 & 22 & 21 & B-100 \\
\hline HDL2 & $1,063-1,125$ & $90-120$ & 16 & 6 & 4 & 30 & 44 & A-I; A-II \\
\hline HDL3 & $1,125-1,210$ & $50-90$ & 12 & 3 & 4 & 26 & 55 & A-I; A-II \\
\hline
\end{tabular}


subclasses podem ser separadas por técnicas de eletroforese, ultracentrifugação e outras.

No tocante às subclasses da LDL, os indivíduos podem ser categorizados de acordo com a uma predominância de partículas grandes, menos densas (fenótipo $\mathrm{A}$ ) ou pequenas, mais densas (fenótipo B ${ }^{7}$. O fenótipo B está associado a níveis de triglicérides plasmáticos elevados, concentrações reduzidas de HDL e maior risco de doença arterial coronária (DAC) quando comparado ao fenótipo A. Embora o fenótipo $B$ seja determinado geneticamente, sofre forte influência de sexo, idade e fatores ambientais, como obesidade abdominal, uso de contraceptivos orais e a concentração de gordura e carboidratos da dieta ${ }^{8}$. A redução dos níveis plasmáticos de colesterol e triglicérides por meio de dieta e hipolipemiantes orais pode modificar o perfil de subclasses de LDL promovendo aumento da concentração das partículas maiores e redução da concentração das menores.

A HDL também apresenta subclasses que diferem na concentração de apolipoproteínas e composição lipídica, assim como tamanho e carga, e podem exibir diferentes funções no metabolismo lipídico ${ }^{9}$.

\section{Lipoproteína (a) [Lp(a)]}

A Lp(a) é semelhante a LDL, mas contém uma glicoproteína adicional, denominada apolipoproteína (a) [apo (a)], acoplada à apo B por pontes de dissulfeto. Tal glicoproteína pertence à família do plasminogênio e atua como um inibidor competitivo do ativador do plasminogênio tecidual (t-PA) inibindo a geração da plasmina e a fibrinólise. Características que conferem à $\mathrm{Lp}$ (a) propriedades pró-aterogênicas. A concentração plasmática da Lp(a)é determinada pelo gene da apo(a) localizado no cromossomo 6. Nada menos que 34 isoformas de apo(a) foram descritas. O tamanho da cadeia peptídica da apo (a) é decorrente do número de kringles ou alças IV semelhantes ao plasminogênio determinados pelo gene.

Aparentemente, a Lp(a) não tem nenhuma função no transporte dce lipídeos. Portanto, sua ausência do plasma não acarreta transtornos metabólicos. Pelo contrário, diversos estudos, inclusive prospectivos têm demonstrado que a $L p(a)$ representa um fator de risco independente para aterosclerose coronariana e de artérias cerebrais nas raças branca e amarela. Na raça negra, a concentração plasmática dessa lipoproteína é elevada, sem que haja correlação com a aterosclerose ${ }^{10,11}$.

\section{Lipoproteínas modificadas}

As lipoproteínas podem ser modificadas in vivo, por oxidação, glicação, dessialização. Essas modificações parecem ser responsáveis pelo desencadeamento do processo aterogênico ${ }^{12,13}$.

\section{Bases fisiopatológicas das dislipidemias pri- márias}

O acúmulo de VLDL no compartimento plasmático resulta em hipertrigliceridemia, principalmente, podendo ocorrer também hiperlipidemia mista, ou seja, hipertrigliceri- demia associada a hipercolesterolemia. O aumento de VLDL pode ser devido a aumento da produção da lipoproteína pelo fígado ou diminuição da catabolização da VLDL, isto é, redução do processo de lipólise da lipoproteína, catalisado pela lipase da lipoproteína. Diminuição da síntese da lipase da lipoproteína ou mutações no gene da enzima, que resultam em diminuição da atividade da enzima, são causas de diminuição da lipólise. Podem ocorrer, no entanto, mutações no gene da apo CII, que estimula a ação da lipase da lipoproteína, o que também resulta em diminuição da lipólise, acúmulo de VLDLe hipertrigliceridemia ${ }^{14}$.

O acúmulo da LDL no compartimento plasmático resulta em hipercolesterolemia. Pode ocorrer por defeito no gene do receptor de LDL com conseqüente "déficit" na expressão ou função dos receptores de LDL, diminuindo o catabolismo da lipoproteína, especialmente pelo fígado. Até o momento, mais de 250 mutações do receptor de LDL foram detectadas em portadores de hipercolesterolemia familiar ${ }^{15}$. Mutação no gene, que codifica a apo B 100 pode levar a acoplamento deficiente da LDL ao receptor e hipercolesterolemia ${ }^{16}$. A maioria dos pacientes com hipercolesterolemia pertence ao grupo das hipercolesterolemia poligênicas. Nesse defeito metabólico, ocorre uma complexa interação entre múltiplos fatores genéticos e ambientais que determinam a concentração da LDL no plasma. Esses fatores estão ligados a responsividade à dieta, à regulação da síntese de colesterol e ácidos biliares, ao metabolismo intravascular de lipoproteínas ricas em apoB e à regulação da atividade do receptor de LDL. O alelo apoE4 pode contribuir para o aumento da colesterolemia ${ }^{17}$.

Outros mecanismos fisiopatológicos estão também envolvidos na gênese das dislipidemias, mas os acima descritos estão entre os mais ilustrativos para o entendimento dos defeitos envolvendo o metabolismo de lípides.

\section{II - Aterogênese}

Definição - Aterosclerose é um processo dinâmico, evolutivo, a partir de dano endotelial de origem multifatorial, com características de reparação tecidual.

Curso evolutivo - Os fatores de risco são capazes de lesar o endotélio vascular causando disfunção endotelial ${ }^{18}$. A partir do dano vascular, ocorre a expressão de moléculas de adesão que mediarão a entrada de monócitos em direção ao espaço intimal, que por sua vez englobarão lipoproteínas modificadas (predominantemente LDL oxidadas), originando as células espumosas. Diferentes mediadores inflamatórios são liberados no espaço intimal, perpetuando e ampliando o processo, levando finalmente à formação da placa aterosclerótica ${ }^{18}$. Esta é constituída por elementos celulares, componentes da matriz extracelular e núcleo lipídico. As placas podem ser divididas em estáveis ou instáveis. As primeiras caracterizam-se por predomínio de colágeno, organizado com capa fibrosa espessa, escassas células inflamatórias e núcleo lipídico menos proeminente. As últimas apresentam atividade inflamatória intensa, especialmente nos seus ângulos, com grande atividade proteolítica, 
núcleo lipídico proeminente e capa fibrótica tênue. Tem sido sugerido que a ruptura das placas parece relacionar-se com as suas características morfológicas e bioquímicas, e não com seu grau de estenose ${ }^{19}$. Ao longo da vida, pequenas rupturas/tromboses parecem ocorrer, determinando remodelação das placas, freqüentemente sem manifestações clínicas. Todavia, o grau de trombose sobreposta à placa rota determinará a magnitude do evento cardiovascular ${ }^{20}$.

Mais recentemente, opapel daadventícia vem sendo revisto na aterogênese, a partir de observações histopatológicas, demonstrando a presença de células inflamatórias e de agentes infecciosos que poderiam migrar para o espaço intimal ${ }^{21}$.

\section{III-Determinações Laboratoriais}

Este documento tem por objetivo discutir as limitações e dificuldades encontradas na dosagem e interpretação dos resultados do perfil lipídico ${ }^{22}$, composto pelas medições de colesterol total (CT), triglicérides (TG), HDL-colesterol (HDL-C) e, quando possível, o LDLcolesterol (LDL-C), e suas repercussões em nível de decisão clínica, fornecendo subsídios para que o clínico atue adequadamente.

* Fórmula de Friedewald: LDL-C =CT-HDL-C-TG/5 (válida se $\mathrm{TG}<400 \mathrm{mg} / \mathrm{dL}$ ).

\section{Variações nas dosagens dos lípides}

As variações muito grandes na dosagem do perfil lipídico limitam sua utilidade clínica' por isso devem ser conhecidas e controladas, na medida do possível.

Estas variações podem ser analíticas, quando relacionadas à metodologia e procedimentos utilizados pelos laboratórios, e pré-analíticas, quando relacionadas a fatores intrínsecos do indivíduo, estilo de vida, uso de medicações, doenças associadas, procedimentos de coleta e preparo da amostra.

Os fatores pré-analíticos, especialmente os de origem biológica, são os principais responsáveis pela variabilidade dos resultados e encontram-se nas tabelas II e III ${ }^{23,24}$.

\section{Variações analíticas}

O National Cholesterol Education Program (NCEP), por meio do Laboratory Standardization Panel (LSP), estabeleceu critérios e recomendações para adequar e orientar o desempenho dos laboratórios ${ }^{25-29}$ (tab. IV). Sua adoção garante que a contribuição do laboratório para a variação total na dosagem dos lípides seja a menor possível.

A variabilidade introduzida pela metodologia e procedimentos laboratoriais pode ser avaliada pelo coeficiente de variação analítico (CVa) e pelo viés. A somatória desses parâmetros, conforme estatística [(CVax 1.96*) + "viés" = erro total], caracteriza o erro total analítico para um intervalo de confiança de $95 \%$.

Vale referir aqui os métodos recomendados para cada dosagem e reforçar que, atualmente, já não se adotam algumas metodologias laboratoriais.

\section{Recomendações ${ }^{25-29}$ :}

- Não se recomenda o exame dos lípides totais, uma vez que existem métodos disponíveis para dosagens específicas de cada um dos principais componentes isoladamente.

a) A eletroforese de lipoproteínas (lipidograma) é uma metodologia semiquantitativa, portanto não é recomendada para a avaliação de risco de doença arterial coronariana (DAC). A indicação específica da eletroforese dá-se em casos especiais como diferenciar entre as hiperlipidemia do tipo IIb e tipo III (Fredrickson) e na constatação de ausência de lipoproteínas.

b) Recomenda-se também, não mais utilizar o termo lipidograma para se referir ao perfil lipídico.

c) Além de seguir estas recomendações é fundamental que o laboratório participe de programas de controle externo da qualidade.

d) Recomenda-se usar o termo perfil lipídico.

Grau de recomendação: B. Nível de evidência: 4.

\section{Variações biológicas}

Os coeficientes de variação biológica $(\mathrm{CVb})$ foram determinados a partir de estudos metanálise ${ }^{23,24}$ (tab. V). Essas variações são significativas e junto com a variação analítica compõem a variação total a que uma dosagem de lípides está sujeita, sendo responsáveis pela maior parte da variabilidade encontrada.

A expressiva variabilidade biológica dos TG permite que os resultados variem muito entre determinações sucessivas e deve ser levado em conta na interpretação desse ensaio.

Recomendações para minimizar as variações préanalíticas $^{25-29}$ :

A) O perfil lipídico deverá ser realizado em indivíduos com um estado metabólico estável.

B) A dieta habitual e o peso devem ser mantidos por pelo menos duas semanas antes da realização do exame.

C) Após infarto agudo do miocárdio (IAM) ou acidente vascular cerebral (AVC) a amostra do paciente deve ser obtida nas primeiras $24 \mathrm{~h}$ ou depois de decorridas pelo menos oito semanas.

D) É importante assinalar, no entanto, que os valores obtidos em amostras de sangue colhidas nas primeiras $24 \mathrm{~h}$ do evento isquêmico (IAM), os resultados correspondam efetivamente ao perfil lipídico do paciente. Entretanto nos demais dias da fase considerada aguda do episódio, os valores de lípides sangüíneos se mostram reduzidos, o que pode prejudicar a interpretação dos exames. Assim, se os valores alcançados já demonstrarem hiperlipidemia, significa que o paciente apresenta na verdade, uma hiperlipidemia acentuada. Se os valores forem os de referência, no entanto, pode a rigor, estar ocorrendo uma noção equivocada, já que os valores lipídicos estão normalmente reduzidos após as primei- 
Tabela II - Principais fontes de variação pré-analítica do perfil lipídico ${ }^{23-24}$

Variáveis fisiológicas

Idade

Sexo

Variabilidade

biológica

Gravidez

Estilo de vida

O efeito da idade nos resultados dos exames laboratoriais tem sido reconhecido pelo ponto que separa o intervalo de referência que distingue as populações pediátrica, adolescente, adulta e geriátrica.

Entre 15 e 55 anos de idade há um progressivo aumento dos níveis de CT e LDL-C, com níveis bastante baixos em mulheres pré-menopausa, talvez pelo efeito protetor dos estrógenos, quando comparados a homens da mesma idade.

Os componentes do perfil lipídico sofrem flutuações ao longo do tempo em resposta a vários estímulos. A magnitude dessas flutuações são próprias de cada indivíduo e caracterizam a variabilidade biológica intra-individual. As variações médias em indivíduos saudáveis, em termos de coeficiente de variação (CV\%) podem ser resumidas em: CT, HDL-C e LDL-C cerca de $10 \%$ e para os TG cerca de $25 \%$. Portanto, para os TG, variações muito expressivas entre duas determinações podem ser encontradas, considerando-se apenas a influência da variabilidade biológica. Durante a gravidez, sobretudo no $2^{\circ}$ e $3^{\circ}$ trimestres, existe um incremento do metabolismo havendo uma maior mobilização dos lipídios, deter minando com isto uma elevação dos níveis séricos das apolipoproteínas, TG e CT, sobretudo o LDL-C. Esses níveis voltam ao normal após a $10^{\mathrm{a}}$ semana do parto em mães que não amamentam no peito seus filhos.

Estilo de vida

A dieta e o exercício interferem nos resultados obtidos em vários exames laboratoriais. Os vegetarianos tendem a apresentar níveis de lípides e lipoproteínas menores do que os não vegetarianos. Dieta rica em gordura saturada, em geral, são lipogênicas e o efeito varia dependendo da quantidade de ingesta de ácidos graxos. Carboidratos complexos e ácidos graxos mono e poliinsaturados, quando substituem os ácidos graxos saturados, tendem a baixar os níveis de LDL-C. Uma dieta rica em óleo de peixe diminui os níveis de triglicérides e VLDL presumivelmente porque o óleo de peixe tem a habilidade para inibir a síntese dos triglicerídes da VLDL. O efeito da cafeína nos níveis lipídicos tem sido controverso, parece ser influenciado pelos métodos de fabricação do café. Os achados em um estudo duplo cego, confrontando um grupo que usa café contendo cafeína com outro que usa café descafeinado, por um período de seis semanas, mostram uma insignificante modificação nos níveis de triglicerides, colesterol e HDL-C, sugerindo que a cafeína não é a substância do café que eleva o nível de colesterol total.

O consumo de etanol, especialmente em sujeitos que usualmente não consomem álcool, aumentam os níveis de TG da fração VLDL. O uso moderado (<30g/dia) contribui para a elevação dos níveis de HDL-C, apolipoproteínas AI e AII. Quando exceder $80 \mathrm{~g} /$ dia, a síntese de VLDL é estimulada junto com ativação da lipase lipoprotéica. A lipase lipoprotéica irá hidrolizar os triglicerides da VLDL, resultando em níveis aparentemente normais de VLDL no plasma, apesar do aumento de síntese de VLDL.

O tabagismo é hábito de vida que, sem dúvida, tem maior impacto na saúde como um todo e, sobretudo, como interferente no perfil bioquímico e celular, como também reduz os níveis de HDL-C sérico que está relacionado com o número de cigarros fumados por dia. Coleta da Amostra

Duração de jejum $\mathrm{O}$ colesterol total pode ser determinado em pacientes recém alimentados, porém a lipemia, quando presente, pode interferir na metodologia de quantificação do colesterol. A padronização para a realização do perfil lipídico recomenda jejum de $12 \mathrm{~h}$ a $14 \mathrm{~h}$ prévio à coleta da amostra. Os valores de referência do NCEP, no qual se baseiam os documentos de consenso, foram obtidos com jejum de $12 \mathrm{~h}$.

Postura durante A mudança da posição deitada para a erecta ou sentada, pode resultar na troca da água corpórea do compartimento intravascular para o extravascular, resultando em alteração na diluição do sangue. Amostras sangüíneas obtidas em indivíduos que estiveram deitados durante 5 min e em seguida se sentaram podem apresentar $10 \%$ de redução no nível de colesterol total e $12 \%$ nos níveis de triglicérides. Portando é recomendável que a punção venosa seja realizada na posição sentada, devendo o paciente permanecer desta maneira em torno de $10 \mathrm{~min}$ a $15 \mathrm{~min}$ antes da realização da coleta.

Duração do
tempo do

torniquete

A utilização do torniquete, por baixar a pressão sistólica, mantém uma efetiva pressão de filtração dentro dos capilares, resultando na transferencia das pequenas moléculas e fluidos do espaço intravascular para o espaço intersticial. A sua permanência por mais de $1 \mathrm{~min}$ até 3 min pode resultar em hemoconcentração, causando elevação de macro moléculas que não são capazes de penetrar na parede dos capilares, como o aumento de 5\% no nível de colesterol sérico. Caso a duração deste torniquete seja superior a 5min, o aumento do nível do colesterol pode oscilar entre $10 \%$ a $15 \%$. Visando minimizar o "efeito torniquete", este deverá ser desfeito tão logo a agulha penetre na veia.

Efeito do

exercício

Anticoagulante

Atividades físicas como caminhadas, atividades extenuantes como a prática de esporte em academias e maratonas, podem afetar os resultados de vários exames. Em função da transferência de líquidos do volume intravascular para o intersticial, face à sudorese durante o exercícios, ocorre uma elevação dos níveis protéicos, contudo causando uma efeito benéfico a longo termo, pela redução dos níveis de LDL-C, Apo B, e elevação do HDL-C e Apo AI. Recomenda-se não praticar exercícios extenuantes na noite que precede à coleta, muito menos na manhã do dia em questão.

EDTA - pode ser utilizado para a medição do colesterol total e triglicérides

Nota 1 - Quando plasma-EDTA for utilizado, multiplicar o valor plasmático por 1,03 para se obter o valor equivalente aos níveis séricos.

Nota 2 - Os métodos para medição do HDL-C (precipitação e homogêneos) sofrem interferência do EDTA e este não pode ser usado.

Heparina - pode ser utilizado para a medição do Colesterol total e HDL-C.

Nota 1 - A heparina não é recomendada para a determinação dos Triglicérides por ativar a lipase das lipoproteínas in vitro (e também in vivo) alterando os níveis deste analito.

Outros anticoagulantes não devem ser utilizados. manipulação da Amostra

\footnotetext{
$\begin{array}{ll}\text { Estocagem e } & \text { O tempo e a temperatura de acondicionamento da amostra coletada bem como os passos da preparação do soro, plasma ou separação de células } \\ \text { manipulação da } & \text { usando técnicas de gradiente de densidade podem introduzir uma variável pré-analítica. }\end{array}$ O soro deve ser separado do contato com as células dentro de $3 \mathrm{~h}$ após a coleta.
}

ras $24 \mathrm{~h}$ do IAM. Nesse caso, recomenda-se repetir a dosagem dos lípides sangüíneos depois de dois meses.

E) Levar em consideração que após qualquer doença ou cirurgia em geral, o perfil lipídico do paciente poderá estar temporariamente comprometido. Recomenda-se, portanto, aguardar pelo menos oito semanas para a determinação dos lípides sangüíneos, pois antes desse período de carência, os resultados podem não refletir o perfil lipídico de base do paciente.
F) Durante a gestação e até o $3^{\circ}$ mês do puerpério, os valores lipídicos normalmente se mantêm aumentados. Desse modo, recomenda-se a dosagem dos lípides sangüíneos, de preferência, a partir de três meses após o parto.

G) Nenhuma atividade física vigorosa deve ser realizada nas $24 \mathrm{~h}$ que antecedem o exame.

H) Realizar jejum prévio de $12 \mathrm{~h}$ a $14 \mathrm{~h}$; se necessário pode-se ingerir água e medicamentos que não possam ser interrompidos. É importante que o médico valorize a solici- 
Tabela III - Interferências endogenas e variáveis relacionadas ${ }^{23-24}$

O efeito das doenças e das drogas e seus metabólitos em testes de laboratório é tão extenso que existem compêndios sobre o assunto, como Effects of Preanalytical Variables on Clinical Laboratory Tests, Donald S Young. MD PhD (American Association for Clinical Chemistry - 1997. Exemplo:

- Doença induzida

- Metabólica e endócrina - Hepática

- Doenças de acúmulo - Renal

- Agudas e transitórias - Outras

- Droga induzida

- Anti-hipertensivos

- Imunossupressivos

- Esteróides sexuais

A discussão das interferências endógenas não seria completa sem se discutir os interferentes mais comuns, como hemólise e turbidez devida à hiperlipidemia. Existem dados conflitantes na literatura científica sobre o efeito da hemólise relacionados não apenas nas diferenças entre os métodos, como também entre os equipamentos. A evidencia visual da hemólise só é percebida quando a concentração de hemoglobina excede $20 \mathrm{mg} / \mathrm{dl}$. Existem relatos de que a aparência de uma amostra com hemólise determinada pela lise de $0,1 \%$ das hemácias, é virtualmente idêntica a outra não hemolisada, podendo isto levar a erros pela não detecção visual do fato. O conhecimento dos efeitos que na fase pré-analítica podem vir a interferir num cem número de tópicos, podendo afetar de forma substancial o resultado de um exame laboratorial, tem se expandido de maneira significativa nos últimos anos. Devemos então, ter sempre em mente, que problemas ligados a interferências pré-analíticas, podem estar surgindo a todo o dia, em função de novos tipos de terapia e/ou metodologia.

\begin{tabular}{|lcccc|}
\hline \multicolumn{5}{|c|}{ Tabela IV - Recomendações para o desempenho e métodos } \\
segundo o NCEP
\end{tabular}

\begin{tabular}{|lcc|}
\hline \multicolumn{3}{|c|}{ Tabela V - Coeficiente de variação biológico médio e intervalo de } \\
variação ${ }^{23,24}$
\end{tabular}

tação do exame laboratorial, insistindo inclusive por escrito na necessidade do jejum de $12 \mathrm{~h}$ a $14 \mathrm{~h}$ para a determinação do perfil lipídico.

I) Realizar as dosagens seriadas sempre que possível no mesmo laboratório para tentar minimizar o efeito da variabilidade analítica.

J) Evitar a ingestão de álcool nas $72 \mathrm{~h}$ que antecederem a coleta do sangue. Quando isso não ocorrer, considerar as sabidas interferências das bebidas alcoólicas nos lípides sangüíneos, sobretudo em relação aos TG.

Grau de recomendação: B. Nivel de evidência: 4.

Chamamos a atenção para as situações em que o glice- rol livre está em maior concentração, superestimando os níveis de TG séricos: exercício recente, estresse emocional, doença hepática, diabetes mellitus, medicação intravenosa contendo glicerol, nutrição parenteral, hemodiálise, exercício recente.

Os fármacos mais importantes que interferem com a dosagem e com os níveis dos lípides encontram-se na tabela $\mathrm{VI}^{30,31}$.

$\mathrm{Na}$ vigência desses fatores, o clinico deverá avaliar com cautela o perfil lipídico. Uma alteração no quadro clínico ou medicamentoso poderá modificar substancialmente os níveis do perfil lipídico.

\section{Validação dos resultados}

Pacientes que apresentam níveis de lípides alterados em comparação aos considerados desejáveis para a idade devem ter seus ensaios confirmados pela repetição de nova amostra. A nova determinação deverá ser realizada com, no

\begin{tabular}{|ll|}
\hline \multicolumn{2}{|c|}{ Tabela VI - Principais fármacos e doenças que interferem nos } \\
níveis lipídicos ${ }^{\mathbf{3 0 , 3 1}}$
\end{tabular}


mínimo, uma semana de intervalo e dentro de, no máximo, dois meses da coleta da primeira amostra. Este procedimento visa reduzir a variabilidade entre os ensaios $(\mathrm{CVt})$.

Cooper e cols. ${ }^{31,32}$ propuseram a utilização da "variação relativa" (VR) para definir o número de amostras necessárias para validar o resultado. A VR é calculada a partir da diferença entre o maior e o menor valor obtido, dividida pela média de todos os valores. A VR é então comparada com os valores máximos propostos por esses autores (tab. VII), calculados a partir dos valores máximos permitidos pelo NCEP para o CVa e do CVb médio obtido por metanálise.

\section{Interferência do jejum no LDL-C estimado}

Quando o jejum preconizado de $12 \mathrm{~h}$ a 14 h não for observado, o resultado na dosagem do TG tenderá a ser superior. Essa superestimação no valor do TG acarreta em uma subestimação da fração do colesterol da LDL, obtido pela fórmula de Friedewald: $\mathbf{L D L}-\mathbf{C}=\mathbf{C T}-(\mathbf{H D L}-\mathbf{C}+\mathbf{T G} / \mathbf{5})$ (TG $<400 \mathrm{mg} / \mathrm{dL}$, ausência de quilomícrons e hiperlipoproteinemia tipo III de Fredrickson)

Neste caso, o colesterol da fração VLDL (estimado por TG/5) aumenta, proporcionando uma redução do LDL-C, estimado pela equação. Vale a pena lembrar que as situações em que o glicerol livre está em maior concentração superestimando o valor de TG, da mesma forma implicará em redução nos valores do LDL-C.

\section{Recomendação}

Quando os níveis de TG superarem os valores limítrofes para ouso da equação de Friedewald, recomenda-se queoLDLC seja quantificado por métodos específicos e disponíveis.

Grau de recomendação: $B$. Nível de evidência: 2.

Novosmarcadoreslaboratoriaisdoriscocardiovascular

Atualmente, novos marcadores de risco têm prenunciado sua eficiência na detecção e prevenção da aterosclerose. Estes vêm determinar aqueles casos onde pacientes, aparentemente sem risco, acabam por desenvolver placa de ateroma e posterior evento coronariano. A identificação de novos marcadores, que são intimamente relacionados à genética, ao metabolismo lipídico, aos fatores de coagulação e à inflamação e que, possivelmente, aumentam o risco da doença aterosclerótica, pode expandir nosso entendimento sobre os mecanismos fisiopatológicos desta doença e possi-

\begin{tabular}{|lcccc|}
\hline \multicolumn{5}{|c|}{ Tabela VII - Variação relativa máxima permitida conforme o } \\
número de amostras
\end{tabular}

bilitar o desenvolvimento de novas medidas preventivas ou terapêuticas. Os principais "novos" marcadores laboratoriais do risco de aterosclerose encontram-se na tabela VIII.

\section{Recomendação}

Ao considerar um novo marcador deve-se levar em conta:

1. Se estudos prospectivos demonstram uma relação do marcador com risco de eventos.

2. A padronização e validação do ensaio para dosagem do marcador-Custos.

3. Níveis plasmáticos estáveis na população ou ao longo dos anos.

4. Existência de terapia eficaz ao controle do marcador.

\section{Lipoproteína (a) - Lp(a)}

A Lp(a) tem sido associada à ocorrência de eventos cardiovasculares em caucasianos e em orientais ${ }^{10}$. Todavia, os numerosos polimorfismos dessa apoproteína e a metodologia ainda não suficientemente validada inviabilizam sua determinação rotineira ${ }^{11}$. Não há provas de que a redução dos níveis de Lp(a) diminuí o risco de aterosclerose.

\section{Recomendação}

A Lp(a) não deve ser determinada rotineiramente ${ }^{10}$.

Grau de recomendação: $C$. Nível de evidência: 3 .

\section{Homocisteína (HCY)}

Elevações deste aminoácido formado durante o metabolismo da metionina têm sido associadas à disfunção endotelial, trombose e maior gravidade da aterosclerose. Defeitos no metabolismo relacionados a remetilação ou formação de cisteína associam-se a diferentes prognósticos da aterosclerose e das possibilidades terapêuticas. Uma relação entre a concentração de homocisteína e risco cardiovascular tem sido demonstrada ${ }^{33}$. Entretanto, ainda não há consenso de que níveis elevados de HCY sejam fator de risco isolado para a aterosclerose.

\section{Recomendação ${ }^{33}$}

A HCY não deve ser determinada rotineiramente.

Grau de recomendação: $C$. Nível de evidência: 3.

\section{Fatores hemostáticos:}

O fibrinogênio e outras variáveis hemostáticas (antígeno do PA-1 e t-PA) têm sido associados ao risco cardiovascular $^{34,35}$.

\section{Recomendação ${ }^{34,35}$}

Devido a sua alta variabilidade biológica, falta de comprovação de valor aditivo aos marcadores convencionais como LDL-C e ausência de comprovação de que intervenções específicas diminuam o risco cardiovascular, não se recomenda a determinação rotineira do fibrinogênio. Até o presente momento não há estudos prospectivos dirigidos 


\begin{tabular}{|c|c|c|c|c|c|c|c|}
\hline Marcadores & Estudos & Risco-relativo & Dificuldades & Facilidades & Metodologia & $\begin{array}{l}\text { Valores de } \\
\text { referência rece }\end{array}$ & $\begin{array}{l}\text { Grau de } \\
\text { recomendação }\end{array}$ \\
\hline $\mathrm{Lp}(\mathrm{a})$ & $\begin{array}{l}\text { Suécia/ } \\
\text { Lipid Research Clinics } \\
\text { Framingham/PROCAM/4S }\end{array}$ & $1,6(1,4-1,8)$ & $\begin{array}{l}\text { CV muito alto } \\
\text { tamanho muito variável } \\
\text { dependentes de herança } \\
\text { genética }\end{array}$ & $\begin{array}{l}\text { Técnicas já padronizadas, } \\
\text { embora não validadas. } \\
\text { constante no indivíduo }\end{array}$ & Nefelometria & $>30 \mathrm{mg} / \mathrm{dl}$ & $\mathrm{C}$ \\
\hline \multicolumn{8}{|c|}{ Conclusão: Sua recomendação de rotina ainda não é preconizada } \\
\hline Homocisteína & $\begin{array}{l}\text { Physicians Health Study } \\
\text { Tromso Study/Framingham }\end{array}$ & $1,8(1,5-2,2)$ & $\begin{array}{l}\text { Metodologia com } \\
\text { custo muito alto. }\end{array}$ & $\begin{array}{l}\text { Técinicas padronizadas } \\
\text { Validadas? } \\
\text { Relação dose-resposta } \\
\text { entreníveis plasmáticos } \\
\text { e risco }\end{array}$ & $\begin{array}{l}\text { Cromatografia } \\
\text { líquida de alta } \\
\text { precisão. (HPLC) }\end{array}$ & $5-15 \mathrm{mmol} / 1$ & $\mathrm{C}$ \\
\hline \multicolumn{8}{|c|}{ Conclusão: Sua determinação laboratorial de rotina ainda não é recomendada. } \\
\hline Fibrinogênio & $\begin{array}{l}\text { Northwick Park Heart Study } \\
\text { PROCAM / Framingham }\end{array}$ & $2,3(1,9-2,7)$ & $\begin{array}{l}\text { Alta } \mathrm{CV} / \text { não valor } \\
\text { aditivo aos outros } \\
\text { marcadores. Influência } \\
\text { de outros fatores }\end{array}$ & $\begin{array}{l}\text { Técnica padronizada } \\
\text { Custos viáveis }\end{array}$ & $\begin{array}{l}\text { Metodo de } \\
\text { Claus }\end{array}$ & $150-400 \mathrm{mg} / \mathrm{dL}$ & $\mathrm{C}$ \\
\hline \multicolumn{8}{|c|}{ Conclusão: Sua determinação laboratorial de rotina não é recomendada, não há valor aditivo a outros marcadores. } \\
\hline & $\begin{array}{l}\text { Northwick Park Heart Study } \\
\text { Angina Pectoris Study Group }\end{array}$ & & $\begin{array}{l}\text { Importância apenas } \\
\text { marginal }\end{array}$ & Técnicas padronizadas & ELISA & $\begin{array}{l}\text { Variáveis dep. } \\
\text { dos Kits. }\end{array}$ & $\mathrm{C}$ \\
\hline \multicolumn{8}{|c|}{ Conclusão: Sua determinação laboratorial de rotina não é recomendada. } \\
\hline $\begin{array}{l}\text { PCR-Alta } \\
\text { sensibilidade }\end{array}$ & $\begin{array}{l}\text { CARE/Women's Health Study/ } \\
\text { Danesh J, Br Med J, 2000. } \\
\text { Ridker,PM/N.Eng.J.Med.,1997. }\end{array}$ & $1,9(1,5-2,3)$ & $\begin{array}{l}\text { Marcador de inflamação, } \\
\text { pode aumentar em outras } \\
\text { inflamações }\end{array}$ & $\begin{array}{l}\text { Técnica padronizada, } \\
\text { marcador independente. }\end{array}$ & Nefelometria & $0,1-1,1 \mathrm{mg} / \mathrm{L}$ & B \\
\hline
\end{tabular}

especificamente ao controle do antígeno do PA-1 e t-PA, e a sua determinação de rotina ainda não recomendada.

Grau de recomendação: C. Nível de evidência: 3.

\section{Proteína C reativa dealta sensibilidade(PCR-as)}

A PCR-as é um marcador do processo inflamatório em indivíduos sadios e tem uma estabilidade comparável ao CT. Todavia, sua determinação para estimativa do risco cardiovascular não se aplica a fumantes, portadores de osteoartrose, obesos, diabéticos, mulheres sob terapia de reposição hormonal, uso de antiinflamatórios ou na presença de infecções. A PCR-as tem sido consistentemente associada ao risco cardiovascular ${ }^{36}$ e sua determinação parece ser de utilidade na estratificação do risco de eventos coronários ${ }^{36,37}$. São considerados de alto risco indivíduos com valores acima do $3^{\circ}$ quintil de distribuição na população (tab. IX) ${ }^{37}$.

\section{Recomendação ${ }^{36,37}$}

A PCR-as poderá ser determinada no auxílio da estratificação do risco de aterosclerose clínica. Indivíduos acima do $3^{\circ}$ percentil de distribuição encontram-se sob risco rela-

Tabela IX - Valores dos percentis da proteína $\mathrm{C}$ reativa de alta sensisbilidade na população americana ${ }^{37}$

\begin{tabular}{|cc|}
\hline Quintil & PCR-as \\
\hline 1. & $0,1-0,7 \mathrm{mg} / \mathrm{L}$ \\
2. & $0,7-1,1 \mathrm{mg} / \mathrm{L}$ \\
3. & $1,2-1,9 \mathrm{mg} / \mathrm{L}$ \\
4. & $2,0-3,8 \mathrm{mg} / \mathrm{L}$ \\
5. & $3,9-15,0 \mathrm{mg} / \mathrm{L}$ \\
\hline
\end{tabular}

tivo maior de eventos do que os nos percentis $1 \mathrm{e} 2$. Nesses indivíduos deve ser considerada mudança agressiva do estilo de vida e controle dos fatores de risco presentes.

Grau de recomendação: B. Nivel de evidência: 2 .

\section{IV - Classificação das Dislipidemias}

\section{I - Classificação laboratorial \\ II - Classificação etiológica}

I-Classificação laboratorial ${ }^{22}$. É recomendável que a caracterização laboratorial das dislipidemias seja feita no indivíduo em dieta livre e sem medicação hipolipemiante há pelo menos quatro semanas. Compreende quatro tipos principais bem definidos:

-Hipercolesterolemia isolada-Elevação isolada do colesterol total (CT), em geral representada por aumento do LDL-colesterol (LDL-C).

-Hipertrigliceridemia isolada-Elevação isolada dos triglicérides (TG), em geral representada por aumento das VLDL, ou dos quilomícrons, ou de ambos.

- Hiperlipidemia mista - Valores aumentados do CTe dos TG.

-HDL-C baixo - Isolado ou em associação com aumento de LDL-C e/ou de TG.

Os valores de referência para o diagnóstico das dislipidemias em adultos $>20$ anos encontram-se na tabela $\mathrm{X}^{38}$ :

II - Classificação etiológica ${ }^{22}$ - Frente a concentrações anormais de lípides no sangue, o clínico precisa, antes de tudo, identificar a possível causa da dislipidemia. De acordo com sua etiologia, as dislipidemias são classificadas em primárias ou secundárias. 


\begin{tabular}{|lcc|}
\hline \multicolumn{2}{|c|}{$\begin{array}{c}\text { Tabela } \mathbf{X} \text { - Os valores de referência para o diagnóstico das } \\
\text { dislipidemias em adultos }>\mathbf{2 0} \text { anos }\end{array}$} \\
\hline Lípides & Valores & Categoria \\
\hline CT & $<200$ & \\
& $200-239$ & Ótimo \\
& $\geq 240$ & Limítrofe \\
& Alto \\
LDL-C & $<100$ & Ótimo \\
& $100-129$ & Desejável \\
& $130-159$ & Limítrofe \\
& $160-189$ & Alto \\
& $\geq 190$ & Muito alto \\
& $<40$ & Baixo \\
HDL-C & $>60$ & Alto \\
& $<150$ & Ótimo \\
TG & $150-200$ & Limítrofe \\
& $200-499$ & Alto \\
& $\geq 500$ & Muito alto \\
& & \\
& &
\end{tabular}

1) Dislipidemias primárias - São conseqüentes a causas genéticas, algumas só se manifestando em função da influência ambiental, devido à dieta inadequada e/ou ao sedentarismo. As dislipidemias primárias englobam as hiperlipidemias e hipolipidemias.

1.1 - Hiperlipidemias primárias (ou genéticas): serão discutidas no capítulo "Genética e Dislipidemias".

1.2 - Hipolipidemias primárias: podem ser devido à: diminuição de LDL-C: abetalipoproteinemia e hipobetalipoproteinemia; diminuição de HDL-C: hipoalfalipoproteinemia e deficiência familiar de apo A (doença de Tangier).

2) Dislipidemias secundárias ${ }^{22}$ - a identificação de uma possível causa secundária da dislipidemia vem se tornando mais comum pela maior experiência acumulada na investigação etiológica das alterações lipídicas. Também o crescimento da população idosa vem se associando à maior freqüência de dislipidemias secundárias, devido à elevada incidência de co-morbidades presentes nas faixas etárias mais avançadas. Basicamente encontramos três grupos de etiologias secundárias:

2.1 - Dislipidemias secundárias a doenças.

2.2 - Dislipidemias secundárias a medicamentos.

2.3 - Dislipidemias secundárias a hábitos de vida inadequados (dieta, tabagismo e etilismo).

\section{1- Dislipidemias secundárias a doenças (tab. XI):}

A) Diabetes melito tipo II - Tem sido proposto que as anormalidades lipídicas em portadores de DM tipo II sejam conseqüentes à resistência à insulina e caracterizadas por hipertrigliceridemia moderada e baixos níveis de HDL-C ${ }^{39}$. A elevação dos níveis de TG neste caso resulta tanto do aumento da disponibilidade de substrato (glicose e ácidos graxos livres) como do decréscimo da lipólise dos triglicérides presentes nas partículas de VLDL. A presença de DM é particularmente prejudicial nas mulheres, especialmente na presença de baixos níveis de HDL-C, que consti-

\begin{tabular}{|lccc|}
\hline \multicolumn{5}{|c|}{ Tabela XI - Dislipidemias secundárias a doenças } \\
\hline \multicolumn{4}{c}{ Lipoproteínas } \\
Causa & CT & TG & HDL-C \\
\hline 1. Diabetes & - & $\uparrow$ & $\downarrow$ \\
2. Hipotireoidismo & $\uparrow \uparrow$ & $\uparrow$ & $\uparrow$ ou $\downarrow$ \\
3. Doenças Renais & & & \\
Síndrome Nefrótica & $\uparrow$ & $\uparrow$ & - \\
\multicolumn{1}{c}{ IRC } & $\uparrow$ & $\uparrow$ & - \\
4. Hepatopatias & & & $\downarrow$ \\
Colestáticas Crônicas & $\uparrow \mathrm{a} \uparrow \uparrow \uparrow \uparrow \uparrow$ & normal ou leve $\uparrow$ & $\uparrow \uparrow — \downarrow$ \\
5. Obesidade & $\uparrow$ & $\uparrow \uparrow$ & $\downarrow$ \\
6. Anorexia Nervosa & $\uparrow$ & - & - \\
7. Bulemia & $\uparrow$ & $\uparrow$ & - \\
\hline
\end{tabular}

tuem um risco desproporcionalmente maior de doença arterial coronariana em comparação à mesma condição no sexo masculino. O controle da dislipidemia do diabetes passa pelo controle da glicemia.

B) Hipotireoidismo-O mecanismo primário da hipercolesterolemia no hipotireoidismoé pelo acúmulo de LDL-C, devido o decréscimo do número correspondente de receptores hepáticos para a $\mathrm{LDL}^{40}$. A reposição hormonal com tiroxina tem respostas variáveis sobre a hipercolesterolemia secundária, devido os diferentes polimorfismos do gene do receptor de LDL-C, podendo ser até 4 vezes maior de um caso para outro ${ }^{41}$. A redução da atividade da lipase das lipoproteínas, que pode ocorrer no hipotireoidismo, é a responsável pelo desenvolvimento de hipertrigliceridemia, estando a velocidade de síntese dos triglicérides normal. As alterações nos lípides séricos podem ocorrer tanto no hipotireoidismo, manifesto clinicamente, como na forma subclínica. Emumestudo de 1.210pacientes com CT acima de 200mg\%, a prevalência de hipotireoidismo manifesto clinicamente foi de 1,3\% e a do hipotireoidismo subclínico de $11,2 \%{ }^{42}$.

C) Síndrome nefrótica - Tanto a hipercolesterolemia, como a hipertrigliceridemia podem ocorrer na síndrome nefrótica. Em um estudo de 100 pacientes com síndrome nefrótica e hipercolesterolemia, encontrou-se: CT> $200 \mathrm{mg} \%$ em $87 \%$; CT $>300 \mathrm{mg} \%$ em $53 \%$ e CT $>400 \mathrm{mg} \mathrm{em}$ $25 \%{ }^{43,44}$. O mecanismo é desencadeado, ao menos em parte, pela redução da pressão oncótica do plasma. Estudos in vitro mostraram que a pressão oncótica baixa estimula diretamente a transcrição do gene da apo B hepático ${ }^{45}$. A razão porque a baixa pressão oncótica estimula a produção de lipoproteínas pelo hepatócito é desconhecida. Entretanto, novas técnicas disponíveis sugerem fortemente que a redução do catabolismo, mais do que o aumento da síntese protéica hepática é primariamente responsável pela hipercolesterolemia em pacientes com síndrome nefrótica ${ }^{46}$. A resolução espontânea, ou por meio de tratamento medicamentoso da síndrome nefrótica, reverte a hiperlipidemia. Do mesmo modo, a hipertrigliceridemia na síndrome nefrótica é devida mais pelo comprometimento do metabolismo do 
que pelo aumento da síntese ${ }^{47}$. A cascata de delipidação, na qual as VLDL são convertidas em IDL, e em seguida, em LDL pela lípase das lipoproteínas está retardada na síndrome nefrótica ${ }^{48}$.

D) Insuficiência renal crônica (IRC) - A dislipidemia é menos proeminente na IRC embora a hipertrigliceridemia isolada ocorra em 30\%-50\% dos casos. As anormalidades no metabolismo lipídico ocorrem também nos portadores de IRC em diálise e após transplante renal. Não está claro o quanto a diálise peritoneal e a hemodiálise diferem nos seus efeitos sobre os lípides séricos. O achado primário na IRCe diálise é a hipertrigliceridemia, o CT é usualmente normal, talvez pelo estado de má-nutrição em alguns pacientes. A elevação dos níveis de TGé devida ao clearance diminuído e também pela redução na atividade da LPLe da lipase hepática, que podem contribuir para o decréscimo na remoção $\operatorname{dos} \mathrm{TG}^{49,50}$.

E) Hepatopatias colestáticas crônicas - A cirrose biliar, a colangite esclerosante e outras hepatopatias que cursam com colestase podem ser acompanhadas de hipercolesterolemia significativa. Entretanto, em um relato de 284 pacientes ${ }^{51}$, a faix de valores da colesterolemia encontrada foi bastante ampla, de $120 \mathrm{mg} \%$ a $1.775 \mathrm{mg} \%$. Não houve correlação entre o colesterol total e os níveis de bilirrubina. O perfil lipídico mostrou elevação dos níveis de LDL-C, mas também elevação significativa de HDL-C nos estágios iniciais da doença. Os triglicérides mantêm-se normais ou levemente elevados. Parte do excesso de LDL-C na cirrose biliar primária é composto por uma partícula de lipoproteína anormal encontrada nas hepatopatias colestáticas, denominada lipoproteína $\mathrm{X}^{52}$, a qual é rica em colesterol livre e fosfolípides. As implicações clínicas dessas expressivas anormalidades lipídicas incluem xantomas e xantelasmas em situações menos comuns de hipercolesterolemia acima de 600mg\%. Entretanto não existem evidências conclusivas sobre o desenvolvimento de doença cardíaca aterosclerótica nesses casos.

F) Obesidade - Trata-se de doença crônica que vem apresentando significativo aumento de incidência mundial. A obesidade é associada com um número de alterações deletérias no metabolismo lipídico, incluindo níveis elevados de colesterol total, LDL-C, triglicérides e redução do HDL-C em torno de $5 \%{ }^{53}$.

G) Síndrome de Cushing - O hipercortisolismo está associado a níveis elevados de LDL-C e triglicérides ${ }^{21}$.

H) Anorexia nervosa - A anorexia nervosa tem sido associada com significativa hipercolesterolemia embora reversível ${ }^{54}$.

I-)Bulimianervosa-A bulimianervosatambémpode ser acompanhada de hipercolesterolemia ehipertrigliceridemia ${ }^{54}$.

\section{2 - Dislipidemias secundárias a medicamentos ${ }^{21}$ :}

As dislipidemias geralmente ocorrem em associação com outros fatores de risco que requerem tratamento, como a hipertensão. Alguns agentes anti-hipertensivos comuns podem causar efeitos adversos nos níveis séricos lipídicos. Outras drogas, como os corticosteróides, podem aumentar tanto o colesterol como os triglicérides. A isotretinoína ${ }^{55}$, utilizada para a acne grave, com freqüência causa dislipidemia mista, geralmente associada à redução do HDL-C. Os medicamentos que afetam desfavoravelmente os lípides séricos, têm seu efeito mais acentuado naqueles pacientes com distúrbios lipídicos de base e outras causas secundárias como a obesidade, ingestão alcoólica excessiva e diabetes. A dose de isotretinoína deve ser reduzida se a dislipidemia falhar em responder a medidas dietéticas. Os inibidores de protease também se associam a dislipidemias (aumento dos triglicérides e diminuição do HDL-C) ${ }^{55}$. A tabela XII ilustra os principais grupos de medicamentos que podem desencadear dislipidemias secundárias e o tipo de alteração lipídica encontrada.

\section{3 - Dislipidemias secundárias a hábitos de vida ina- dequados (tab.XIII):}

A) Tabagismo-O fumo causa reduções em graus variáveis no HDL-C e pode induzir resistência à insulina ${ }^{56}$. No estudo Bezafibrate Infarction Prevention Study Group, o HDL-C médio foi de 39,6mg\% em não fumantes e de $35 \mathrm{mg} \%$ nos fumantes ${ }^{57}$.

B) Etilismo - A ingestão alcoólica excessiva é freqüentemente acompanhada do aumento dos TG e, às vezes dos

\begin{tabular}{|c|c|c|c|}
\hline \multicolumn{4}{|c|}{ Tabela XII - Dislipidemias secundárias a medicamentos } \\
\hline \multicolumn{4}{|c|}{ Lipoproteínas (principal alteração) } \\
\hline Medicamento & $\mathrm{CT}$ & TG & HDL-C \\
\hline Diuréticos & - & $\uparrow$ & $\downarrow$ \\
\hline Beta-bloqueadores $(*)$ & $\longrightarrow$ & $\uparrow$ & $\downarrow$ \\
\hline Anticoncepcionais & $\uparrow$ & $\uparrow$ & $\longrightarrow$ \\
\hline Corticosteróides & $\uparrow$ & $\uparrow$ & - \\
\hline Anabolizantes & $\uparrow$ & - & $\downarrow$ \\
\hline Estrógenos & $(* *)$ & $\rightarrow \uparrow$ & $\rightarrow \downarrow$ \\
\hline Progestágenos & $(* *)$ & $\rightarrow \uparrow$ & $\rightarrow \downarrow$ \\
\hline Isotretinoína & $\uparrow$ & $\uparrow$ & $\uparrow$ \\
\hline Ciclosporinas & $\uparrow$ & $\uparrow \uparrow$ & $\uparrow$ \\
\hline Inibidores de Protease & $\uparrow$ & $\uparrow \uparrow \uparrow$ & $\longrightarrow$ \\
\hline \multicolumn{4}{|c|}{$\begin{array}{l}\text { (*) destituídos de atividade simpatomimética intrínseca; }(* *) \text { efeitos } \\
\text { dependem do tipo de estrógeno e progestágeno e da rota de administra- } \\
\text { ção: o estradiol VO apesar de poder causar hipertrigliceridemia, produz } \\
\text { redução do LDL-C e aumento do HDL-C; a via transdérmica não eleva } \\
\text { os triglicérides. }\end{array}$} \\
\hline
\end{tabular}

\begin{tabular}{|c|c|c|c|}
\hline \multicolumn{4}{|c|}{$\begin{array}{c}\text { Tabela XIII - Dislipidemias conseqüentes à hábitos de vida } \\
\text { inadequados }\end{array}$} \\
\hline \multicolumn{4}{|c|}{ Lipoproteínas (principal alteração) } \\
\hline & $\mathrm{CT}$ & TG & HDL-C \\
\hline Tabagismo & - & - & $\downarrow$ \\
\hline Etilismo & 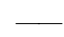 & $\uparrow$ & $\uparrow$ \\
\hline
\end{tabular}


quilomícrons, ocorrendo níveis variáveis de LDL-C e aumento do HDL-C ${ }^{58}$.

\section{Recomendação ${ }^{22}$}

Todos os pacientes com hipercolesterolemia (e hipertrigliceridemia), devem ser investigados com relação à possibilidade de dislipidemias secundárias antes de ser dado um tratamento farmacológico específico.

\section{Grau de recomendação: $B$. Nível de evidência: 4.}

3 - Classificação de Fredrickson (tab. XIV) - A classificação proposta por Fredrickson ${ }^{59}$ é baseada nos padrões de lipoproteínas associados a concentrações elevadas de colesterol e/ou triglicérides, não sendo considerado o HDL-C. A classificação de Fredrickson nãoé uma classificação etiológica de doença e não diferencia hiperlipidemias primárias de secundárias, mas tem sido útil para caracterização de anormalidades das lipoproteínas. Permite diferenciar quando a elevação de TG é procedente de fontes alimentares (TG contidos nos QM) ou de partículas ricas em TG de origem endógena (VLDL produzida pelo fígado - por exemplo, em indivíduos com alta ingestão de carboidratos). Entretanto, estabelecer o fenótipo das lipoproteínas plasmáticas, não substitui o diagnóstico da etiologia da dislipidemia. A classificação de Fredrickson tem por base a separação eletroforética e/ou por ultracentrifugação das frações lipoprotéicas, distinguindo-se seis tipos:

Tipo I - CT normal ou pouco elevado, trigliceridemia bastante elevada à custa de quilomícrons (QM). Aparência do soro com presença de camada cremosa sobre a coluna líquida de plasma transparente.

Tipo IIa - Aumento de CT com elevação de betalipoproteínas da eletroforese e TG normal. O plasma de jejumé límpido. Elevação de LDL.

Tipo IIb - Elevação concomitante de CT e TG à custa de aumento de pré-beta e beta-lipoproteínas. O plasma de jejum é límpido ou turvo. Elevação de LDL e VLDL.

Tipo III - Aumento de CT e TG, à custa da beta-larga da eletroforese, correspondendo à elevação da IDL. A relação CTe TGé em torno de 1. Oplasma de jejumé freqüentemente turvo e, às vezes, com tênue camada de QM.
Tipo IV - Aumento dos TG devido ao acúmulo das prébetalipoproteínas, correspondendo à elevação das VLDL. O CT é normal ou pouco aumentado, à custa do colesterol contido nas VLDL. O soro tem aspecto turvo.

Tipo V - CT pouco aumentado e aumento importante dos TG por elevação concomitante de QMe pré-betalipoproteínas. O plasma de jejumé turvo com camada de QM presente.

\section{V - Lípides e Aterosclerose: Aspectos Epide- miológicos, Clínicos e Preventivos}

\section{Panoramanacional}

Durante os últimos 30 anos temos presenciado um declínio razoável da mortalidade por causas cardiovasculares, em países desenvolvidos, enquanto que elevações relativamente rápidas e substanciais têm ocorrido em países em desenvolvimento, dentre os quais o Brasil é um dos representantes. De acordo com as projeções da Organização Mundial de Saúde, essa tendência de elevação na doença cardiovascular tende a persistir, agravando ainda mais o quadro de morbidade e mortalidade elevadas nos países em desenvolvimento. Caso medidas preventivas efetivas não sejam tomadas, prevê-se uma verdadeira epidemia de doença cardiovascular com conseqüências desastrosas para a saúde pública. Em nosso país, o panorama da saúde cardiovascular pode ser descrito resumidamente através dos seguintes dados:

Tabagismo - De acordo com dados do IBGE (1991), a prevalência de tabagismo em pessoas acima de 5 anos de idade foi de $24 \%$, com maior concentração na faixa etária entre 30 e 49 anos. Outros estudos realizados entre 1971 e 1988 mostram taxas de prevalência variando de 35 a $40 \%$. Recentemente, no Estudo Transversal da Sociedade de Cardiologia do Estado de São Paulo (1999) as taxas de prevalência de tabagismo foram de $17 \%$ (idade mediana de $46 \pm 16$ anos), após avaliação de aproximadamente 20 mil indivíduos em 19 cidades do estado.

Hipertensão - A estimativa de hipertensão arterial na população brasileira adulta de acordo com o Ministério da Saúde (1991) e IBGE (Censo Populacional de 1991) foi de

\begin{tabular}{|c|c|c|c|c|c|c|c|}
\hline \multirow{2}{*}{ Fenótipo } & \multicolumn{6}{|c|}{ Tabela XIV - Classificação fenotípica das hiperlipidemias (Fredrickson) } & \multirow{3}{*}{$\begin{array}{l}\text { Aparência do plasma } \\
\text { ou soro }\end{array}$} \\
\hline & \multicolumn{4}{|c|}{$\begin{array}{c}\text { Lipoproteínas } \\
\text { (principal alteração) }\end{array}$} & \multicolumn{2}{|c|}{$\begin{array}{l}\text { Lípides } \\
\text { (valores mais comuns) }\end{array}$} & \\
\hline & QM & VLDL & IDL & LDL & $\mathrm{CT}(\mathrm{mg} / \mathrm{dl})$ & $\mathrm{TG}(\mathrm{mg} / \mathrm{dl})$ & \\
\hline Tipo I & $\uparrow \uparrow \uparrow$ & & & & $160-400$ & $1.500-5.000$ & Sobrenadante cremoso \\
\hline Tipo IIa & & & & $\uparrow \mathrm{a} \uparrow \uparrow \uparrow$ & $>240$ & $<200$ & Transparente \\
\hline Tipo IIb & & $\uparrow \mathrm{a} \uparrow \uparrow$ & & $\uparrow \mathrm{a} \uparrow \uparrow \uparrow$ & $240-500$ & $200-500$ & Turvo \\
\hline Tipo III & & & $\uparrow \uparrow \mathrm{a} \uparrow \uparrow \uparrow$ & & $300-600$ & $300-600$ & Turvo \\
\hline Tipo IV & & $\uparrow \mathrm{a} \uparrow \uparrow \uparrow$ & & & $<240$ & $300-1000$ & Turvo \\
\hline Tipo V & $\uparrow \mathrm{a} \uparrow \uparrow \uparrow$ & $\uparrow \mathrm{a} \uparrow \uparrow \uparrow$ & & & $160-400$ & $1.500-5.000$ & Camada superior cremosa \\
\hline & & & & & & & Camada inferior turva \\
\hline
\end{tabular}


$15 \%$ (datasus.org.br), entretanto, estudos transversais na cidade do Rio de Janeiro em 1990, mostravam taxas de 30\% e no estudo transversal da Sociedade de Cardiologia do Estado de São Paulo mostrou uma prevalência de 25\%.

Diabetes - Com base no Censo Nacional de Diabetes de 1980, a prevalência ajustada por idade (30-69 anos) foi de $7,6 \%$, com variação de $5 \%$ a $10 \%$ de acordo com a capital brasileira avaliada (datasus.org.br), sendo que no estudo transversal da Sociedade de Cardiologia do Estado de São Paulo mostrou uma prevalência de 7,6\%.

Obesidade - Aproximadamente $32 \%$ da população brasileira apresentava sobrepeso (IMC $\geq 25$ ), sendo esta taxa de $38 \%$ para o sexo feminino e de $27 \%$ para o sexo masculino, de acordo com os dados do Ministério da Saúde de 1993. A obesidade foi encontrada em $8 \%$ da população brasileira (IMC > 30) (datasus.org.br).

Dislipidemias - Os níveis séricos de colesterol total foram avaliados em alguns estudos no Brasil em regiões específicas, entretanto, um estudo conduzido em nove capitais, envolvendo 8.045 indivíduos com idade mediana de

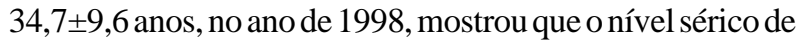
colesterol total foi de $183 \pm 39,8 \mathrm{mg} / \mathrm{dL}$. Nesse estudo, os valores foram mais elevados no sexo feminino e nas faixas etárias mais elevadas ${ }^{60}$. Níveis elevados de CT foram encontrados em $8,8 \%$ dos indivíduos.

\section{Tópicos essenciais de epidemiologia clínica e medidas de benefício clínico: importância de desfechos clínicos ${ }^{61,62}$}

Em primeiro lugar, as evidências clínico-epidemiológicas priorizam os desfechos de saúde-doença que apresentam um significado real ao paciente e à sociedade, como morte (vida), doença (cura, saúde), recidiva, perda de órgão ou função, dor, custo etc. Como esses eventos são geralmente raros, contados em 100, 1.000, ou até 10 mil indivíduos, as pesquisas que geram essas evidências requerem um grande número de pacientes. Dados de pesquisa que representam eventos intermediários na causalidade de doença (fisiopatológicos, bioquímicos etc.), embora fundamentais para justificar a necessidade de estudos maiores, com desfechos mais convincentes, não se configuram, via de regra, em evidência capaz de justificar intervenções de alto risco, inconveniência ou alto custo.

Além disso, as evidências clínico-epidemiológicas procuram expressar objetivamente a realidade do contexto clínico, permitindo considerar as incertezas das decisões baseadas em tal evidência.

\section{Metodologia clínico-epidemiologia resumida}

Erros metodológicos no planejamento, execução ou análise da pesquisa podem distorcer as conclusões de um estudo, destruindo sua validade interna. Quando isso ocorre diz-se que houve um erro sistemático (viés, vício, tendenciosidade), porque a verdade foi direcionada para um lado ou para outro. Ao contrário dos estudos feitos em laboratório experimental, estudos em seres humanos são muito propensos a esses tipos de erros. Os erros sistemáticos podem ser classificados em três grupos - vieses de seleção, aferição e confusão. Vieses de seleção são aqueles que distorcem os resultados pelo recrutamento diferencial dos participantes ou por perdas diferenciais ao longo do estudo. O ensaio clínico minimiza esse risco pela técnica de randomização. Para acontecer um viés de aferição, o processo de medida deve ser sistematicamente diferente nos dois grupos em comparação. A aplicação da técnica de mascaramento (ou, em outras palavras, tornar os pacientes e observadores cegos a quem está recebendo o tratamento em estudo) é uma maneira comum de minimizar risco deste viés em ensaios clínicos.

Vieses por confusão de efeito de variáveis (confundimento) acontecem quando não há comparabilidade dos grupos estudados na análise de uma associação. Confundidores podem ser controlados na análise dos resultados com técnicas estatísticas (análise estratificada, modelos matemáticos etc.). Porém, de maneira mais importante, vieses de confusão podem também ser controlados por técnicas aplicáveis no delineamento do estudo, como randomização. O menor risco desses vieses em ensaios clínicos randomizados e duplo-cegos é a principal razão para prestigiar tal delineamento na graduação do nível de evidência para a tomada de decisões clínicas. Além de controlar para erros sistemáticos, é necessário avaliar também a possibilidade de erros aleatórios. A inferência estatística é o método universalmente empregado para avaliar a capacidade de generalização de dados considerados internamente válidos para uma população maior. O erro inerente a este método é conhecido como erro aleatório ou amostral, que pode ser expresso em termos probabilísticos. Os testes estatísticos estimam a probabilidade de que o efeito encontrado na amostra em estudo tenha ocorrido tão somente pelo acaso. Quando a possibilidade é remota (probabilidade pequena de erro), a diferença ou associação é dita estatisticamente significativa.

Como apresentado na tabela XV há quatro possibilidades de erro/acerto para uma conclusão estatística sobre uma população, inferida a partir dos dados de uma amostra. Em duas possibilidades a conclusão está correta: o teste estatístico mostra significância quando a diferença na população realmente existe; ou o teste não mostra significância quando a diferença na população realmente não existe. Nas outras duas possibilidades, a conclusão é incorreta: o teste estatístico mostra significância, quando a diferença na população não existe (erro tipo I ou erro alfa); ou o teste não mostra significância quando a diferença na população realmente existe (erro tipo II ou erro beta).

Antes de iniciar um estudo, o investigador estabelece um limite de erro alfa que ele está disposto a aceitar (valor

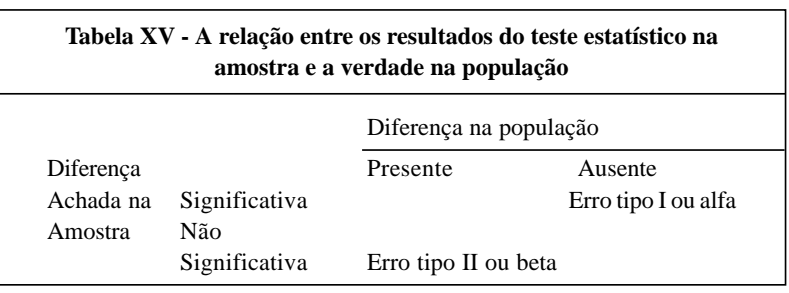


alfa, geralmente 5\%). Se, na análise dos dados, a probabilidade de erro alfa ( $\mathrm{p}$ alfa) determinada pelo teste estatístico for menor do que o valor alfa estipulado, diz-se que o resultado é estatisticamente significativo. Se a probabilidade encontrada for maior que o valor alfa, diz-se que o resultado não é estatisticamente significativo. Uma técnica alternativa para a avaliação da significância estatística é o intervalo de confiança. Sua vantagem é permitir a avaliação direta da faixa de valores possíveis para uma estimativa, dado o grau de variabilidade indicado pelos dados. Assim, um intervalo de confiança de $95 \%$ (equivalente a um valor alfa de $5 \%$ ) permite dizer que, na ausência de vieses, com repetição da pesquisa em múltiplas amostras, o verdadeiro valor da estimativa cairia dentro de uma faixa de valores assim constituído em $95 \%$ das vezes, que o estudo fosse replicado. Intervalos de confiança para medidas de associação que são definidas pela razão entre duas freqüências (risco relativo ou razão de chances) indicam significância estatística quando o intervalo de confiança não inclui o valor 1 (ausência de associação). Intervalos estreitos refletem pequena variabilidade, outra informação útil visível do intervalo de confiança. Tanto maior o número de testes estatísticos realizados na pesquisa, maior a chance de que um deles mostre significância estatística tão somente pelo acaso. Tanto maior o número de vezes que um pescador jogar o anzol na água, maior será sua chance de pescar um peixe. Mesmo sem saber pescar, poderá acabar pescando um peixe!. Assim, um resultado estatisticamente significativo em meio a comparações múltiplas com resultados negativos deve ser interpretado com cautela. Isto é uma das grandes razões para o menor valorização de resultados oriundo de análises a posteriori de subgrupos ou de hipóteses secundários de ensaios clínicos (por exemplo, quando um remédio não demonstrou benefício estatisticamente significativo em todos os pacientes, mas somente em um subgrupo de pacientes com uma determinada característica). Em presença de resultados não significativos estatisticamente, também se pode estimar a probabilidade de que tal resultado negativo tenha ocorrido tão somente pelo acaso (neste caso, o p beta). Costuma-se expressar esta probabilidade pelo seu complemento ( 1 - p beta), o chamado poder estatístico, ou sensibilidade do estudo para detectar um resultado estatisticamente significativo. Quando o poder é pequeno, conclui-se que o estudo não tem sensibilidade suficiente para detectar um resultado significativo.

\section{Medidas de benefício em estudos clínico-epidemiológicos}

A forma básica de avaliar, em termos quantitativos, o benefício de uma terapia é o risco relativo (RR) (tab. XVI). Por exemplo, se uma intervenção para prevenir doença aterotrombótica demonstra um risco relativo de 0,75 , isso significa que somente $75 \%$ dos eventos que ocorreram no grupo controle ocorreram no grupo tratado, isto é, os outros $25 \%$ foram evitados. Em termos técnicos, diz-se que houve uma redução de risco relativo (RRR) de eventos de 0,25 (ou $25 \%$ ) com a intervenção ( $R R R=1-R R)$.

Como o risco básico a ser evitado em ações terapêu-

\begin{tabular}{|c|c|}
\hline \multicolumn{2}{|c|}{$\begin{array}{l}\text { Tabela XVI - Medidas de avaliação de benefício ou impacto de um } \\
\text { tratamento ou medida preventiva }\end{array}$} \\
\hline Medida & Fórmula para cálculo \\
\hline $\begin{array}{l}\text { Risco absoluto } \\
\text { Número de eventos que aparecem na } \\
\text { população durante o estudo (incidência) }\end{array}$ & $\begin{array}{l}\text { RA = Número de eventos } \\
\text { (população e tempo) }\end{array}$ \\
\hline $\begin{array}{l}\text { Risco relativo } \\
\text { Razão entre a incidência de eventos dos } \\
\text { tratados e dos não-tratados (determina a } \\
\text { força da associação) }\end{array}$ & $\begin{array}{l}\mathrm{RR}=\text { Incidência. nos tratados } \\
\text { Incidência no placebo }\end{array}$ \\
\hline $\begin{array}{l}\text { Redução relativa de risco } \\
\text { Proporção de eventos que deixam de } \\
\text { ocorrer com o tratamento }\end{array}$ & $\mathrm{RRR}=1-\mathrm{RR}$ \\
\hline $\begin{array}{l}\text { Redução absoluta de risco } \\
\text { Número de eventos que deixa de } \\
\text { acontecer nos indivíduos tratados }\end{array}$ & $\begin{array}{l}\text { RAR = Inc. tratados - Inc. } \\
\text { placebo, ou RRR x risco basal } \\
\text { estimado do paciente }\end{array}$ \\
\hline $\begin{array}{l}\text { Número que necessitam ser tratado } \\
\text { Número de indivíduos a serem tratados por } \\
\text { determinado tempo para evitar um evento. }\end{array}$ & $\mathrm{NNT}=1 / \mathrm{RAR}$ \\
\hline
\end{tabular}

ticas é, com freqüência, relativamente baixo, e varia de uma situação clínica para outra, argumenta-se que uma expressão do efeito da intervenção de maior relevância para o clínico (e seu paciente) seria a redução absoluta de risco (RAR), ou seja, o número de eventos evitados (expresso, por exemplo, em termos de mil indivíduos tratados). Por exemplo, se somente $2 \%$ (20/1.000) dos pacientes com determinadas características, como hiperlipidemia, sofrem um evento por ano, uma redução de $25 \%$ nesse risco resultaria em uma diferença de apenas cinco eventos por ano por mil indivíduos tratados. Porém, pressupondo o mesmo RRR, se $6 \%$ sofrerem o evento por ano, o mesmo tratamento evitaria 15 eventos por ano por mil tratados, ou seja, teria um efeito três vezes maior, em termos absolutos. Assim a importância da estimação do risco basal do paciente. Um remédio indicado em situações de alto risco não necessariamente tem indicação em situações de baixo risco, mesmo existindo estudos demonstrando sua eficácia em pacientes de baixo risco, uma vez que em pacientes de baixo risco, os paraefeitos, custos e desarranjos da terapia podem ser maiores que os benefícios previstos.

Uma maneira mais recente de expressar a magnitude de um efeito terapêutico em termos absolutos é o número de pacientes que precisa receber tratamento para evitar um evento (número que necessita ser tratado ou NNT), o recíproco da redução absoluto de risco (RAR), ou seja, 1/RAR. Seguindo o exemplo, para evitar 15 eventos, quando a incidência anual é $6 \%$, precisariam ser tratados mil indivíduos por um ano. Assim, o número de pessoas que necessita tratamento (para evitar um evento) é 67 (1.000/15).

Como o risco basal de eventos varia de paciente a paciente, pode se estimar o NNT usando o risco basal do paciente em questão. Inicialmente, estima-se a redução absoluta de risco (RAR), multiplicando-se o risco estimado de eventos do paciente pela redução relativa de risco (RRR) da literatura, em seguida, invertendo-se o valor obtido para chegar ao NNT. Na 
ausência de uma estimativa desse risco basal, freqüentemente o NNT no ensaio clínico randomizadoé extrapolado ao paciente em questão. Com o NNT, pode-se pesar os benefícios da terapia contra seus custos e riscos, comparando-os com aqueles de outras opções terapêuticas.

\section{Estudos observacionais avaliando perfil lipídico e risco cardiovascular}

Estudos de coorte e de caso-controle são ambos estudos observacionais de fatores de risco. Muitas vezes são confundidos, porém uma característica distintiva do delineamento de caso-controle é que os casos têm o desfecho de interesse na ocasião em que a informação sobre os fatores de risco é pesquisada. Fornecem base mais forte para interpretação causal.

Tanto os estudos de coortes quanto os de caso-controle são chamados de longitudinais, porque as análises de causalidade partem de dois momentos históricos sucessivos. Os estudos de intervenção serão sempre classificados como longitudinais, na medida em que, por definição da sua própria arquitetura, envolvem um seguimento. Nos estudos seccionais ou transversais, fator e efeito são medidos num mesmo momento histórico. A análise de dados dos estudos transversais baseia-se fundamentalmente na comparação de indivíduos "acometidos", doentes (D), entre os expostos (E) e os não expostos (NE).

Nos últimos 25 anos, o papel do colesterol ficou bem demonstrado por meio de estudos clínicos e observacionais, comprovando que a redução dos seus níveis, mais especificamente o do LDL-C, promovia benefícios na prevenção da doença arterial coronariana (DAC), como demonstram os estudos abaixo:

"Estudo de Framingham" (estudo longitudinal) ${ }^{63}$ 1948: evidenciou a importância do nível de colesterol em indivíduos normais no desenvolvimento de complicações da doença aterosclerótica.

MRFIT (Multiple Risk Factor Intervention Trial estudo longitudinal - 1986) ${ }^{64}$ : durante um período superior a seis anos, realizou-se um seguimento em mais de $360 \mathrm{mil}$ pacientes nos EUA para definir e estudar o comportamento dos principais fatores de risco coronarianos, demonstrando ao seu final, a relação negativa entre DAC e HDL-C e positiva entre LDL-CeDAC.

PROCAM (Prospective Cardiovascular Munster Study ${ }^{65}$ - estudo longitudinal: 1979-1991): demonstrou, de forma clara, a confirmação dos outros benefícios provenientes da redução da hipertrigliceridemia no que diz respeito a outros fatores de risco para DAC, mostrando assim a importância do tratamento dessa dislipidemia.

"Estudo dos sete países" 66 - estudo transversal 1990: demonstrou haver correlação entre níveis médios de colesterol de diferentes populações e índices de mortalidade por DAC.

\section{Hierarquia das evidências}

$\mathrm{Na}$ área de intervenção terapêutica o padrão-ouro para recomendações na prática clínica é o estudo clínico controlado randomizado. Descreveremos abaixo, as estratégias de pesquisa, realçando os pontos fortes e fracos de cada uma, e, no final, sintetizaremos os níveis de evidências e graus de recomendações para intervenções terapêuticas. A hierarquia da evidência para a decisão clínica envolvendo terapêutica obedece a seguinte seqüência, da melhor (mais válida, menos vieses) para menos adequada (menos válida, mais vieses): 1) revisões sistemáticas de estudos randomizados com poder estatístico adequado; 2) estudos randomizados com poder estatístico adequado; 3) estudos randomizados com menor tamanho de amostra; 4) estudos de coorte prospectivos de alta qualidade; 5) estudos caso-controle de alta qualidade; 6) estudos transversais; 7) série de casos; 8) relato de série; 9) “experiência pessoal” isolada.

\section{Graus de recomendações}

A) Conclusiva e/ou unanimemente recomendado (sempre usar): conduta terapêutica conclusivamente útil e segura; eficácia e segurança comprovadas (quase sempre se requer níveis de evidência excelentes 1 ou 2). Portanto, terapêutica a ser sempre implementada, salvo por impedimentos individualizados. Sem justificativa individualizada, será errado não implementar.

B) recomendadocomo aceitável, mas com ressalvas (devese geralmente indicar): conduta aceitável e segura, grande potencial de utilidade, mas ainda sem comprovação conclusiva (evidência menos sólida). Portanto, conduta terapêutica pode ser considerada de escolha, mas geralmente é opcional e alternativa, e nunca constituirá erro indubitável não adotá-la.

C) Recomendação indefinida (é inteiramente a critério individual, usar ou não): Conduta para a qual não há evidência segura, nem favorável, nem desfavorável, quanto à eficácia e segurança. (pode ser conduta terapêutica tradicionalmente utilizada, sem comprovação científica). Portanto, é inteiramente opcional, sendo, a priori, impossível caracterizar como erro usá-la ou deixar de fazê-lo

D) Conduta terapêutica não recomendada, embora possa, em alguns contextos de excepcionalidade ser adotada (opção muito fraca, geralmente não indicar): evidência minimamente sugestiva de eficácia e segurança, embora se divise algum potencial de utilidade em algumas circunstâncias. Portanto, conduta terapêutica pode ser considerada opção ou alternativa muito secundária, com real possibilidade de, sendo adotada, praticar-se erro.

E) Conclusiva e/ou ou unanimemente não-recomendado (nunca usar): conduta sem utilidade potencial, podendo ser neutra ou mesmo prejudicial (níveis de evidência usualmente sólidos, contra a conduta). Portanto, terapêutica que constituirá erro grave implementar, salvo circunstâncias excepcionalmente individualizáveis (Comissão de Cardiologia Baseada em Evidências da Sociedade Brasileira de Cardiologia e Associação Médica Brasileira-no prelo).

\section{Níveis de evidência}

Nível 1 - Evidência baseada em múltiplos estudos 
randomizados, controlados, amplos, concordantes e com poder estatístico adequado; preferencialmente com revisão sistemática conclusiva.

Nível 2 - Evidência baseada em poucos estudos randomizados, controlados, concordantes, de médio porte ou metanálise de vários estudos dessa natureza, pequenos (equivalendo a estudo de moderado porte).

Nível 3 - $\geq 1$ estudo randomizado, controlado, de ótima qualidade.

Nível 4 - $\geq 1$ estudo de coorte de alta qualidade.

Nível 5 - $\geq 1$ estudo de caso-controle de alta qualidade. registros.

Nível 6 - $\geq 1$ série de casos de alta qualidade - inclui

Nível 7 - Evidência apenas baseada em: extrapolações de resultados coletados para outros propósitos (testar outras hipóteses); conjecturas racionais, experimentos com animais, ou baseados em modelos mecanísticos de fisiopatologia; conduta antiga, adotada em prática comum; opiniões sem referência a estudos anteriores. Consenso de expertos. (Comissão de Cardiologia Baseada em Evidências da Sociedade Brasileira de Cardiologia e Associação Médica Brasileira-no prelo).

\section{Desfechos clínicos substitutos e relevantes}

Desfechos substitutos ou intermediários são medidas laboratoriais ou fisiológicas utilizadas em estudos clínicos como substitutos para desfechos clinicamente relevantes (benefícios clinicamente tangíveis) sobre os quais há a expectativa de predizer os efeitos da intervenção terapêutica. As razões para utilização de desfechos substitutos incluem: menor extensão de seguimento, maior facilidade de avaliação em algumas situações, cenários onde a prevalência da doença é baixa e a avaliação do desfecho tangível torna-se difícil, redução do tamanho da amostra com conseqüente redução de custos. A luz dos resultados de estudos randomizados com poder estatístico suficiente e adequadamente conduzidos, desfechos substitutos ou intermediários não devem ser considerados avaliações autênticas, válidas e confiáveis de segurança e eficácia.

Discrepâncias entre resultados de estudos randomizados e incorporação na prática clínica (evidências sobre a prática do tratamento das dislipidemias)

Desde a publicação dos resultados do Lipid Research Clinic-Coronary Primary Prevention Trial (LRC-CPPT) ${ }^{67}$, demonstrando que a redução dos níveis de colesterol com a utilização da colestiramina poderia reduzir o risco de eventos coronarianos, passaram-se mais de 20 anos. De lá para cá, inúmeros estudos, avaliando a eficácia de diferentes intervenções: dieta, estilo de vida, medicamentos e até cirurgias, têm confirmado o conceito de que reduzindo os níveis de colesterol, pode-se reduzir o risco de evento coronariano ${ }^{68-73}$. Nos últimos sete anos, cinco grandes estudos, envolvendo mais de 35 mil participantes no total, provaram que a redução dos níveis de colesterol com a utilização de vastatinas reduz o risco de eventos coronarianos, tanto em prevenção primária (WOSCOPS, AFCAPS/TexCAPS) ${ }^{74,75}$ co- mo na secundária (4S, CARE, LIPID) ${ }^{76-78}$ de uma forma significativa. Esses estudos incluíram participantes de perfis de risco diversos, o que passou a permitir uma maior facilidade para que nós, na prática do dia a dia, pudéssemos "enquadrar" os nossos pacientes num dos perfis de risco avaliados nos estudos:

\section{Prevenção primária \\ - WOSCOPS \\ - homens de alto risco, \\ -LDL-Cmédio=192mg/dL. \\ - AFCAPS/TexCAPS}

- homens e mulheres com níveis médios de LDL-C,

HDL-C:

-LDL-Cmédio=156mg/dL, HDL-C <40mg/dl.

Prevenção secundária

- 4S

- homens e mulheres de alto risco,

-LDL-C médio=189mg/dL.

- CARE, LIPID

- homens e mulheres com risco médio,

-LDL-C médio=139mg/dL.e $150 \mathrm{mg} / \mathrm{dl}$

Os estudos demonstraram, entre outras conclusões que, esse tipo de intervenção:

- Reduz a incidência de novos eventos coronarianos.

- Reduz a mortalidade cardiovascular.

- Reduz a necessidade de procedimentos invasivos percutâneos e cirúrgicos.

- Não aumenta a incidência de mortes violentas.

- Reduz a mortalidade total.

Apesar dessas evidências, levantamentos recentes sobre a conduta dos profissionais, que lidam com portadores de doença arterial coronariana (DAC), demonstram que a incorporação dos resultados de estudos randomizados adequadamente planejados, ainda não ocorreu de maneira satisfatória ${ }^{79}$.

\section{Revisão dos estudos de intervenção terapêutica em preven- ção primária e secundária com vastatinas}

Os principais estudos de prevenção com vastatinas encontram-se na tabela XVII ${ }^{80}$, nessa análise considera-se a diminuição dos eventos cardiovasculares totais (morte, infarto do miocárdio, angina instável, revascularização do miocárdio, acidente vascular cerebral).

\section{Análises econômicas em prevenção cardiovascular}

O ônus econômico das doenças cardiovasculares tem crescido exponencialmente nas últimas décadas. Em 2000, as doenças cardiovasculares foram responsáveis pela principal alocação de recursos públicos em hospitalizações no Brasil (aproximadamente $\$ 821$ milhões), e foram a $3^{\text {a }}$ causa de permanência hospitalar prolongada ${ }^{81,82}$. Entre $1991 \mathrm{e}$ 2000, os custos hospitalares atribuídos às doenças cardiovasculares aumentaram $176 \%{ }^{81}$. Esse aumento nos custos na área de saúde é universal e diversos países, mesmo aqueles que despendem uma quantidade significativa do 


\begin{tabular}{|c|c|c|c|c|c|c|c|}
\hline & $\mathrm{N}$ & Idade & $\begin{array}{c}\text { Intervalo } \\
\mathrm{CT} / \mathrm{LDL}-\mathrm{C} \mathrm{mg} / \mathrm{dL}\end{array}$ & Fármaco & $\begin{array}{l}\text { Redução } \\
\text { \% LDL-C }\end{array}$ & $\begin{array}{c}\text { Redução } \\
\text { relativa do risco \% }\end{array}$ & $\begin{array}{c}\text { Redução absoluta } \\
\text { do risco (NNT) }\end{array}$ \\
\hline AFCAPS/ & 6605 & H- $45-73$ & $180-264$ & Lovastatina & -25 & -37 & $2,03(50)$ \\
\hline $\begin{array}{l}\text { TEXCAPS } \\
\text { WOSCOPS }\end{array}$ & 6595 & $\begin{array}{l}\text { M-55-73 } \\
\text { H- } 45-64\end{array}$ & $\begin{array}{c}130-190 \\
>240 \\
155-230\end{array}$ & Pravastatina & -26 & -31 & $2,45(40)$ \\
\hline CARE & 4159 & $\mathrm{H}$ e M-21-75 & $\begin{array}{l}<240 \\
<174\end{array}$ & Pravastatina & -28 & -24 & $3,17(32)$ \\
\hline LIPID & 9014 & Н е М-31-75 & $155-171$ & Pravastatina & -25 & -24 & $3,54(28)$ \\
\hline $4 \mathrm{~S}$ & 4444 & $\mathrm{H}$ e $\mathrm{M}-35-70$ & $\begin{array}{c}213-310 \\
(-)\end{array}$ & Sinvastatina & -35 & -34 & 7,68 (13) \\
\hline
\end{tabular}

seu produto interno bruto para este setor, estão buscando racionalizar e otimizar os recursos disponíveis com o risco eminente de que parte da população não se beneficie pela falta de recursos ou distribuição e sua alocação inadequada.

Tradicionalmente, as recomendações para prática médica provenientes de sociedades e grupos de especialistas são baseadas em dados sobre a efetividade e segurança de determinadas intervenções ou condutas. Embora, fundamentais, tais critérios, não consideram a relação de custoefetividade absoluta ou relativa das mesmas. Em um contexto socioeconômico desafiador, em uma era de contenção de recursos, torna-se imperativa a preocupação com a eficiência das ações em saúde, buscando beneficiar um maior número possível de indivíduos.

Metodologias específicas, análises econômicas sobre a relação de custo-efetividade de intervenções terapêuticas, têm sido utilizadas para auxiliar a adequação de recursos financeiros. O principal objetivo dos estudos de custoefetividade é comparar o valor relativo de diferentes intervenções direcionadas em promover saúde e/ou prolongar a vida. Embora, esses estudos têm crescido muito na literatura científica, ainda não existem dados sobre as relações de custo-efetividade das intervenções médicas no Brasil.

\section{O custo das doenças ateroscleróticas}

A maioria das análises econômicas e dos estudos de custo-efetividade sobre o manejo da dislipidemia concentra-se nos custos associados com as doenças cardiovasculares que são prevenidas, resultante da redução dos níveis de colesterol. Muitos estudos assumem uma perspectiva da sociedade, incluindo todos desfechos e custos relacionados a doença, independente de quem arca com o custo. As consequiências clínicas da cardiopatia isquêmica têm efeitos importantes nos custos em saúde. Dados norte-americanos, baseados no acompanhamento de pacientes com doença isquêmica por cinco anos (em U\$ 1986), demonstraram que são gastos em média por paciente $\$ 51.211$ para infarto agudo, $\$ 24.890$ para angina de peito, $\$ 4.0581$ para angina instável e $\$ 9.078$ para morte súbita ${ }^{83}$. Concomitante ao aumento nas opções terapêuticas para o manejo da cardiopatia isquêmica, sabe-se que estratégias intervencionistas no tratamento das manifestações clínicas desta doença também aumentaram significativamente. Atualmente, é muito expressivo o percentual de pacientes submetidos a procedimentos de revascularização percutânea e cirúrgica, com um custo médio por procedimento em torno de $\$ 3.800$ a $\$ 5.800$ (dados SUS 2000). Cabe ressaltar que no Brasil as doenças cerebrovasculares são responsáveis por parcela significativa da morbimortalidade, em alguns estados brasileiros elas apresentam coeficientes de mortalidade superiores a doenças isquêmicas do coração ${ }^{84,85}$.

Não existem dúvidas de que as seqüelas clínicas da aterosclerose representam uma cifra expressiva dos gastos em saúde. Entretanto, baseado em resultados de inúmeros ensaios clínicos randomizados, existem evidências concretas que a redução do colesterol pode diminuir significativamente muitos desses eventos. Infelizmente, a magnitude do problema na nossa população (prevalência de dislipidemia e grupos de risco com valores de colesterol muito acima do recomendável) associado ao elevado custo do manejo da dislipidemia torna proibitivo o controle populacional global deste fator de risco, mesmo para países ricose desenvolvidos ${ }^{86,87}$. Através de metodologias sistemáticas, podemos estimar as relações de custo-efetividade para os diferentes manejos da dislipidemia e identificar subgrupos com maior impacto para adoção de estratégias preventivas.

\section{Estudos de custo-efetividade}

O principal objetivo dos estudos de custo-efetividade é comparar o valor relativo de diferentes intervenções direcionadas em promover saúde e/ou prolongar a vida, fornecendo informações concretas para que a tomada de decisões na alocação de recursos seja a mais apropriada. Esses estudos necessitam, por definição, de uma comparação entre dois (ou mais) métodos alternativos de tratar um paciente num determinado estado de saúde ${ }^{88,89}$. A maior aplicabilidade dos estudos de custo-efetividade na área de saúde envolve a comparação entre alternativas que competem na mesma condição clínica. Por exemplo, a escolha entre diferentes drogas hipolipemiantes, uso de dosagens alternativas de um mesmo fármaco, etc. Na avaliação de duas intervenções são calculadas razões que expressam o custo adicional necessário para atingir uma unidade extra de benefício clínico. A razão de custo-efetividade é definida como a 
diferença entre o custo de duas intervenções, dividida pela diferença entre as suas efetividades, expressas, por exemplo como anos de vida salvos ajustados para qualidade de vida (AVAQ):

$$
\mathrm{CE}_{2-1}=\frac{\text { Custo }_{2}-{ }_{\text {Custo }}}{\mathrm{AAQ}_{2}-\mathrm{AVAQ}_{1}}
$$

O denominador da razão de custo-efetividade é a diferença entre a efetividade de uma intervenção e a alternativa que está sendo comparada. Para estimar o benefício "líquido", é determinado o impacto na saúde de tais intervenções, a probabilidade de que cada estado de saúde possa ocorrer, quando cada situação é mais provável que ocorra e por quanto tempo. Estes estados de saúde são a sequiência de eventos e decisões conseqüentes que ocorrem durante ou seguindo uma intervenção. Por exemplo, nos estudos de custo-efetividade no manejo da dislipidemia são considerados o efeito terapêutico das drogas, seus efeitos adversos e potenciais complicações, testes laboratoriais de controle, incidência de cardiopatia isquêmica, acidente vascular cerebral, além de morte. As principais categorias de utilização de recursos (também chamados custos diretos) incluídas nestas análises são: custos nos serviços de saúde e, eventualmente, outros custos: tempo que o paciente despende para o tratamento, custo associado com familiares ou outras pessoas que cuidam do paciente, despesas com viagem, absenteísmo do trabalho, etc. Os custos diretos nos serviços de saúde incluem os custos de exames laboratoriais, drogas, suprimentos, do pessoal da área médica e das dependências físicas. Na determinação dos custos de uma intervenção devem ser computados todos os efeitos ou ações decorrentes que resultaram da intervenção. Por exemplo, na comparação de dois tratamentos hipolipemiantes são incluídos os custos e consequiências associados com os efeitos adversos das drogas, suas intervenções decorrentes, tais como exames laboratoriais ou suspensão do tratamento. Os estudos de custo-efetividade fornecem informações sobre o custo para a sociedade de um ano de vida salvo na população. Não existe consenso no valor de uma vida humana, mas alguns pesquisadores, em outros países, colocam que um tratamento com uma relação menor que US $\$ 40.000$ (dólares americanos) por ano de vida salvo, grosseiramente o custo da hemodiálise, é custo-efetivo, enquanto que aquele com relação superior a US\$75.000 por ano de vida salvo é muito caro ${ }^{86,90}$. Este valor, além de não ser consensual, não é fixo para as diferentes nações. Teoricamente, quanto maior o poder aquisitivo de uma sociedade, mais ela pode pagar para beneficiar a sua população e vice-versa.

É importante enfatizar a escassez de análises econômicas das intervenções médicas realizadas no Brasil. A maioria dos estudos de custo-efetividade é baseada em dados dos sistemas americano, canadense ou de países europeus. Muitos dados utilizados nesses estudos são claramente transponíveis para o sistema de saúde brasileiro. Por exemplo, a eficácia de um tratamento anti-hipertensivo deve ser a mesma em pacientes americanos, europeus ou trata- dos no Brasil, mas sua efetividade e seu custo talvez não o sejam. Existem diversos fatores que sugerem que os resultados de análises econômicas também não são facilmente transferíveis para outros contextos. Entre eles destacam-se: as diferenças demográficas e epidemiológicas das doenças, a disponibilidade de recursos médicos e variabilidade da prática médica, os incentivos, as formas de remuneração dos profissionais e instituições de saúde, o custo dos medicamentos relativo aos custos do manuseio de complicações e as diferenças no custo absoluto e relativo dos aspectos relacionados á saúde. Apesar destas considerações sobre a generalidade de análises conduzidas em outros contextos socioeconômicos, estas são as únicas informações disponíveis, que inicialmente podem nortear alguma tomada de decisão local para otimização de recursos.

\section{Custo-efetividade domanejo da dislipidemia}

As análises de custo-efetividade de fármacos hipolipemiantes demonstraram que os resultados dependem de algumas variáveis, como idade, presença de doença coronariana, sexo, bem como do tratamento avaliado. Inicialmente, as vastatinas mostraram um benefício clínico na prevenção secundária de doença isquêmica. Uma das primeiras estimativas econômicas, publicada por Goldman e cols., demonstrou que lovastatina era altamente custo-efetiva $(<20.000 / a n o$ de vida salvo, em dólares americanos em 1993) para prevenção secundária tanto em homens quanto em mulheres com níveis de CT elevado ${ }^{91,92}$. Entretanto, para níveis mais baixos de CT $(<250 \mathrm{mg} / \mathrm{dl})$, lovastatina demonstrou ser custo-efetiva em homens em todas faixas etárias, mas somente em mulheres acima dos 55 anos de idade. Esses resultados favoráveis foram reforçados por dados coletados sobre internações hospitalares no ensaio clínico 4S. Nesse estudo, o uso da sinvastina resultou em menos hospitalizações e tempo de permanência hospitalar ( $<34 \%$ dias hospitalares) quando comparado com placebo. $\mathrm{O}$ custo global com o manejo das doenças cardiovasculares também foi reduzido (US\$ 3.872 por paciente), mas considerando o custo do tratamento por 5.4 anos (US\$4.400), esta economia em termos financeiros não prevaleceu ${ }^{93}$. Dados dos ensaios clínicos PLAC I e PLAC II também foram utilizados para avaliar a relação de custo-efetividade da pravastatina na prevenção secundária de doença isquêmica. Em uma estimativa conduzida somente para homens, as relações de custo-efetividade foram muito favoráveis ( $<$ US \$15.000/ano de vida salvo), utilizando-se o ponto de corte norte-americano ${ }^{94}$.

Análises econômicas provenientes de ensaios clínicos são as principais fontes de informação para novos fármacos. Entretanto, é importante salientar que embora essas análises tenham validade interna, a capacidade de generalizar muitos dos resultados é limitada, especialmente no referente a adesão e seguimento do tratamento. O elevado percentual de adesão relatado na maioria dos ensaios clínicos está aquém da observada na prática clínica. Além disso, são selecionados pacientes sem contra-indicações ou intolerância prévias. Por este motivo, outras análises agregando da- 
dos em um contexto mais próximo da realidade devem ser valorizadas. Prosser e cols., utilizando o mesmo modelo americano de risco para doença isquêmica do coração, publicado por Goldman e cols., recentemente reavaliaram as relações de custo-efetividade do tratamento com dieta e com vastatinas em diferentes subgrupos de pacientes ${ }^{95}$ com LDL $\geq 160 \mathrm{mg} / \mathrm{dL}$. Os resultados observados para prevenção secundária com vastatinas foram semelhantes aos resultados obtidos anteriormente. $O$ custo por ano de vida salvo ajustado para qualidade foi <US\$ 45.000 para todos grupos de risco e ficou <US\$10.000 para grupos de maior risco (fig. 1). Para pacientes de maior risco (homens, entre 45-64 anos, tabagistas) o uso de vastatinas é uma ação com potencial de ter uma relação negativa, quando avaliado com planilhas de custos norte-americanos, ou seja, no cômputo global economiza os recursos financeiros, enquanto que salvas mais vidas quando comparado com não tratar ${ }^{95}$. Análises recentes envolvendo uso de vastatinas em pacientes pós-infarto do miocárdio, mas com níveis médios de colesterol também mostraram um custo por ano de vida salvo razoável para parâmetros internacionais (US\$ 16.000 a US\$32.000), sendo eficiente com níveis de LDL-C $>125 \mathrm{mg} / \mathrm{dL}^{96}$.

No cenário de prevenção primária, embora esteja documentado o benefício clínico da redução dos níveis de colesterol, a relação de custo-efetividade não é favorável. São necessários muito mais recursos para prevenção de uma morte ou evento. De um modo geral, dieta tipo I tem sido descrita como mais favorável, com relações de custo-efetividade < US\$ 100.000/ano de vida salvo ajustado para qualidade, tanto em homens quanto em mulheres, com ou sem fa-

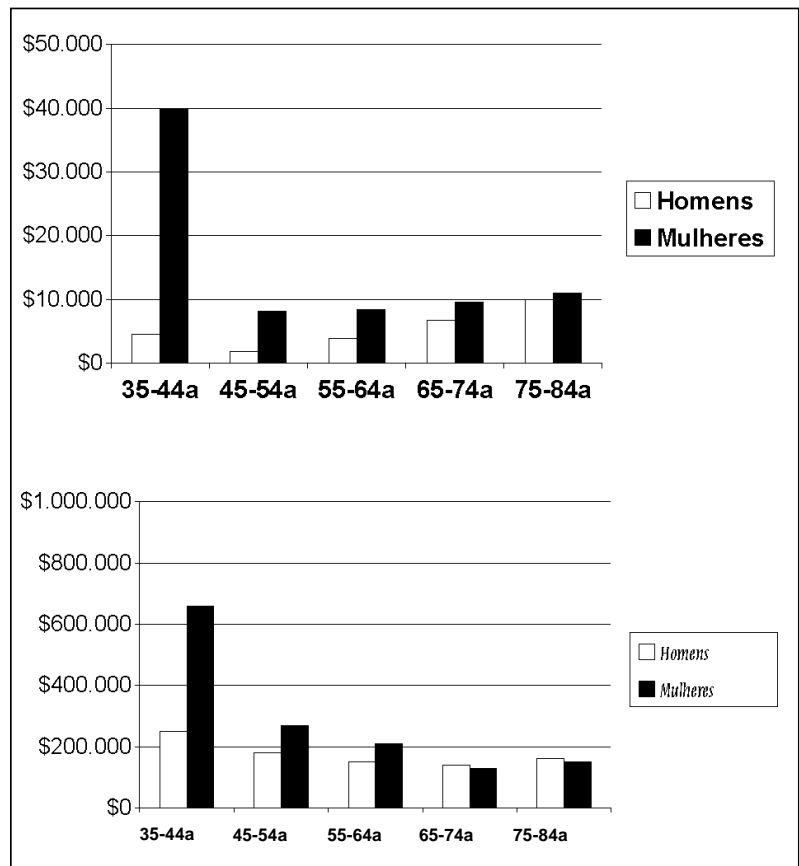

Fig. 1 - Relações de custo-efetividade da prevenção secundária de doença arterial coronariana com vastatinas (parte superior) e prevenção primária (parte inferior) em indivíduos com colesterol LDL $\geq 160 \mathrm{mg} / \mathrm{dl}$. Adaptado de Prosser et al ${ }^{95}$. tores de risco. Quanto maior a concomitância dos fatores de risco e maior a idade, menor é a relação observada ${ }^{91,92,95}$. Em prevenção primária, o uso de vastatinas representa custos por ano de vida salvo ajustado para qualidade que variam de US\$130.000 a US\$260.000 para homens e US\$156.000a US\$730.000 para mulheres. Quanto mais fatores de risco e maior o grupo etário, menor a relação (fig. 2). A maioria dos cenários onde as vastatinas não seriam custo-efetivas, incluem mulheres com menos de 65 anos de idade ou mais idosas mas sem outros fatores de risco, bem como homens jovens com poucos fatores de risco. Na prevenção primária o custo da medicação é responsável por $90 \%$ do custo total, de forma que uma redução do custo dos fármacos em 50$60 \%$ se traduziria diretamente nas relações descritas ${ }^{95}$.

Em conclusão, quando comparado a outras intervenções aceitas na área de saúde, os resultados de estudos conduzidos em outros países demonstram que dieta e o uso de estatina são custo-efetivos para quase todos pacientes com dislipidemia (LDL $\geq 160 \mathrm{mg} / \mathrm{dL}$ ) e para maioria daqueles sem doença mas com múltiplos fatores de risco. De um modo geral, os resultados são semelhantes, com relações de custo-efetividade mais favoráveis para aqueles de maior risco.

Em outros termos, quanto maior o risco absoluto basal (pré-tratamento) maior o benefício clínico e maior o retornofinanceiro. O desafio para o futuro é documentar a relações de custo-efetividade no nosso meio para identificar subgrupos e estratégias de maior eficiência para a população brasileira.

\section{VI-Estratificação de Risco e Metas Lipídicas para Prevençãoe Tratamentoda Aterosclerose}

O risco de doença aterosclerótica é avaliado baseandose na análise conjunta de características que aumentem a chance de um indivíduo desenvolver a doença. É necessário se separar o conceito de fator de risco (FR) (agente causal) de marcador de risco (associação com risco maior, porém sem causalidade estabelecida) ${ }^{97}$. A estratificação é feita pelo risco absoluto, ou seja, risco que tem uma pessoa de desenvolver determinado evento clínico num período de tempo.

\section{Estratificação de risco}

O LDL-C é considerado fator causal e independente de aterosclerose e sobre o qual devemos agir para diminuir a morbi-mortalidade ${ }^{38,74-78,98-100}$. O poder preditor de risco e a meta lipídica adotada para prevenção irão variar dependendo da associação com outros FR. Os principais FR para a aterosclerose ${ }^{38}$ encontram-se na tabela XVIII. A diretriz recomenda, para todos os níveis de risco, modificações no estilo de vida (MEV). A instituição do tratamento farmacológico dependerá do nível de risco, dos níveis do LDL-C, e da eficácia ou não das MEV em modificar os FR. Os níveis de prevenção são divididos em três Categorias: (I) prevenção primária de baixo risco (<10\% em 10 anos), (II) médio risco $(>10 \%$ porém $<20 \%$ em 10 anos), (III) alto risco (risco absoluto de eventos coronarianos $\geq 20 \%$ em 10 anos) e secundária (diabéticos e portadores de aterosclerose). 
Tabela XVIII - Fatores de risco para aterosclerose que modificam as metas de $\mathrm{LDL}-\mathrm{C}^{38}(\mathrm{D})$

Fumo

Hipertensão arterial sistêmica ( $\mathrm{PA} \geq 140 / 90 \mathrm{mmHg}$ )

HDL-C* $<40 \mathrm{mg} / \mathrm{dL}$

Diabetes melito (diabéticos são considerados como portadores de aterosclerose)

Idade ( $\geq 45$ anos homens e $\geq 55$ anos mulheres)

História familiar precoce de aterosclerose (parentes de $1^{\circ}$ grau $<55$ anos homens e $<65$ anos mulheres)

*HDL-C $>60 \mathrm{mg} / \mathrm{dL}$ são considerados um fator protetor devendo ser descontado um fator de risco da soma.

As recomendações propostas são as seguintes:

(I) Baixo risco - Risco absoluto de eventos $<10 \% \mathrm{em}$ 10 anos $^{38}$. Geralmente são indivíduos com 1 FR (excetuando DM) além do colesterol (LDL-C > $160 \mathrm{mg} / \mathrm{dL}$ ). Nesses casos não é recomendado o uso de tabelas de estratificação de $\operatorname{risco}^{38}$.

\section{Recomendação}

Prevenção primária meta: LDL-C <130mg/dL ${ }^{38,74,75}$, entretanto, tolera-se LDL-C até $160 \mathrm{mg} / \mathrm{dL}$.

Perfil desejado: $C T<200 \mathrm{mg} / \mathrm{dL}^{76}, \mathrm{HDL}-\mathrm{C}>40 \mathrm{mg} / \mathrm{dL}$ e $T G<150 \mathrm{mg} / \mathrm{dL}$.

\section{Grau de recomendação: $B$. Nível de evidência: 2 .}

\begin{tabular}{|lcc|}
\hline \multicolumn{3}{|c|}{ Tabela XIX - Tratamento proposto tempo de seguimento e valor } \\
índice do LDL-C.
\end{tabular}

\section{Grau de recomendação: $B$. Nível de evidência: 2 .}

(II) Médio risco - Risco de evento coronário maior que $10 \%$ porém menor do que $20 \%$ em $10 \operatorname{anos}^{38}$.

Geralmente, indivíduos com 2 FR (excetuando DM) além do colesterol (LDL-C $>160 \mathrm{mg} / \mathrm{dL}$ ). O cálculo do risco absoluto de eventos poderá ser feito pelo uso do escore de risco de Framingham ${ }^{101,102}$ (ERF) que avalia o risco de eventos coronarianos em 10 anos. O ERF dá uma idéia do risco de eventos coronarianos em diabéticos, entretanto, não é recomendado para se estabelecer a meta lipídica, já que a mesma nesses indivíduos é LDL-C <100mg/dL. Da mesma forma, o ERF nãoé indicado para os indivíduos portadores de manifestações clínicas da aterosclerose ou dislipidemias de origem genética.

\section{Recomendação \\ Prevenção primária meta: $L D L<130 \mathrm{mg} / d L^{38,74,75}$. \\ Grau de recomendação para o $L D L-C: A$. \\ Nível de evidência: 1 . \\ Perfil desejado: CT <200mg/dL ${ }^{76}$, HDL-C >40mg/dLe \\ TG $<150 \mathrm{mg} / \mathrm{dL}$. \\ Grau de recomendação para os TG e HDL-C:B. \\ Nível de evidência: 2.}

\begin{tabular}{|llll|}
\hline \multicolumn{4}{|c|}{ Tabela XX - Tratamento proposto tempo de seguimento e valor } \\
índice do LDL-C.
\end{tabular}

\section{Grau de recomendação: A. Nível de evidência: 1 .}

(III) Alto risco - Risco de evento $\geq 20 \%$ em 10 anos ou $>20 \%$ extrapolando-se a idade para os 60 anos $^{\mathrm{NR}}$ de vida ${ }^{38,103}$.

Geralmente $>$ de 2 FR (excetuando DM) além do colesterol (LDL-C >160mg/dL), principalmente homens com idade acima dos 55 anos e outros FR associados ${ }^{104}$. Nessa categoria também se incluem, diabéticos ${ }^{105}$ e portadores de doença aterosclerótica coronariana ou não (aneurisma de aorta, insuficiência vascular periférica ou doença cerebrovascular sintomática) ${ }^{38}$. Portadores de síndromes genéticas, como a hipercolesterolemia familiar e a dislipidemia familiar combinada também encontram-se nesse grupo ${ }^{106,107}$. O cálculo do risco absoluto de eventos poderá ser feito pelo uso do escore de risco de Framingham ${ }^{101,102}$ que avalia o risco de eventos coronarianos em 10 anos. OERF dá uma idéia do risco de eventos coronarianos em diabéticos, entretanto, não é recomendado para se estabelecer a meta lipídica, já que a mesma nesses indivíduos é LDL-C $<100 \mathrm{mg} / \mathrm{dL}$. Da mesma forma, o ERF não é indicado para os indivíduos portadores de manifestações clínicas da aterosclerose ou dislipidemias de origem genética. Quando se projeta a idade para os 60 anos de idade tem-se como meta a prevenção a longo prazo. O objetivo desta extrapolação é o controle agressivo dos FR (colesterol, fumo hipertensão arterial e modificação dos hábitos de vida, por exemplo, excesso de peso e sedentarismo).

\section{Recomendação:}

Prevenção primária de alto risco e prevenção secundária meta: $\mathrm{LDL}<100 \mathrm{mg} / \mathrm{dL}^{38,77}$

Grau de recomendação para o LDL-C: $A$.

Nível de evidência: 1.

NR Extrapola-se a idade substituindo-se a idade real do indivíduo por 60 anos, exemplo: Homem 45 anos, coloca-se idade de 60 anos na escala da Framingham no lugar de 45 anos, dessa forma, ao invés de considerarmos 2 pontos na escala de risco iremos considerar 5 pontos. Se o risco absoluto for $\geq 20 \%$, o indivíduo é considerado de alto risco e não de médio risco. 
Perfil desejado: $\mathrm{CT}<200 \mathrm{mg} / \mathrm{dL}^{76}$, HDL-C $>40 \mathrm{mg} / \mathrm{dL}$ (HDL-C $>45 \mathrm{mg} / \mathrm{dL}$ em diabéticos ${ }^{108}$ ) e TG $<150 \mathrm{mg} / \mathrm{dL}$. (B).

Recomendação para o CT: A. Nível de evidência: 2 . Grau de recomendação para o HDL-C e TG: B. Nível de evidência: 2.

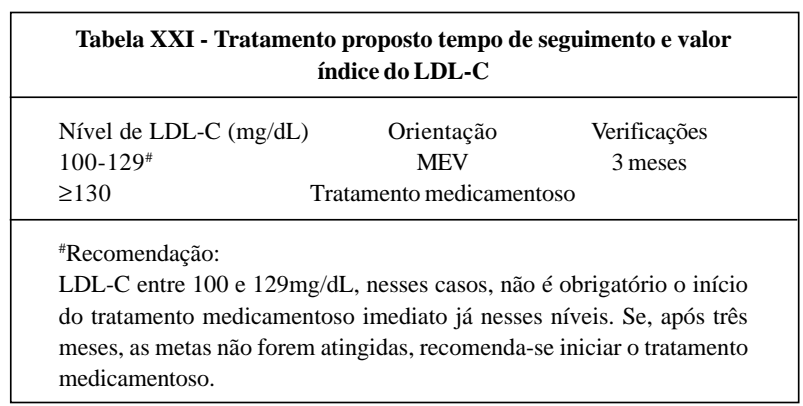

\section{Grau de recomendação: A. Nível de evidência: 1 .}

Uso de escores de risco de Framingham como ferramenta de auxílio na estratificação do risco de eventos clínicos coronarianos

Para a uma melhor identificação do risco absoluto de eventos clínicos foi adotado o ERF como guia de ava-

\begin{tabular}{|ccc|}
\hline \multicolumn{3}{|c|}{ Passo 1 } \\
\hline Idade & Homens & Mulheres \\
\hline $30-34$ & -1 & -9 \\
$35-39$ & 0 & -4 \\
$40-44$ & 1 & 0 \\
$45-49$ & 2 & 3 \\
$50-54$ & 3 & 6 \\
$55-59$ & 4 & 7 \\
$60-64$ & 5 & 8 \\
$65-69$ & 6 & 8 \\
$70-74$ & 7 & 8 \\
\hline
\end{tabular}

\begin{tabular}{|lcc|}
\hline \multicolumn{3}{|c|}{ Passo 2 } \\
\hline Colesterol Total & Homens & Mulheres \\
\hline$<160$ & -3 & -2 \\
$160-199$ & 0 & 0 \\
$200-239$ & 1 & 1 \\
$240-279$ & 2 & 1 \\
$\geq 280$ & 3 & 3 \\
\hline
\end{tabular}

\begin{tabular}{|lcc|}
\hline \multicolumn{3}{|c|}{ Passo 3 } \\
\hline HDL-C & Homens & Mulheres \\
\hline$<35$ & 2 & 2 \\
$35-44$ & 1 & 2 \\
$45-49$ & 0 & 1 \\
$50-59$ & 0 & 0 \\
$\geq 60$ & -1 & -3 \\
\hline
\end{tabular}

\begin{tabular}{|lccc|}
\hline \multicolumn{4}{c|}{ Passo 4 } \\
\hline PAS & PAD & Homens & Mulheres \\
\hline$<120$ & $<80$ & 0 & -3 \\
$120-129$ & $80-84$ & 0 & 0 \\
$130-139$ & $85-89$ & 1 & 0 \\
$140-159$ & $90-99$ & 2 & 2 \\
$\geq 160$ & $\geq 100$ & 3 & 3 \\
\hline
\end{tabular}

Quando os valores da PAS e PAD discordarem usar o mais alto

\begin{tabular}{|lcc|}
\hline \multicolumn{3}{|c|}{ Passos 5 e 6 } \\
\hline Diabetes & Homens & Mulheres \\
\hline Sim & 2 & 4 \\
Não & 0 & 0 \\
Fumo & & \\
Sim & 2 & 0 \\
Não & 0 & \\
\hline
\end{tabular}

\begin{tabular}{|c|}
\hline Passo 7 somar os pontos \\
\hline Idade + CT + HDL-C + PAS ou PAD + DM + Fumo = total de pontos \\
\hline
\end{tabular}

\begin{tabular}{|llll|}
\hline \multicolumn{5}{|c|}{ Passo 8 veja o risco absoluto nas tabelas } \\
\hline Homens & Homens Risco de & Mulheres & Mulheres Risco de \\
Pontos & DAC em 10 anos \% & Pontos & DACem 10 anos \% \\
\hline$<-1$ & 2 & $\leq-2$ & 1 \\
0 & 3 & -1 & 2 \\
1 & 3 & 0 & 2 \\
2 & 4 & 1 & 2 \\
3 & 5 & 2 & 3 \\
4 & 7 & 3 & 3 \\
5 & 8 & 4 & 4 \\
6 & 10 & 5 & 4 \\
7 & 13 & 6 & 5 \\
8 & 16 & 7 & 6 \\
9 & 20 & 8 & 7 \\
10 & 25 & 9 & 8 \\
11 & 31 & 10 & 10 \\
12 & 37 & 11 & 11 \\
13 & 45 & 12 & 13 \\
$\geq 14$ & 53 & 13 & 15 \\
& & 15 & 20 \\
& & 16 & 24 \\
& & 17 & $\geq 27$ \\
\hline
\end{tabular}

liação ${ }^{101,102} \mathrm{O}$ ERF calcula o risco absoluto de eventos coronarianos (morte, IAM e angina de peito) em 10 anos. São atribuídos pontos para idade, pressão arterial sistólica (PAS) e diastólica (PAD), CT, HDL-C, fumo (qualquer cigarro no último mês) e presença ou não de DM. Após o calculo dos pontos deve-se consultar a tabela anexa para ambos os sexos. 


\section{Excessodepeso,obesidade esíndrome plurimetabólica}

O excesso de peso (índice de massa corpórea - IMC $>25 \mathrm{~kg} / \mathrm{m}^{2}$ ), principalmente associado ao acúmulo de gordura na região abdominal, obesidade denominada do tipo central ou androgênica, está associado a um maior risco de doença aterosclerótica ${ }^{109}$. Geralmente, esses indivíduos apresentam: dislipidemia (TG elevado, HDL-C baixo, padrão tipo B da LDL), resistência à insulina, intolerância à glicose e hipertensão arterial, o que caracteriza a síndrome plurimetabólica. Portadores dessa síndrome apresentam risco elevado de aterosclerose ${ }^{38,109}$. A medida da circunferência da cintura nos permite identificar portadores de obesidade androgênica. A cintura é uma medida que se apresenta como um marcador de risco para alterações metabólicas independente do índice de massa corpórea ${ }^{109,110}$. O diagnóstico da síndrome plurimetabólica é feito pela presença de, pelo menos 3 dos 5 critérios abaixo: obesidade abdominal (tab. XXII), TG $\geq 150 \mathrm{mg} / \mathrm{dL}$, HDL-C $<40 \mathrm{mg} / \mathrm{dL}$ nos homens e $<50 \mathrm{mg} / \mathrm{dL}$ nas mulheres, pressão arterial $\geq 130 / 85 \mathrm{mmHg}$ e glicemia $\geq 110 \mathrm{mg} / \mathrm{dL}^{38}$.

\section{Recomendação:}

Nesses indivíduos enfatizamos que a MEV que levem a perda de peso exercício, dieta e em casos específicos farmacoterapia é de extrema importância ${ }^{111}$.

\section{Grau de recomendação: $B$. Nível de evidência: 2 .}

\begin{tabular}{|c|c|c|}
\hline \multicolumn{3}{|c|}{$\begin{array}{c}\text { Tabela XXII - Medida da cintura, e risco "aumentado" e "muito } \\
\text { aumentado" para complicações metabólicas associadas à } \\
\text { obesidade, em caucasianos }{ }^{110}\end{array}$} \\
\hline \multirow[t]{2}{*}{ Sexo } & \multicolumn{2}{|c|}{ Risco de complicações metabólicas } \\
\hline & Aumentado & Muito aumentado \\
\hline Homem & $>94 \mathrm{~cm}$ & $>102 \mathrm{~cm}$ \\
\hline Mulher & $>80 \mathrm{~cm}$ & $>88 \mathrm{~cm}$ \\
\hline
\end{tabular}

\section{VII - Mudança do Estilo de Vida (MEV)}

\section{A - Terapia nutricional}

\section{A.1-Dieta para hipercolesterolemia}

As dislipidemias relacionadas à doença arterial coronariana têm sidoestudadas extensivamente e foi demonstradoque pessoas de países, grupos sociais ou raças que consomem grandes quantidades de gordura têm níveis elevados de colesterol séricoe maior incidência de aterosclerose coronariana e aórtica em relação àqueles que consomem menos gordura.

A terapia nutricional é conduta terapêutica a ser adotada na prevenção e/ou tratamento das dislipidemias. Para alcançar esse objetivo, os pacientes devem ser informados sobre a importância da adesão da dieta, a necessidade na mudança de estilo de vida e, principalmente, como proceder diante dessas situações, provavelmente utilizando técnicas adequadas de mudança de comportamento. Essas modificações deverão ser acompanhadas por nutricionistas.

\section{Recomendação}

O tratamento dietético da hipercolesterolemia deverá seguir a recomendação da "Associação Americana do Coração" 111 ( tab. XXIII).

Grau de recomendação: A. Nivel de evidência: 2 .

\begin{tabular}{|c|c|}
\hline \multicolumn{2}{|c|}{$\begin{array}{c}\text { Tabela XXIII - Dieta da Associação Americana do Coração para } \\
\text { controle da hipercolesterolemia }{ }^{111}\end{array}$} \\
\hline \multicolumn{2}{|c|}{ Recomendações dietéticas para o tratamento das hipercolesterolemias } \\
\hline Nutrientes & Ingestão recomendada \\
\hline Gordura total & 25 a $35 \%$ das calorias totais \\
\hline Ácidos graxos saturados & $<7 \%$ das calorias totais \\
\hline Ácidos graxos poliinsaturados & $>10 \%$ das calorias totais \\
\hline Ácidos graxos monoinsaturados & $>20 \%$ das calorias totais \\
\hline Carboidratos & 50 a $60 \%$ das calorias totais \\
\hline Proteínas & ximadamente $15 \%$ das calorias totais \\
\hline Colesterol & $<200 \mathrm{mg} / \mathrm{dia}$ \\
\hline Fibras & 20 a $30 \mathrm{~g} / \mathrm{d}$ \\
\hline Calorias & a atingir e manter o peso desejável \\
\hline
\end{tabular}

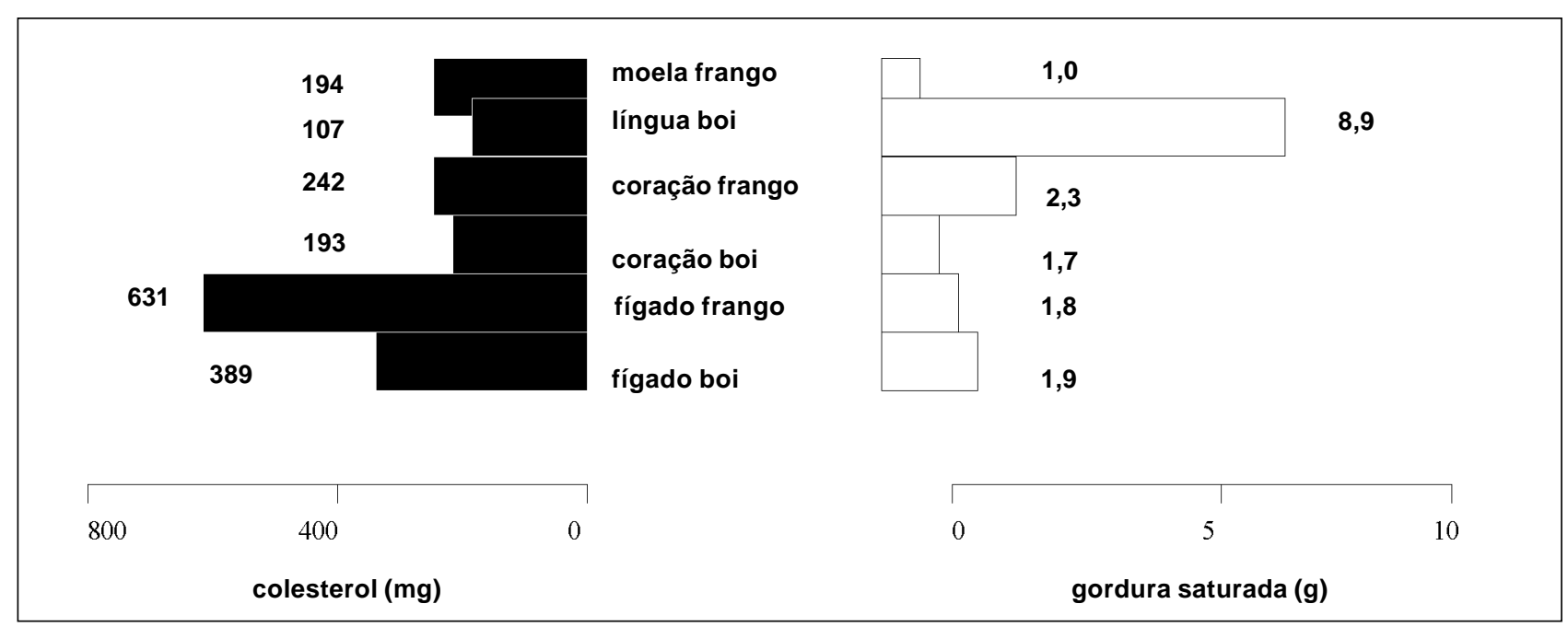

Fig. 2 - Conteúdo de colesterol e gordura saturada em miúdos de bovinos e de frango 
Para melhor adesão à dieta, esta deverá aproximar o máximo possível da habitual, devendo ser nutricionalmente adequada e agradável ao paladar.

O paciente deverá receber também orientações relacionadas à seleção, quantidades e técnicas de preparo e substituições dos alimentos.

\section{1) Colesterol alimentar}

O colesterol alimentar influencia diferentemente os níveis plasmáticos de colesterol. A maioria da população é hipo-responsiva e uma minoria, atribuída, em parte, ao fenótipo de apoE (indivíduos E-4) é hiper-responsiva ${ }^{112}$. O colesterol é encontrado apenas em alimentos de origem animal e possui um menor efeito sobre a colesterolemia, quando comparado à gordura saturada.
Para reduzir a ingestão de colesterol, deve-se restringir o consumo de vísceras (fígado, miolo, miúdos - fig. 2), leite integral e seus derivados (queijo, manteiga, creme de leitefig. 3), biscoitos amanteigados, croissants, folhados, sorvetes cremosos, embutidos (salsicha, lingüiça, bacon, torresmo), frios (presunto, salame, mortadela), pele de aves, frutos do mar (lagosta, camarão, ostra, marisco, polvo-fig. 4). Especial atenção deve se dar à redução na ingestão da gema de ovo (225mg/unidade).

\section{2) Ácidos graxos saturados}

Os ácidos graxos saturados elevam a colesterolemia por reduzirem receptores celulares B-E, inibindo a remoção plasmática das partículas de LDL. Além disso, a gordura saturada, em função da sua estrutura retilínea, permite

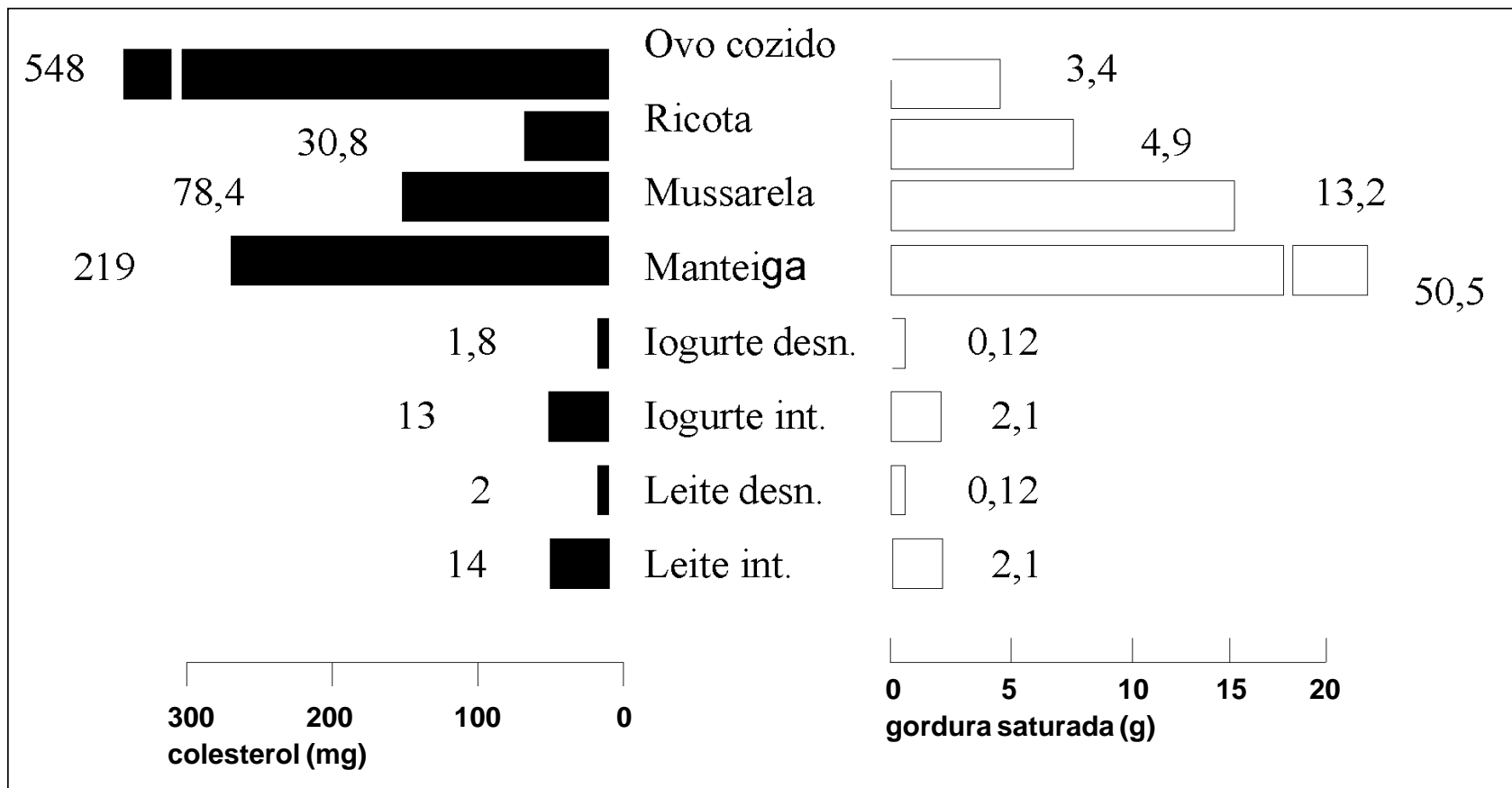

Fig. 3 - Conteúdo de colesterol e gordura saturada em ovos e laticínios

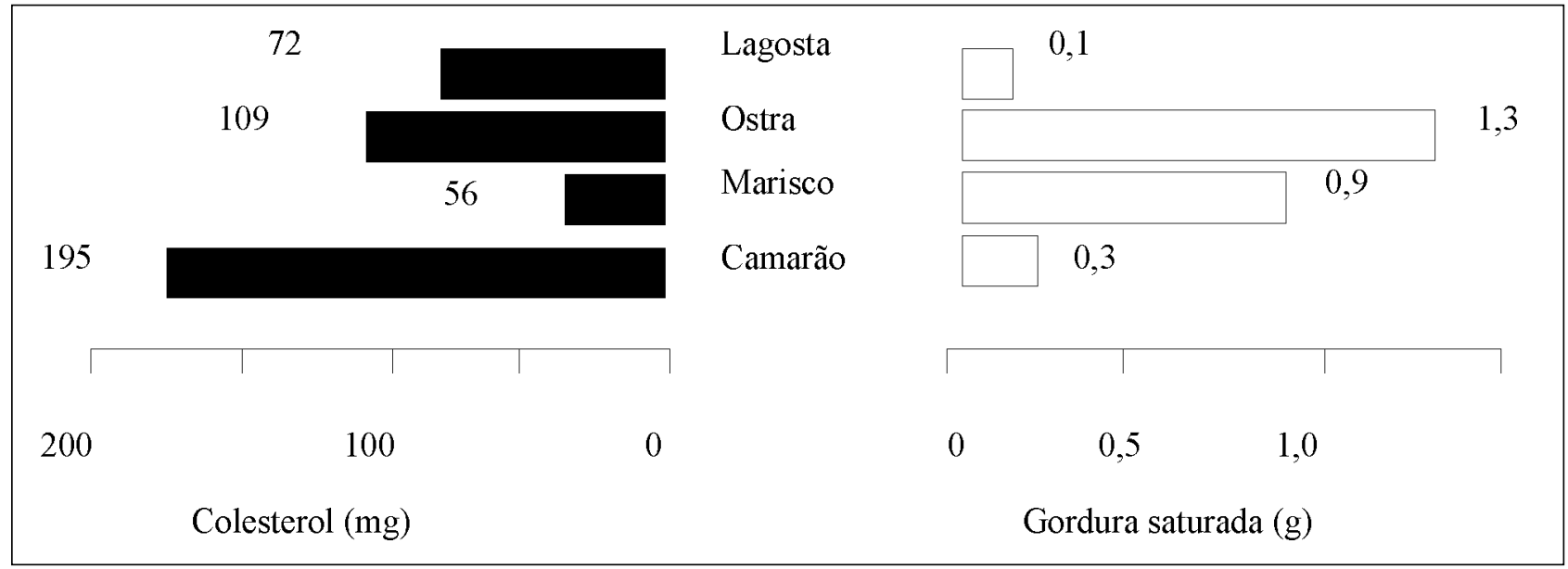

Fig. 4 - Conteúdo de colesterol, e gordura saturada em crustáceos e moluscos (100g). 
maior entrada de colesterol nas partículas de LDL. A ingestão de gordura saturada é a principal causa alimentar de elevação do colesterol do plasma ${ }^{111}$.

Para diminuir o consumo de ácidos graxos saturados, aconselha-se a restrição na ingestão de gordura animal (carnes gordurosas, leite e derivados) polpa de côco e de alguns óleos vegetais (dendê e côco) no preparo dos alimentos ${ }^{113}$.

\section{3) Ácidos graxos insaturados}

Os ácidos graxos insaturados são representados pelas séries ômega-6 (linoléico e araquidônico), ômega-9 (oléico) e ômega-3 ( $\alpha$-linolênico, eicosapentaenóico-EPA e docosahexaenóico-DHA). O ácido linoléico é essencial e é o precursor dos demais ácidos graxos poliinsaturados da série ômega-6, cujas fontes alimentares são os óleos vegetais, exceto os de côco, cacau e palma (dendê). A substituição isocalórica dos ácidos graxos saturados por ácidos graxos poliinsaturados reduz o colesterol total e o LDL-C plasmáticos, por vários mecanismos, sendo os principais: menor produção e maior remoção de LDL e alteração da estrutura das LDL de forma a diminuir o conteúdo de colesterol da partícula. Os ácidos graxos poliinsaturados possuem o inconveniente de baixar os níveis plasmáticos de HDLC e de induzir maior oxidação lipídica. Os ácidos graxos monoinsaturados (ácido oléico) reduzem igualmente o colesterol, sem, no entanto, diminuir o HDL-C e provocar oxidação lipídica. Suas principais fontes dietéticas são o óleo de oliva e óleo de canola, azeitona, abacate e oleaginosas (castanhas, nozes, amêndoas). Os ácidos graxos ômega-3 (EPA e DHA) são encontrados em peixes de águas muito frias e a sua concentração depende da composição do fitoplâncton local. As fontes do ácido $\alpha$-linolênico são os tecidos verdes das plantas, óleo de soja e de canola. Os ácidos graxos ômega-3 diminuem a trigliceridemia plasmática por reduzirem a secreção hepática de VLDL ${ }^{114}$. As principais fontes de ômega-3 encontram-se na tabela XXIV ${ }^{115}$.

\section{4) Ácidos graxos trans}

Os ácidos graxos trans são sintetizados durante o processo de hidrogenação dos óleos vegetais na produção de margarinas ${ }^{116}$. As moléculas de hidrogênio na posição cis (ácido oléico) produzem configuração com ângulo na cadeia de carbono, enquanto que na forma trans a cadeia é retilínea (semelhante à dos ácidos graxos saturados). Pela semelhança estrutural com a gordura saturada, a gordura

\begin{tabular}{|lcc|}
\hline & Tabela XXIV - Fontes de ômega-3 & \\
\hline $100 \mathrm{115}$ & $\mathrm{EPA}+\mathrm{DHA}(\mathrm{g})$ & Alfa linolênico (\%) \\
Cavala & 2,5 & - \\
Sardinha & 1,7 & - \\
Arenque & 1,6 & - \\
Salmão & 1,0 & - \\
Truta & 0,5 & - \\
Bacalhau & 0,2 & - \\
Óleo de canola & - & 9,0 \\
Óleo de soja & - & 7,08 \\
\hline
\end{tabular}

trans também provoca elevação da colesterolemia, com uma desvantagem maior de elevar o LDL-C e reduzir o HDL-C. Quanto mais dura for a consistência da margarina, maior será o teor de trans. Outras fontes importantes de gordura trans são: óleos e gorduras hidrogenadas, e shortenings, estes definidos como gorduras industriais presentes em sorvetes, chocolates, pães recheados, molhos para salada, maionese, cremes para sobremesas e óleos para fritura industrial.

\section{5) Fibras}

São carboidratos complexos, não absorvidos pelo intestino, com ação reguladora na função gastrointestinal. São classificadas, de acordo com sua solubilidade em água, em solúveis e insolúveis. As fibras solúveis são representadas pela pectina (frutas) e pelas gomas (aveia, cevada e leguminosas: feijão, grão de bico, lentilha e ervilha), reduzem o tempo de trânsito gastrointestinal e ajudam na eliminação do colesterol ${ }^{111}$. As fibras insolúveis não atuam sobre a colesterolemia, mas aumentam a saciedade, auxiliando na redução da ingestão calórica. São representadas pela celulose (trigo), hemicelulose (grãos) e lignina (hortaliças). A redução dos níveis de colesterol observada com o uso de fibras nas dietas, muitas vezes não é suficiente para a normalização da colesterolemia e requer grandes quantidades, que são pouco toleradas. Todavia, aceleram o trânsito gastrointestinal, o que é útil quando se usam as resinas quelantes de ácidos biliares, droga hipolipemiante com ação na redução do colesterol, porém obstipante ${ }^{117}$.

\section{Recomendação}

A recomendação de ingestão de fibra alimentar total para adultos é de 20 a 30g/dia, sendo em torno de $25 \%$ (6g) de fibra solúvel ${ }^{111}$.

Grau de recomendação: $B$. Nível de evidência: 2.

\section{6) Fitosteróis}

Os fitosteróis são encontrados apenas nos vegetais e desempenham funções estruturais análogas ao colesterol em tecidos animais. O beta-sitosterol é o principal fitosterol encontrado nos alimentos e é extraído dos óleos vegetais. A esterificação do beta-sitosterol, formando sitosterol-éster, melhorou a sua solubilidade possibilitando a sua adição a alimentos. O sitostanol-éster é sintetizado através da saturação do beta-sitosterol. O sitostanol-éster e o beta-sitosterol reduzem igualmente a colesterolemia, por diminuírem a absorção do colesterol alimentar, que é deslocado para fora da micela, por um mecanismo de competição com os fitosteróis ${ }^{118}$. Uma dieta balanceada com quantidades adequadas de vegetais fornece aproximadamente $200 \mathrm{mg}-400 \mathrm{mg}$ de fitosteróis e os níveis plasmáticos variam de $0,3 \mathrm{mg} / \mathrm{dL}$ $1,7 \mathrm{mg} / \mathrm{dL}$. A ingestão de $3 \mathrm{~g}-4 \mathrm{~g} /$ dia de fitosteróis promove a redução de nível de LDL-C ao redor de 10\%-15\% em média. O fitosterol não influencia os níveis plasmáticos de HDL e de triglicérides. 


\section{Recomendação}

A ingestão de $3 \mathrm{~g}-4 \mathrm{~g} / \mathrm{dia}$ de fitosteróis pode ser utilizada como adjuvante ao tratamento hipolipemiante ${ }^{118}$.

Grau de recomendação: $B$. Nível de evidência: 2 .

\section{7) Soja}

As principais fontes de soja na alimentação são: feijão de soja, óleo de soja, queijo de soja (tofu), molho de soja (shoyu), farinha de soja, leite de soja e o concentrado protéico da soja, que exclui a presença de gorduras, mantém a presença de carboidratos e possui $75 \%$ da sua composição em proteínas. Este concentrado de proteínas da soja é amplamente utilizado como base de alimentos liofilizados e como "suplemento protéico". Uma metanálise mostrou 38 trabalhos sobre os efeitos da ingestão da proteína da soja sobre os lípides séricos. O consumo de proteína de soja em substituição à proteína animal, provocou uma redução de $9,3 \%$ no nível de colesterol total, 12,9\% no LDL-C e 10,5 nos TG. Nesses estudos, foram utilizados subprodutos protéicos da soja (proteína isolada de soja e proteína texturizada de soja). A ingestão de proteína de soja variou entre $17 \mathrm{~g} \mathrm{a} 124 \mathrm{~g} / \mathrm{dia}^{119}$.

Quanto à ação específica nos mecanismos propostos envolvidos na gênese da aterosclerose, acredita-se que as isoflavonas, grupo de fitoquímicos classificados como fitoestrógenos, estariam relacionados à prevenção da aterosclerose, pela ação que exercem sobre as concentrações dos lípides plasmáticos, efeitos antioxidantes e antiproliferativos sobre as células musculares lisas e efeitos sobre a formação do trombo e na manutenção da reatividade vascular normal. A presença das fibras na soja modificando a absorção e o metabolismo dos ácidos biliares e, também, as saponinas, glicosídeo vegetal que atua no aumento da eliminação da bile no intestino e, subseqüentemente, na redução dos níveis de colesterol plasmático, estariam relacionados também na prevenção.

Com a finalidade de salientar os efeitos saudáveis da soja, um produto deve conter $6,25 \mathrm{~g}$ de proteína da soja ou mais, pouca quantidade de gordura total $(<3 \mathrm{~g})$ e gordura saturada $(<1 \mathrm{~g})$ e possuir baixo teor de colesterol $(<20 \mathrm{mg})$.

\section{Recomendação}

O consumo de produtos contendo $6,25 \mathrm{~g}$ de proteína da soja ou mais, menos de $3 \mathrm{~g}$ de gordura total e menos de $1 \mathrm{~g}$ de gordura saturada e com menos de $20 \mathrm{mg}$ de colesterol podem ser consumidos para a redução do LDL-C ${ }^{119}$.

\section{Grau de recomendação: B. Nível de evidência: 2 .}

\section{8) Café}

Os grãos de café contêm duas substâncias denominadas cafestol e kahweol que elevam o colesterol sérico ${ }^{120}$. A água quente utilizada para o preparo do café, remove algumas dessas substâncias gordurosas dos grãos e estas ficam presentes no líquido que não é coado. Portanto, a recomendação é sempre que possível usar o filtro de papel, pois este tem a propriedade de reter as substâncias citadas. O café preparado em determinados países, como a Noruega,
França e Finlândia e os conhecidos café árabe e tipo expresso, possuem quantidades variadas dessas substâncias que podem elevar os níveis de colesterol, bem como no Brasil, com o uso do coador de pano.

\section{Recomendação}

Pacientes com níveis aumentados de colesterol, devem consumir café somente filtrado, para evitar a ingestão de substâncias presentes nos grãos que contribuem para a elevação do colesterol ${ }^{120}$.

\section{Grau de recomendação: B. Nível de evidência: 3 .}

\section{9) Antioxidantes}

Inúmeras pesquisas têm demonstrado que a oxidação da LDL desempenha importante papel na patogênese da aterosclerose $^{121}$.

A utilização de substâncias antioxidantes, como flavonóides, vitaminas $\mathrm{C} \mathrm{e} \mathrm{E,} \mathrm{e} \mathrm{os} \mathrm{carotenóides,} \mathrm{com} \mathrm{o} \mathrm{objetivo}$ de prevenir ou reduzir o desenvolvimento da doença aterosclerótica, vem sendo amplamente pesquisada e estudada ${ }^{122}$.

Flavonóides - São antioxidantes polifenólicos encontrados nos alimentos, principalmente nas verduras, frutas, grãos, sementes, castanhas, condimentos e ervas e também em bebidas como vinho e chá ${ }^{122}$. Os flavonóides mais importantes são: quercitina, campferol, miricetina e crisina. A quercetina é encontrada principalmente nas frutas (cereja, amora, uva, morango, jabuticaba), grãos, batata, berinjela, feijão marrom e cebola. O campferol está presente no rabanete, couve, escarola e nabo. A quantidade de flavonóides presente nas bebidas é alta e a miricetina é o mais importante, encontrado principalmente em vinhos e suco de uva. Os mecanismos e locais de absorção dos polifenóis nos humanos, e sua biodisponibilidade em geral, não estão bem esclarecidos. Estão presentes em complexas formas poliméricas e glicosídicas, que não podem ser facilmente degradadas pelos sucos digestivos, e sua insolubilidade pode limitar ou mesmo impedir sua absorção. Estudos demonstraram relação inversa entre o consumo de alimentos ricos em flavonóides e a mortalidade por doença arterial coronariana em função de sua ação na inibição da oxidação da LDL e na redução da agregação plaquetária ${ }^{121}$.

Com relação ao vinho tinto e suco de uva, algumas pesquisas demonstraram a ação antioxidante de ambos in vitro, sendo que in vivo apenas o vinho tinto foi eficaz. Portanto, os estudos apenas sugerem que os flavonóides presentes na dieta podem estar envolvidos na prevenção da aterosclerose por inibirem a oxidação das LDL, diminuindo sua aterogenicidade e, conseqüentemente, o risco de doença arterial coronariana ${ }^{122,123}$.

Vitaminas - De acordo com a hipótese oxidativa ${ }^{121}$, as vitaminas antioxidantes, por terem propriedades lipofílicas, exerceriam o seu efeito antiaterogênico através da sua incorporação à partícula da LDL, tornando-a menos sensível à oxidação. As vitaminas $\mathrm{C}, \mathrm{E}$ e os carotenóides demonstraram in vitro capacidade de aumentar a resistência da LDL à oxidação. Para a prática atual, após uma análise dos trabalhos realizados com vitaminas antioxidantes, não há evi- 
dência de estudos randomizados, controlados e com número suficiente de eventos de que a suplementação de vitamina E, C ou beta caroteno previna eventos clínicos relacionados à aterosclerose ${ }^{12,123}$. Pelo contrário, a suplementação com betacaroteno pode até aumentar o risco de neoplasia pulmonar em fumantes ${ }^{123-130}$. Principais fontes de antioxidantes naturais (tab. XXV).

\section{Recomendação}

Não há evidência de que vitaminas antioxidantes previnam manifestações clínicas da aterosclerose, portanto essas não são recomendadas ${ }^{124-130}$. Uma alimentação rica em frutas e vegetais diversificados fornece doses apropriadas de substâncias antioxidantes, que certamente contribuirão para a manutenção da saúde.

\section{Grau de recomendação: D. Nível de evidência: 1 .}

\section{0) Álcool}

A literatura documenta a ação do consumo de quantidade moderada de álcool a efeitos benéficos sobre a mortalidade por doença coronariana ${ }^{131-133}$. Esse efeito cardioprotetor do álcool é parcialmente atribuído a sua capacidade de elevar a concentração de HDL-C e, também, efeito sobre a hemostasia, reduzindo o fibrinogênio e inibindo a agregação plaquetária. Há controvérsias a respeito da equivalência protetora que todas as bebidas alcoólicas exerceriam sobre a doença aterosclerótica, entretanto não há provas de que uma seja superior a outra ${ }^{133}$. Alguns autores relatam redução de $26 \%$ no risco de doença cardiovascular em homens que consomem $5 \mathrm{ml}$ a $30 \mathrm{ml}$ de álcool/dia (350ml de cerveja, 30ml de bebidas destiladas e $100 \mathrm{ml}$ de vinho), quando comparados com os abstêmios. Pela análise de inúmeros estudos, pode-se observar que a relação consumo de etanol versus o risco de aterosclerose se faz na forma de um "J", sendo o eixo das abcissas, o tempo e o eixo das ordenadas, o risco. Segundo revisão de alguns estudos populacionais, caminhando-se de forma ascendente, há redução do risco até um limite, passando por uma fase de estagnação, onde o aumento do consumo não interfere, até chegar-se ao ponto onde há elevação vertiginosa desse risco, já associada à maior mortalidade geral. Entretanto, os efeitos deletérios do álcool devem ser considerados, principalmente em indivíduos propensos à hipertrigliceridemia, onde a alta

\begin{tabular}{|ll|}
\hline \multicolumn{2}{|c|}{ Tabela XXV - Fontes alimentares de substâncias antioxidantes } \\
\hline Antioxidante & Fontes alimentares \\
\hline Vitamina E (alfa-tocoferol) & $\begin{array}{l}\text { Óleos de sementes, nozes, abacate, } \\
\text { grãos, cereais, ovos, vegetais verdes e } \\
\text { grãos de soja. }\end{array}$ \\
Vitamina C (ácido ascórbico) & $\begin{array}{l}\text { Frutas cítricas e vegetais, } \\
\text { principalmente brócolis, } \\
\text { repolho e tomate. }\end{array}$ \\
& $\begin{array}{l}\text { Verduras, frutas, grãos, sementes, } \\
\text { Flavonóides }\end{array}$ \\
& $\begin{array}{l}\text { condimentos e ervas, chás verdes e vinho. } \\
\text { Carotenóides }\end{array}$ \\
& pimentão, espinafre e outros legumes. \\
\hline
\end{tabular}

ingestão de álcool pode causar elevação dos níveis de triglicerídeos por meio da estimulação da produção de VLDL pelo fígado. O álcool também pode levar ao aumento da pressão arterial, do peso corporal, da glicemia além de alterações gastrointestinais, como cirrose hepática, câncer de pâncreas e insuficiência múltipla de órgãos e sistemas.

\section{Recomendação}

Não se recomenda o consumo de álcool para prevenção da aterosclerose ${ }^{131-133}$.

\section{Grau de recomendação: D. Nível de evidência: 4 .}

\section{1) Homocisteína}

Embora a literatura não seja ainda conclusiva sobre o fato de a homocisteína ser considerada fator de risco independente, a elevação deste aminoácido pode ser um possível marcador para o desenvolvimento de doença vascular e para um pior prognóstico dos indivíduos com aterosclerose ${ }^{33,134}$. A interpretação dos valores plasmáticos de homocisteína deve ser realizada com cautela, considerando-se que fatores como baixos níveis plasmáticos de albumina e de vitaminas (B12, B6 e ácido fólico) podem, respectivamente, interferir na sua dosagem ou provocar a sua elevação no plasma. Portanto, a elevação da homocisteína poderia ser apenas um indicador de deficiência nutricional. Outro fator importante a ser considerado é o de que alguns indivíduos têm polimorfismos de enzimas que participam do metabolismo da metionina como a MTHFR (metilenotetrahidrofolato redutase), que participa da conversão do homocisteína a metionina nos tecidos extra-hepáticos. Alguns polimorfismos, mesmo em sua forma heterozigota, podem predispor a elevações de homocisteinemia. Para o metabolismo normal da homocisteína, é necessária a ingestão adequada de vitamina B12, B6 e ácido fólico. A recomendação diária de ácido fólico é de $200 \mathrm{mcg}$, vitamina B12 é de $2 \mathrm{mcg}$ e vitamina B6é de $2 \mathrm{mg}$ (RDA).Uma dieta nutricionalmente balanceada, com quantidades adequadas de hortaliças, frutas, grãos e carnes magras, supre tais recomendações.

\section{Recomendação}

Não há recomendação para suplementação de ácido fólico e ou vitaminas B12 e B6 para a prevenção da aterosclerose ${ }^{111}$.

\section{Grau de recomendação: D. Nível de evidência: 4.}

\section{A. 2 - Dieta para a hipertrigliceridemia Recomendação}

Pacientes com níveis muito elevados de TG e que apresentem quilomicronemia, devem reduzir a ingestão de gordura total da dieta ${ }^{111}$. Na hipertrigliceridemia secundária à obesidade ou diabetes, recomenda-se, respectivamente, dieta hipocalórica, restrição de carboidratos e compensação do diabetes. Recomenda-se restrição total do consumo de álcool.

Grau de recomendação: $B$. Nível de evidência: 4. 


\section{B-Exercício físico}

O sedentarismo constitui fator de risco para a aterosclerose $^{135}$. O exercício previne a doença aterosclerótica ${ }^{136,137}$. O estilo de vida que conte com exercícios físicos e alimentação saudável tem sido destacado como aspecto essencial na prevenção e tratamento da cardiopatia isquêmica ${ }^{136,139}$. Modificações dietéticas acompanhadas de um programa de exercícios físicos areróbios otimizam as mudanças do perfil lipoprotéico plasmático ${ }^{140}$.

Quanto ao impacto isolado do exercício sobre o HDLC, LDL-C e TG, a literatura tem evidenciado modificações variáveis após programas aeróbios com mais de quatro semanas de duração em indivíduos sem sobrepeso, com os estudos sendo ainda insuficientes para uma posição definitiva em relação a subgrupos, como o caso de obesos e idosos ${ }^{141-146}$. O impacto dos programas regulares de treinamento físico aeróbio tem sido mais expressivo em homens com baixo HDL-C, elevada trigliceridemia e obesidade abdominal ${ }^{147}$.

Tanto a implementação de exercícios de alta como de baixa intensidade, realizados em faixas de $85 \%$ a $90 \%$ e em torno de $50 \%$ a $70 \%$ do consumo máximo de oxigênio, respectivamente, podem reduzir os triglicérides e aumentar do HDL-C. Além disso, há melhora da condição cardiorrespiratória melhora da composição corporal, redução da obesidade, do estresse, do nível de catecolaminas e também do efeito benéfico na pressão arterial ${ }^{148}$.

\section{Recomendação ${ }^{136,137}$}

Devem ser adotadas, com freqüência de três a seis vezes por semana, sessões de em média, 40min. De atividade física aeróbia. A zona alvo do exercício aeróbio deve ficar na faixa de $60 \%$ a $80 \%$ da frequiência cardíaca máxima, observada em teste ergométrico, realizado na vigência dos medicamentos de uso corrente. O componente aeróbio das sessões de condicionamento físico deve ser acompanhado por atividades de aquecimento, alongamento e desaquecimento. É interessante que sejam oferecidas, em média duas vezes por semana, sessões de exercícios que aprimorem a força e a flexibilidade.

\section{Grau de recomendação: B. Nível de evidência: 2 .}

\section{C-Tabagismo}

O tabagismo é fator de risco independente para a aterosclerose e deve ser combatido de forma agressiva ${ }^{38}$. O tratamento do tabagismo passa por duas etapas: abordagem cognitivo comportamental e farmacoterapia ${ }^{149,150}$.

\section{1) Métodos eficazes para a cessação de fumar}

Abordagem Cognitivo-Comportamental

Os componentes principais dessa abordagem envolvem: 1) a detecção de situações de risco de recaída; 2) o desenvolvimento de estratégias de enfrentamento. A abordagem é caracterizada por: 1) preparar o fumante para soluções de seus problemas; 2) estimular habilidades para resistir as tentações de fumar; 3) preparar para prevenir a recaí$\mathrm{da} ; 4)$ preparar o fumante para lidar com o estresse.
Quanto maior for o tempo dedicado em cada abordagem do fumante maior a taxa de cessação. Assim, quando comparadas com as situações em que nenhum aconselhamento é dado ao fumante, a abordagem mínima ( $<3 \mathrm{~min})$ aumenta a taxa de cessação de fumar em $30 \%$, a abordagem de $3 \mathrm{~min}$ a $10 \mathrm{~min}$ aumenta em $60 \%$ e a abordagem com de 10 min de duração aumenta em mais de $100 \%$.

\section{Recomendação ${ }^{149,150}$}

Deve ser realizada abordagem cognitivo comportamental em todos os pacientes pois essa aumenta a taxa de cessação de fumar.

\section{Grau de recomendação: A. Nivel de evidência: 2 .}

\section{Farmacoterapia ${ }^{149,150}$}

A farmacoterapia pode ser utilizada como um apoio, em situações bem definidas, para alguns pacientes que desejam parar de fumar. Ela tem a função de facilitar a abordagem cognitivo-comportamental, que é a base para a cessação de fumar e deve sempre ser utilizada.

Os medicamentos eficazes são divididos em duas categorias: medicamentos nicotínicos e medicamentos não nicotínicos. Os medicamentos nicotínicos, também chamados de terapia de reposição de nicotina (TRN), apresentam-se nas formas de adesivo, goma de mascar, inalador e aerossol. As duas primeiras, correspondem a formas de liberação lenta de nicotina, e são, no momento as únicas formas disponíveis no mercado brasileiro. Os medicamentos não-nicotínicos, são os anti-depressivos bupropiona e nortriptilina e o anti-hipertensivo clonidina. A bupropiona é o medicamento de eleição nesse grupo, pois, segundo estudos científicos, é um medicamento que não apresenta, nas doses usuais, tanto efeitos colaterais como a nortriptilina e a clonidina.

A) Critérios para utilização da farmacoterapia - Para prescrição de apoio medicamentoso sugerimos critérios de acordo com o grau de dependência física da nicotina: fumantes pesados, ou seja, que fumam 20 ou mais cigarros por dia; fumantes que fumam o $1^{\circ}$ cigarro até $30 \mathrm{~min}$ após acordar e fumam no mínimo 10 cigarros por dia; fumantes com escore do teste de Fagerström (tab. XXVI), igual ou maior do que 5, ou avaliação individual, a critério do profissional; fumantes que já tentaram parar de fumar anteriormente apenas com a abordagem cognitivo-comportamental, mas não obtiveram êxito, devido a sintomas da síndrome de abstinência; não haver contra-indicações clínicas.

B) Critérios para seleção do medicamento - Em geral, a monoterapia é suficiente, para a maioria dos pacientes. A escolha entre uma das formas de terapia de reposição de nicotina (TRN) (adesivo e goma de mascar) e bupropiona dependerá da avaliação individual do paciente pelo profissional. Não havendo contra-indicações clínicas, podem ser escolhidos os medicamentos acima, de acordo com a posologia e facilidade de administração. Assim, entre os medicamentos de $1^{\mathrm{a}}$ linha, não existe um critério fechado de escolha, devendo-se na ausência de contra-indicações, fazer a opção levando em conta a opinião e vontade do paciente, o que tende a aumentar a aderência ao tratamento. 
Tabela XXVI - Escore do teste de Fagerström para fumantes

1 - Quanto tempo após acordar você fuma seu primeiro cigarro? Dentro de 5 minutos (3) Entre 6 e 30 minutos Entre 31 e 60 minutos Após 60 minutos

(0)

2 - Você acha difícil não fumar em lugares proibidos como igrejas, bibliotecas, etc?

$$
\begin{aligned}
& \text { Sim } \\
& \text { Não }
\end{aligned}
$$

3 - Qual o cigarro do dia que traz mais satisfação?

O primeiro da manhã

Outros

(0)

4 - Quantos cigarros você fuma por dia?

Menos de 10

(0)

De 11 a 20

(1)

De 21 a 30

(2)

Mais de 31

(3)

5 - Você fuma mais freqüentemente pela manhã? Sim

Não

(1)

(0)

6 - Você fuma mesmo doente quando precisa ficar de cama a maior parte do tempo?
Sim
(1)

Não

(0)

Grau de Dependência
$0-2$ pontos $=$ muito baixo
$3-4$ pontos $=$ baixo
5 pontos $=$ médio
$6-7$ pontos $=$ elevado
$8-10$ pontos $=$ muito elevado

Nos casos em que houver falha de tratamento, ou seja, em que o paciente não conseguiu parar de fumar após ter sido realizada abordagem cognitivo-comportamental e utilizado apenas um dos medicamentos de $1^{\mathrm{a}}$ linha, pode-se pensar na associação dessas formas terapêuticas. Estudos mostram que a associação entre adesivo e goma de mascar de nicotina, ou entre adesivo de nicotina e bupropiona ou mesmo entre goma de mascar de nicotina e bupropiona, elevam as taxas de sucesso no processo de cessação de fumar ${ }^{151}$.

Devidos a seus efeitos colaterais, e por terem sido testados em pequenas amostras de poucos estudos científicos, a nortriptilina e a clonidina só devem ser utilizadas após insucesso das terapias de primeira linha, sob supervisão médica.

Medicações de primeira linha - Apresentações e dosagens: adesivo de nicotina $21 \mathrm{mg}, 14 \mathrm{mg} \mathrm{e} 7 \mathrm{mg}$; goma de mascar de nicotina $2 \mathrm{mg}$; goma de mascar de 4mg*; inalador de nicotina $4 \mathrm{mg}^{*}$; spray nasal de nicotina $1 \mathrm{mg} *$; bupropiona comprimidos de 150mg. (* Não disponíveis no Brasil)

Medicações desegundalinha-Nortriptilina $10 \mathrm{mg}, 25 \mathrm{mg}$, $75 \mathrm{mg}$; clonidina $0,10 \mathrm{mg}, 0,15 \mathrm{mg}, 0,20 \mathrm{mg}$.

\section{Posologia e forma de uso}

Gomademascar denicotina-Pacientesquefumamaté 20 cigarros por dia e fumam seu $1^{\circ}$ cigarro nos primeiros $30 \mathrm{~min}$ após acordar, utilizar goma de mascar com o seguinte esquema: semana 1 a 4: 1 tablete a cada $1 \mathrm{~h} \mathrm{a} 2 \mathrm{~h}$; semana 5 a 8: 1 tablete a cada $2 \mathrm{ha} 4 \mathrm{~h}$; semana $19 \mathrm{a} 12: 1$ tablete a cada $4 \mathrm{ha} 8 \mathrm{~h}$.
Pacientes que fumam mais de 20 cigarros por dia, utilizar o seguinte esquema: semana 1 a 4: 1 tablete de $4 \mathrm{mg}$ a cada $1 \mathrm{~h}$ a $2 \mathrm{~h}$ (obs: até o momento dessa publicação ainda não havia goma de $4 \mathrm{mg}$ no mercado brasileiro); semana 5 a 8: 1 tablete de $2 \mathrm{mg}$ a cada $2 \mathrm{~h}$ a $4 \mathrm{~h}$; semana 9 a $12: 1$ tablete de $2 \mathrm{mg}$ a cada $4 \mathrm{~h}$ a $8 \mathrm{~h}$.

Atenção: lembrar de recomendar que se deve parar de fumar ao iniciar o medicamento.

A goma deve ser mastigada com força algumas vezes, até sentir formigamento, ou o sabor da nicotina. Nesse momento, deve-se parar de mastigar e repousar a goma entre a bochecha e a gengiva, até o formigamento passar. Após, voltar a mastigar com força e repetir a operação por $30 \mathrm{~min}$, quando deve-se jogar fora a goma de mascar. Durante o uso da goma não se pode beber nenhum líquido, mesmo que seja água. A dose máxima recomendada é de 15 gomas por dia.

Adesivo de nicotina - Pacientes com escore do teste de Fagerström entre 8 a 10, e/ou fumante de mais de 20 cigarros por dia, utilizar o seguinte esquema: semana 1 a 4 : adesivo de $21 \mathrm{mg}$ a cada $24 \mathrm{~h}$; semana 5 a 8 : adesivo de $14 \mathrm{mg}$ a cada $24 \mathrm{~h}$; semana 9 a 12: adesivo de $7 \mathrm{mg}$ a cada $24 \mathrm{~h}$.

Pacientes com escore do teste de Fagerström entre 5 a 7 , e/ou fumante de 10 a 20 cigarros por dia e fumam seu $1^{\circ}$ cigarro nos primeiros $30 \mathrm{~min}$ após acordar, utilizar o seguinte esquema: semana 1 a 4 : adesivo de $14 \mathrm{mg}$ a cada $24 \mathrm{~h}$; semana 5 a 8 : adesivo de $7 \mathrm{mg}$ a cada $24 \mathrm{~h}$.

Em casos especiais, em grandes dependentes físicos de nicotina, pode-se avaliar a possibilidade da utilização de dois adesivos de $21 \mathrm{mg}$, concomitantes, perfazendo o total de $42 \mathrm{mg}$, desde que não haja contra-indicações.

Atenção: lembrar de recomendar que se deve parar de fumar ao iniciar o medicamento.

O adesivo deve ser aplicado apenas na região do tronco ou braços, fazendo um rodízio do local da aplicação a cada 24h. A região deve estar protegida da exposição direta do sol, porém, não há restrição quanto ao uso na água.

Bupropiona - Deve-se utilizar a seguinte dosagem, porém em caso de intolerância, pode-se fazer ajuste posológico, a critério clínico: 1 comprimido de 150mg pela manhã por 3 dias; 1 comprimido de $150 \mathrm{mg}$ pela manhã e outro comprimido de $150 \mathrm{mg}$, $8 \mathrm{~h}$ após, a partir do $4^{\circ}$ dia, até completar 12 semanas.

Atenção! Deve-se parar de fumar no $8^{\circ}$ dia após início da medicação.

A dose máxima de bupropiona recomendada é de $300 \mathrm{mg}$ por dia.

\section{Contra-indicações e precauções}

As contra-indicações e precauções das medicações acima são:

Goma de mascar de nicotina - Contra-indicações: incapacidade de mascar, úlcera péptica, período de 15 dias após episódio de infarto agudo do miocárdio,

Precauções - Para gestantes ou mulheres em fase de amamentação, deve-se considerar o uso da goma de mascar, em situações em que o risco de continuar fumando é maior do que o da goma. Nesse caso, é preferível usar a goma de 
mascar e não o adesivo de nicotina. Isso se deve ao fato de que a absorção da nicotina a partir da goma de mascar nãoé contínua, como ocorre com o adesivo.

Adesivo de nicotina - Contra-indicações: doenças dermatológicas que impeçam a aplicação do adesivo, período de 15 dias após episódio de infarto agudo do miocárdio, gestante e amamentação.

Bupropiona - Contra-indicações: absolutas: risco de convulsão: antecedente convulsivo, epilepsia, convulsão febril na infância, anormalidades eletroencefalográficas conhecidas e alcoolistas em fase de retirada de álcool; uso de benzodiazepínico ou outro sedativo, uso de outras formas de bupropirona (Wellbutrin), doença cerebrovascular, tumor de sistema nervoso central, bulimia, anorexia nervosa e uso de inibidor da MAO há menos de 15 dias; relativas: uso de carbamazepina, uso de cimetidina, uso de barbitúricos, uso de fenitoína, uso de anti-psicóticos, uso de antidepressivos, uso de teofilina, uso de corticoesteróides sistêmicos, uso de pseudoefedrina, diabetes melito em uso de hipoglicemiante oral ou insulina; hipertensão não controlada.

Precauções - A pressão arterial deve ser monitorada como rotina em pessoas que recebem a bupropriona. É importante ressaltar que a associação de qualquer forma de TRN e bupropiona pode elevar a pressão arterial, portanto deve-se ter cuidado ${ }^{151}$. No entanto, quando a bupropiona é usada como antidepressivo, pessoas com pressão normal (entre 120 e 140 de sistólica ou entre 85-90 de diastólica) tendem a sofrer um aumento dos níveis de pressão ${ }^{152}$.

\section{Recomendação ${ }^{149,150}$}

A farmacoterapia pode ser utilizada como um apoio, em situações bem definidas, para alguns pacientes que desejam parar de fumar. A TRN (adesivo e goma de mascar)e a bupropiona, são considerados medicamentos de $1^{\mathrm{a}}$ linha, e devem ser utilizados preferencialmente. A nortriptilina e a clonidina são medicamentos de $2^{\mathrm{a}}$ linha, e só devem ser utilizados após insucesso das medicações de $1^{\mathrm{a}}$ linha.

Grau de recomendação: $B$. Nível de evidência: 2 .

\section{VIII - Tratamento Medicamentoso das Dislipidemias}

\section{A) Vastatinas ou estatinas ou inibidores da HMG-CoA redutase}

São os medicamentos de escolha para se reduzir o LDL-C em adultos (18\%-55\% em média) ${ }^{38}$. Sua ação ocorre por inibição da HMG-CoA redutase que é a enzima chave na síntese do colesterol, fato que leva à menor síntese de colesterol hepática, e ao aumento da expressão dos receptores da LDL na superfície do fígado ${ }^{153}$. Conseqüentemente, haverá menor síntese e remoção das VLDL e LDL pelo fígado. As vastatinas elevam também o HDL-C de 5\%$15 \%$ e reduzem os TG de 7\%-30\%, podendo assim, também ser utilizadas nas hipertrigliceridemias leves a moderadas. As vastatinas diminuem eventos isquêmicos coronarianos, necessidade de revascularização do miocárdio, mortalidade cardíaca e total e AVC (nos estudos de prevenção secun- dária) ${ }^{74-78,100,153}$. Consideramos que o benefício do uso das vastatinas é decorrente de um efeito de classe secundário à redução do LDL-C, embora, alguns mecanismos possam diferenciar os diversos fármacos ${ }^{101,153}$.

\section{Recomendação ${ }^{74-78,100,153,154}$}

Para o tratamento adequado devem ser atingidas as metas de LDL-C propostas, utilizando-se as doses necessárias das vastatinas (lovastatina $20 \mathrm{mg}-80 \mathrm{mg}$, sinvastatina $10 \mathrm{mg}-80 \mathrm{mg}$, pravastatina $20-\mathrm{mg} 40 \mathrm{mg}$, fluvastatina $10 \mathrm{mg}-80 \mathrm{mg}$, atorvastatina $10 \mathrm{mg}-80 \mathrm{mg}$, cerivastatina $\left.0,2 \mathrm{mg}-0,8 \mathrm{mg}^{\mathrm{NR}}\right)$. Uma vez estabelecido o tratamento este deverá ser seguido por tempo indeterminado. As vastatinas devem ser suspensas caso haja aumento das aminotransferases $>3$ vezes os valores normais, ou se houver dor muscular ou aumento da creatinoquinase $>10$ vezes o valor normal.

Grau de recomendação: A. Nível de evidência: 1.

\section{B) Resinas de troca}

As resinas de troca (colestiramina e colestipol) são fármacos não absorvíveis que diminuem a absorção de sais biliares e, conseqüentemente, do colesterol ${ }^{155}$. Em conseqüência, ocorre maior excreção fecal de ácidos biliares e a sua oferta ao fígado diminui. O catabolismo assim acelerado estimula a atividade enzimática na célula hepática, incluindo a da HMG-CoA redutase, e o conteúdo diminuído do colesterol intracelular aumenta a expressão de receptores BE, que apresentam elevada afinidade para as LDL circulantes. Verifica-se aumento da síntese hepática de colesterol e da atividade da enzima $7 \alpha$-hidroxilase, que regula a formação de ácidos biliares a partir do colesterol. A capacidade de aumentar o número de receptores in vivo depende da integridade genética, estando diminuída na hipercolesterolemia familiar heterozigótica e ausente na homozigótica. O efeito final é o resultado do balanço entre a aceleração da síntese do colesterol e de seu catabolismo (pelo bloqueio da via êntero-hepática de reabsorção de ácidos biliares e colesterol). No Brasil, em agosto de 2001, apenas a colestiramina está disponível. Em decorrência da maior aceleração dessa via metabólica, há maior síntese hepática de VLDL, o que explicaria o eventual aumento da trigliceridemia, habitualmente discreto. Pode ocorrer também maior síntese de apoproteína A1, levando a pequena elevação de HDL-colesterol. A colestiramina nas doses $16 \mathrm{~g}-24 \mathrm{~g} /$ dia reduz o LDL-C (15\%$30 \%$ ) e no estudo Lipid Research Clinics diminuiu o risco de infarto do miocárdio em $19 \%{ }^{156}$.

\section{Posologia e via de administração}

A colestiramina é apresentada em envelopes de $4 \mathrm{~g}$ na forma de grânulos. A posologia inicial é de um envelope ao dia, podendo atingir o máximo de quatro a seis envelopes diariamente (16g/dia a $24 \mathrm{~g} / \mathrm{dia}$ ); posologia acima de $16 \mathrm{~g} / \mathrm{dia}$ é dificilmente tolerada, principalmente em idosos. O paladar

NR Cerivastatina retirada do mercado pelo fabricante para avaliação de segurança 
não é agradável; para melhorá-lo, aconselha-se dissolver o conteúdo do envelope em suco de fruta e ingerir a solução junto às refeições, de modo fracionado. A apresentação na forma light pode melhorar sua tolerância, mas contém $16,8 \mathrm{mg}$ de fenilalamina por dose de $5 \mathrm{~g}$, o que restringe seu uso em portadores de fenilcetonúria.

Como para os demais hipolipemiantes, seu uso deve ser prolongado, pois, uma vez interrompido, restabelece-se o ciclo êntero-hepático, retornando a colesterolemia a valores anteriores ao tratamento.

Efeitos colaterais - Os principais efeitos colaterais da colestiramina relacionam-se ao aparelho digestivo, por interferir na motilidade intestinal: obstipação, empachamento, náuseas e meteorismo, além de exacerbação de hemorróidas preexistentes. Raramente, pode ocorrer obstrução intestinal e acidose hiperclorêmica em idosos e crianças, respectivamente. Diminui eventualmente a absorção de vitaminas lipossolúveis (A, D, K) e de ácido fólico. Suplementação das mesmas a crianças, ou eventualmente a adultos, é aconselhável. Com o uso prolongado, pode ocorrer hipoprotrombinemia conseqüente à deficiência de vitamina $\mathrm{K}$, prevenida ou revertida pela administração oral ou parenteral dessa vitamina. Entre os efeitos bioquímicos, citam-se discreto aumento dos triglicérides e eventual de fosfatase alcalina e transaminases. Seu uso deve ser evitado se houver hipertrigliceridemia. A colestiramina é indicada em casos de hipercolesterolemia discreta ou moderada, conseqüente a causas ambientais ou genéticas (caráter heterozigótico). Não atua na hipercolesterolemia familiar homozigótica devido à impossibilidade de expressão de receptores B-E. Pode ser administrada a pacientes de qualquer idade, ressalvando que os idosos a toleram com maior dificuldade devido aos efeitos colaterais. Entretanto, é a única droga permitida para crianças e adolescentes que apresentam hipercolesterolemia resistente às medidas de restrição alimentar. É fármaco de escolha em crianças e como adjuvante às vastatinas. Não deve ser usada na hipertrigliceridemia.

\section{Recomendação ${ }^{22,156}$}

A colestiramina deve ser usada como adjuvante às vastatinas no tratamento das hipercolesterolemias graves, é droga de primeira escolha em crianças em mulheres no período reprodutivo, e em pacientes que não toleraram as vastatinas.

\section{Grau de recomendação: A. Nível de evidência: 2.}

\section{C) Fibratos}

São fármacos derivados do ácido fíbrico, indicados no tratamento da hipertrigliceridemia endógena - aumento correspondente de VLDL plasmáticas - sempre que houver falha da intervenção dietética específica. Além do clofibrato, droga inicialmente introduzida a partir de 1962, fazem parte deste grupo: bezafibrato, fenofibrato, genfibrosila, etofibrato e ciprofibrato, todos em uso no Brasil.

Seu mecanismo de ação é complexo e não totalmente esclarecido. Admite-se que ${ }^{157,158}$ :

a) reduzem a síntese hepática das VLDL, em decor- rência do menor fluxo de ácidos graxos livres para o fígado;

b) estimulam a atividade da enzima lipase das lipoproteínas;

c) aumentam a excreção de colesterol hepático pelas vias biliares;

d) aumentam a afinidade dos receptores B/E pelas LDL;

e) provocam a redistribuição das subfrações de LDL, diminuindo a concentração relativa das LDL pequenas e densas (mais aterogênicas);

f) reduzem a lipemia pós-prandial;

g) tornamas LDL, in vitro, menos suscetíveis à oxidação;

h) podem diminuir os níveis circulantes de Lp (a) por mecanismo ainda não esclarecido;

i) estudos experimentais mostraram possível ação inibidora da enzima HMG-Coa redutase, interferindo deste modo na cascata de síntese do colesterol hepático.

Pesquisas recentes têm vinculado os $\operatorname{PPAR}(\mathrm{s})$ peroxisome proliferator activated receptors- à ação hipolipemiante dos fibratos. Os PPAR(s) são fatores de transcrição intranucleares e sua subclasse alfa, quando ativada, inibe a transcrição da apolipoproteína C III (que por sua vez se contrapõe à ação da lipase das lipoproteínas), aumenta a produção da lipase das lipoproteínas e estimula a transcrição de apo AI e apo AII, o que contribui para elevar o nível circulante de $\mathrm{HDL}^{159}$.

Apresentam alto grau de ligação à albumina, são metabolizados no citocromo P450 (CYP) 3A4 e interagem com as drogas que utilizam a mesma via metabólica. São administrados por via oral e absorvidos pelo trato gastrintestinal; a excreção é feita quase totalmente por via renal, após conjugação com o ácido glicurônico.

Os fibratos são indicados sempre que os níveis de trigliceridemia não atingirem os valores ideais após restrição dietética devidamente dirigida e controlada. Entretanto, deve-se estar atento para os casos de quilomicronemia (quilomícrons - ou triglicérides exógenos - presentes em amostras colhidas após jejum de 12h) nos quais esses medicamentos não têm qualquer efeito.

Quando a trigliceridemia endógena for muito elevada $(>500 \mathrm{mg} / \mathrm{dL})$, o que acarreta maior risco de pancreatite aguda ou de trombose, deve-se iniciar a terapêutica farmacológica concomitante à restrição alimentar. Ao se considerar os fenotipos lipoprotéicos, a indicação preponderante é o tipo IV, mas podem ser empregados também no fenotipos IIb, III (muito raro) e IV, que têm em comum a presença de VLDL em excesso. A redução da trigliceridemia, com doses habituais de fibratos, situa-se em torno de $30 \%$, tomandose o cuidado de manter dieta adequada. A redução relativa será tanto maior quanto mais alto for o nível basal de triglicérides, podendo alcançar até $60 \%$. Paralelamente ocorre aumento da fração HDL-C, em média de $10 \%$ em relação ao valor basal, mas este aumento pode chegar eventualmente até cerca de $30 \%$. Os fibratos podem também, nas doses habituais (clofibrato 1000-2000mg/dia, genfibrosila 600mg$1200 \mathrm{mg}$, bezafibrato $200 \mathrm{mg}-600 \mathrm{mg} /$ dia liberação simples, li- 
beração prolongada $400 \mathrm{mg} / \mathrm{dia}$, etofibrato $500 \mathrm{mg} / \mathrm{dia}$, fenofibrato $200 \mathrm{mg} / \mathrm{dia}$ (micronisado)-simples $250 \mathrm{mg} / \mathrm{dia}$, ciprofibrato $100 \mathrm{mg} / \mathrm{dia}$ ) diminuir a fração LDL-C em percentuais variáveis segundo a droga utilizada: genfibrosila - 10\%; bezafibrato - $15 \%$; ciprofibrato de - $24 \%$ a - $35 \%$; fenofibrato $28 \%$. Assim eles podem ser indicados quando houver intolerância às vastatinas. Trabalhos ainda escassos mostraram redução da $L p$ (a) após uso de bezafibrato (-26\% a - 39\%) e de genfibrosila $(-25 \%)^{160}$.

Além de seu efeito sobre as lipoproteínas, os fibratos podem interferir beneficamente no mecanismo da hemostasia ${ }^{160}$ e no metabolismo dos carboidratos. Estes efeitos não são homogêneos e podem variar de acordo com a droga. Assim, têm sido observados os seguintes dados, alguns deles ainda controversos: a) diminuição da viscosidade sangüínea, agregação plaquetária, do fibrinogênio, fator VII e PAI - 1; b) melhora da tolerância à glicose e do controle da glicemia em diabéticos não insulino-dependentes.

Embora infreqüentes, o uso de fibratos pode desencadear efeitos adversos ${ }^{157}$ : distúrbios gastrintestinais, mialgia, astenia, litíase biliar (mais comum com clofibrato), diminuição de libido, erupção cutânea, prurido, cefaléia, perturbação do sono. Ocorrem em 5\% a 10\% dos casos tratados, são geralmente bem tolerados e desaparecem com a interrupção do tratamento. Raramente, observa-se aumento de enzimas hepáticas e/ou CPK, também de forma reversível. Recomenda-se cautela nas seguintes condições clínicas: a) portadores de doença biliar; b) uso concomitante de anticoagulante oral, cuja posologia deve ser ajustada (eventualmente diminuída); c) pacientes com função renal diminuída e/ou proteinúria podem apresentar piora pelo uso desses hipolipemiantes; d) associação com vastatinas (a associação da genfibrosila com vastatinas é proscrita).

No estudo de Helsinki ${ }^{68}$ a genfibrosila diminuiu os eventos cardiovasculares de homens hipercolesterolêmicos em $19 \%$. No estudo VA-HIT ${ }^{161}$ esse mesmo fármaco diminuiu em $22 \%$ o risco de eventos coronarianos em homens comLDL-C < 140mg/dL (média 111mg/dL), HDL-C < 40 (média $32 \mathrm{mg} / \mathrm{dL}$ ) e TG $<300 \mathrm{mg} / \mathrm{dL}$ (média $160 \mathrm{mg} / \mathrm{dL}$ ). Nesse estudo mais de $70 \%$ dos indivíduos apresentavam resistência à insulina e $25 \%$ eram diabéticos tipo II. Os efeitos foram atribuídos ao aumento do HDL-C. Dessa forma, os fibratos podem ser úteis na prevenção primária e secundária em indivíduos com as características descritas.

\section{Recomendação ${ }^{22,38,68,161}$}

São indicados no tratamento da hipertrigliceridemia endógena quando houver falha das MEV ou quando esta for muito elevada $(>500 \mathrm{mg} / \mathrm{dL})$. Têm papel na prevenção da aterosclerose clínica em indivíduos com as características dos estudos de Helsinki e VA-HIT.

Grau de recomendação: A. Nível de evidência: 2.

\section{D) Ácidonicotínico}

O ácido nicotínico diminuí o LDL-C de 5\%-25\%, aumenta oHDL-C 15\%-35\% e diminuí os TG 20\%-50\% ${ }^{38}$. Nos hepatócitos, o ácido nicotínico reduz a mobilização intra- celular de ácidos graxos, reduzindo por conseqüência a síntese e o acoplamento dos triglicérides à apo B-100 ${ }^{162}$. Como resultado, as lipoproteínas com apo B-100, VLDLe LDL, não constituídas adequadamente, são degradadas antes de sua liberação para o plasma. Em outras palavras, o ácido nicotínico aumenta a degradação intracelular hepática das lipoproteínas VLDL e LDL, reduzindo assim a concentração plasmática do LDL-C e VLDL-C. Naturalmente, este mesmo efeito contribui para a redução dos níveis plasmáticos de triglicérides. Atualmente, o ácido nicotínico é considerado como a droga que possui o mais intenso efeito de elevar o HDL-C, podendo atingir uma elevação de $48 \%$ em associação com fibratos ${ }^{163}$.

Posologia - Na forma tradicional, utiliza-se a dose de $2 \mathrm{~g}$ a $6 \mathrm{~g} /$ dia ajustadas conforme o efeito ou a tolerância. A limitação ao uso do ácido nicotínico são freqüentes efeitos colaterais que são rubor facial, hiperglicemia, hiperuricemia e alterações do trânsito intestinal. No Brasil está disponível o acipimox, derivado do ácido nicotínico que pode ser rutilizado nas doses de $250 \mathrm{mg}-750 \mathrm{mg} /$ dia. O ácido nicotínico deve ser utilizado com cuidado em diabéticos, pois pode piorar o controle glicêmico. No estudo de prevenção secundária Coronary Drug Project, houve diminuição de $27 \%$ nos eventos coronarianos ${ }^{73}$.

\section{Recomendação ${ }^{22,38,73}$}

O ácido nicotínico pode ser utilizado como alternativa aos fibratos e vastatinas ou em associação com esses fármacos em portadores de hipercolesterolemia, hipertrigliceridemia ou dislipidemia mista.

\section{Grau de recomendação: $B$. Nível de evidência: 2.}

\section{E) Ômega-3}

Os ácidos graxos ômega-3 (EPA e DHA) reduzem os triglicérides por diminuir a produção de VLDL no fígado ${ }^{111}$. Os ômega-3 também apresentam propriedades antitrombóticas ${ }^{164} \mathrm{e}$, possivelmente, antiarrítmicas. A dose mínima recomendada é de 4g/dia. O estudo GISSI Prevenzzione demonstrou que a suplementação de $1 \mathrm{~g} / \mathrm{dia}$ de ômega-3 reduziu em $10 \%$ os eventos cardiovasculares (morte, infarto do miocárdio, acidente vascular cerebral) em portadores de doença arterial coronariana ${ }^{129}$. Entretanto, o papel da suplementação farmacológica desses ácidos na prevenção da aterosclerose clínica ainda não está totalmente estabelecido.

\section{Recomendação ${ }^{111}$}

Os ácidos graxos ômega-3 (EPA e DHA) podem ser utilizados como adjuvantes aos fibratos na terapia das hipertrigliceridemias ou em substituição a esses em pacientes intolerantes.

Grau de recomendação: B. Nível de evidência: 2 .

\section{F) Probucol}

O probucol é um potente agente anti-oxidante que reduz oLDL-C e oHDL-C em cerca de $10 \%$ e 15-20\% respectivamente ${ }^{21}$. Atualmente, devido ao fato de diminuir o HDLCele não é mais utilizado como hipolipemiante. 


\section{G) Orlistat}

O orlistat ou tetrahidrolipstatin é um derivado hidrogenado do lipstantin, um intenso inibidor das lipases, naturalmente produzido pelo Streptomyces toxytricini ${ }^{165}$. Com uma absorção gastrintestinal desprezível, o orlistat atua exclusivamente na luz intestinal ligando-se covalentemente aos sítios catalíticos das lipases gástrica e pancreática, o que é confirmado com a observação clínica de seu efeito residual prolongado. Com a inibição da lípase, a lipólise dos triglicérides dietéticos é substancialmente reduzida e, como consequiência, cerca de 30\% dos triglicérides ingeridos são excretados inalterados nas fezes. Nos indivíduos com obesidade ou sobrepeso, a alteração lipídica esperada é composta de triglicérides elevados, HDL-C baixo e aumento da proporção de partículas de LDL com o fenótipo tipo B ou simplesmente LDL pequena e densa, o que passou a ser chamado de tríade lipídica. Como não é esperado um aumento acentuado do LDL-C nesses indivíduos, também não se espera uma redução expressiva nos níveis de LDL-C após tratamento da obesidade. No entanto, nestes estudos clínicos com orlistat, observou-se uma redução expressiva do LDL-C, além dos esperados efeitos sobre a tríade lipídica. Dessa forma, o orlistat passou a ser também considerado em suas ações hipolipemiantes. A dose recomendada de orlistat é de $360 \mathrm{mg} /$ dia dividida em três tomadas. A despeito dos seus comprovados efeitos sobre importantes fatores de risco, ainda não existem estudos com objetivos clínicos relacionados à manifestação da aterosclerose e, portanto, ainda não se conhece definitivamente o papel do uso do orlistat na prevenção da aterosclerose.

\section{H) Associação entremedicamentos e com produtos alimen- tares: quando usar?}

A associação de dois ou mais medicamentos, com mecanismos de ação diferentes, é justificada nas seguintes situações ${ }^{55}$ :

1) Quando, com apenas um produto, não se consegue a adequação dos valores lipídicos. Por exemplo, um produto que tem ação principal sobre o colesterol, não possibilita a obtenção de valores desejáveis de triglicérides. Assim, a associação de outro medicamento, agora com ação preferencial sobre os triglicérides pode trazer os dados do perfil lipídico para odesejável.Exemplo: associação de uma vastatina comum fibrato ou com o ácido nicotínico ${ }^{166}$. Outra possibilidade é no tratamento da dislipidemia mista, ou da hipertrigliceridemia, quando o emprego inicial de um fibrato (recomendado, em geral, quando os níveis de triglicérides excedem os $400 \mathrm{mg} / \mathrm{dl}$ ) possibilita a adequação dos níveis de triglicérides, mas não produz controle adequado do colesterol e/ou doLDL-C, ou até sua elevação, estando indicada a associação, num segundo tempo, de medicamento com ação preferencial sobre oLDL-C, como uma vastatina ou a colestiramina.

2) Quando, apesar da utilização de doses altas de um medicamento, não se obtém o valor desejável para um componente do perfil lipídico, pode ser mais interessante a associação de medicamentos com ações diferentes e complementares, do que aumentar mais ainda a dose da primeira medicação. Por exemplo, a associação entre uma vastatina com a colestiramina possibilita reduções bastante significativas do LDL-C. Outra possibilidade é a associação da colestiramina ou vastatina com um fibrato ou com o ácido nicotínico para redução do LDL-C. O emprego de três medicamentos, como vastatina, colestiramina e ácido nicotínico ou fibrato pode, eventualmente, ser necessária. A associação entre um fibrato e o ácido nicotínico ou seu derivado, o acipimox pode ter a ação individual de cada um desses medicamentos potencializada para diminuição da trigliceridemia. Nesta última situação, eventualmente, pode ser adicionado também o óleo de peixe (ômega-3).

3) Os efeitos colaterais dos medicamentos que influem sobre o perfil lipídico costumam ser dose dependentes. Assim, quando, para controle do valor lipídico, está sendo necessária a utilização de dose alta de um único medicamento, pode ser mais interessante a associação, o que propicia, em geral, maior redução com menor chance de efeitos colaterais.

4) $O$ custo da associação de medicamentos pode ser mais baixo do que o emprego de apenas um produto em doses mais altas.

5) As resinas, como a colestiramina, tipicamente, aumentam a secreção de VLDL, manifestada com aumento dos triglicérides. Quando os valores dos triglicérides já são elevados, isso pode impossibilitar, caso necessário, o emprego da colestiramina como redutor do colesterol. A adição de um fibrato, niacina (ou acipimox) ou do óleo de peixe, por diminuir os triglicérides, pode permitir o emprego da resina.

Outra possibilidade é a associação do emprego de um ou mais medicamentos com produtos alimentares ${ }^{167}$. Como exemplo, cita-se a utilização de uma vastatina com uma margarina adicionada de fitosteróis, que pode ser mais eficaz em reduzir o LDL-C do que o emprego de doses mais altas da vastatina. Assim, quando é dobrada a dose de uma vastatina, o efeito adicional de redução do LDL-C é de apenas $5 \%$ a $7 \%$, enquanto a associação com a margarina pode produzir, por possuir mecanismo de ação diferente e adicional, diminuições do LDL-colesterol de $10 \%$ a $15 \%$.

\section{Vantagens e desvantagens}

Além de o custo poder ser maior, quando são necessárias mais de duas medicações em associação, a possibilidade de interações medicamentosas não deve ser desprezada. É o caso do uso concomitante de uma vastatina com a colestiramina ou com a niacina, que pode ter, pela associação, maior propensão para a miopatia. Esta possibilidade, entretanto, não contra-indica a associação, mas recomenda controle rigoroso da CPK e de sintomas, principalmente dores musculares em membros inferiores.

\section{Recomendação ${ }^{55,166}$}

A terapia medicamentosa combinada somente deve ser considerada após período adequado de correção alimentar e de uma única medicação ter-se mostrado insuficiente. Deve ser encarada passo a passo, adicionandose um medicamento de cada vez. O perfil lipídico e 
possíveis efeitos colaterais devem ser avaliados após 4 a 8 semanas da adição de cada medicamento. A associação de um terceiro fármaco só deve ser considerada após os efeitos dos dois, já em uso, terem sido medidos pelo menos duas vezes com intervalos não menores do que 4 a 6 semanas.

Grau de recomendação: $B$. Nível de evidência: 2.

\section{I - Interações medicamentosas \\ Vastatinas}

A principal característica das vastatinas relacionada ao potencial de interações medicamentosas é sua propriedade de solubilidade lipofílica ou hidrofílica. Atualmente, a única estatina hidrossolúvel em uso clínico, excretada primariamente pelos rins e que sofre metabolismo hepático de pequena intensidade, é a pravastatina ${ }^{168}$. As demais vastatinas disponíveis - lovastatina, sinvastatina, fluvastatina, atorvastatina e cerivastatina - são lipossolúveis e sofrem metabolismo hepático e entérico via sistema citocromo P450. Lovastatina e sinvastatina são metabolizadas extensamente pela isoenzima CYP 3A4/5; atorvastatina e cerivastatina são metabolizadas pela mesma via, porém em menor proporção. O metabolismo da fluvastatina processa-se principalmente pela via CYP 2C9/10 ${ }^{168}$.

Em conseqüência dessas vias metabólicas, lovastatina e sinvastatina e, em menor proporção, atorvastatina e cerivastatina, têm o potencial de interagir com diversos fármacos que são substratos ou inibidores da CYP 3A4/5, incluindo diltiazem e verapamil, antifúngicos orais (itraconazol, fluconazol e cetoconazol), e antibióticos macrolídeos (eritromicina, claritromicina, azitromicina) ${ }^{168}$. Fluvastatina pode interagir com substratos e inibidores da CYP 2C9/10, tais como amiodarona, antiinflamatórios não hormonais, fenitoína, varfarina, cisaprida, astemizol e terfenadina. Pravastatina é indutor fraco da CYP 3A4/5 e apresenta potencial mínimo de interação com outros fármacos ${ }^{168}$.

A elevação da creatinoquinase (CPK), acompanhada ou não de dores musculares, é pouco freqüente com as vastatinas isoladamente. Entretanto, a incidência de miopatia aumenta com o uso concomitante de fibratos $(5 \%)$ e de ácido nicotínico (3\%). A interação das vastatinas com os fármacos inibidores da CYP3A4/5 envolve risco aumentado de miopatia, inclusive rabdomiólise, relatada em diversos estudos ${ }^{168,169}$.Em pacientes submetidos a transplante de órgãos, tratados com ciclosporina, deve ser evitado o uso de lovastatina e sinvastatina, pelo risco potencial de rabdomiólise e insuficiência renal. Essas graves complicações são reversíveis após a supressão das vastatinas. $\mathrm{O}$ medicamento de escolha para o tratamento da hipercolesterolemia induzida pela ciclosporina é a pravastatina, cujo metabolismo pela CYP 3A4/5 é insignificante $^{170,171}$.

\section{Fibratos}

Os fibratos ligam-se avidamente às proteínas plasmáticas e podem deslocar fármacos como varfarina, fenitoína e sulfoniluréias de seus locais de ligação protéica. Em conseqüência, aumentam as concentrações da fração livre desses fármacos, cujas doses devem ser diminuídas, quando co-administradas com fibratos. A combinação de fibratos e resinas é segura, porém, com as vastatinas pode aumentar o risco de miopatia e rabdomiólise ${ }^{172}$.

\section{Ácidonicotínico}

O ácido nicotínico pode potencializar os efeitos dos anti-hipertensivos e exacerbar hipotensão ortostática. Em diabéticos e em pacientes suscetíveis, pode aumentar a glicemia (efeito dose-dependente), implicando ajuste da dose dos agentes antidiabéticos. A administração de qualquer fármaco hepatotóxico deve ser evitada em conjunto com o ácido nicotínico, que tem o potencial de causar lesão hepática. O álcool acentua os efeitos colaterais do ácido nicotínico, como rubor e prurido. Ácido nicotínico pode ser usado em associação com outros hipolipemiantes, quando necessário para atingir os níveis lipídicos desejados ${ }^{170,173}$.

\section{Resinas}

Colestiramina e colestipol podem alterar a absorção de diversos fármacos, pela formação de complexos com os mesmos. Exemplos clássicos são a digoxina, propranolol, varfarina, vitaminas lipossolúveis e corticostesóides. $\mathrm{Na}$ prática clínica, a administração de medicamentos a pacientes em uso de resinas deve ser feita com intervalo mínimo de $2 \mathrm{~h}$ antes e 4 h após ${ }^{170}$.

\section{Probucol}

Probucol pode prolongar o intervalo QT. Esse efeito é acentuado com a administração concomitante de diuréticos, devido a hipopotassemia, ou de antiarrítmicos das classes IA ou III, com o risco de precipitar torsade de pointes ${ }^{173}$.

\section{Ácidos graxos ômega-3}

Os efeitos antitrombogênicos (antiplaquetários) dos ácidos graxos ômega-3 -EPA e DHA - são mais significantes do ponto de vista clínico que os efeitos no perfil lipídico. Sua interação mais importante é com os antiplaquetários, pelo potencial de aumentar o risco hemorrágico ${ }^{174}$.

\section{J)-Fármacosadjuvantes para a prevenção daaterosclerose clínica}

São medicamentos que diminuem a morbimortalidade de indivíduos de alto risco e que devem ser prescritos na ausência de contra indicações.

\section{Ácido acetilsalicílico(AAS)}

O uso do AAS reduz o risco de eventos coronarianos em pacientes de prevenção secundária e de prevenção primária de alto risco. Entretanto, isso ocorre às custas de aumento significativo de sangramentos digestivos 108,130,175-176

\section{Recomendação}

O AAS nas doses $\geq 100 \mathrm{mg} /$ dia deve ser prescrito para indivíduos que se encontrem sob alto risco de eventos cardiovasculares (prevenção secundária, diabéticos ou risco 
absoluto de eventos coronarianos $\geq 20 \%$ em 10 anos) que não apresentem contra-indicação. Indivíduos hipertensos devem ter a pressão arterial controlada ${ }^{108,130,175-176}$.

\section{Grau de recomendação: A. Nível de evidência: 1.}

\section{Inibidores da enzima de conversão (IECA)}

O estudo HOPE ${ }^{178}$ (The Heart Outcomes Prevention Evaluation study) demonstrou que pacientes com doença arterial aterosclerótica importante, mais freqüentemente atingindo o território coronariano e independentemente da fase em que se encontravam, ou pacientes diabéticos com algum outro fator de risco adicional beneficiavam-se com o uso de ramipril $10 \mathrm{mg} /$ dia a longo prazo. Em cinco anos observou-se redução do risco relativo de óbito de $26 \%$ ( $<<0,001)$, infarto $20 \%(\mathrm{p}<0,001)$ e acidente vascular cerebral $32 \%$ ( $\mathrm{p}<0,001)$. Os benefícios se somaram ao uso de betabloqueadores risco relativo - RR, 0,77 ; (intervalo de confiança 95\% - 0,65 a 0,90), terapia hipolipemiante RR 0,75 (intervalo de confiança $95 \% 0,60 \mathrm{a} 0,93$ ) ou aspirina (RR 0,85 ; intervalo de confiança $95 \%(0,76 \mathrm{a} 0,96)$.

\section{Recomendação}

Os IECA devem ser prescritos para indivíduos em prevenção secundária, principalmente os que apresentem disfunção ventricular esquerda ou para diabéticos que apresentem algum outro FR associado ou nefropatia ${ }^{177-180}$.

Grau de recomendação: B. Nível de evidência: 1.

\section{Betabloqueadores}

Os betabloqueadores diminuem o risco de reinfarto e mortalidade em indivíduos que sofreram infarto do miocárdio, principalmente nos que apresentam disfunção ventricular esquerda ${ }^{181}$.

\section{Recomendações}

Os betabloqueadores devem ser prescritos para indivíduos que sofreram infarto agudo do miocárdio, principalmente os que apresentam disfunção ventricular esquerda ${ }^{181}$.

Grau de recomendação: $A . \quad$ Nível de evidência: 1.

\section{IX - Dislipidemias em grupos especiais}

\section{A) Doença renal}

Dislipidemiaéfreqüente em pacientes com vários tipos de doençarenal ${ }^{182}$.Estefatotem grandeimportânciaclínica pordois motivos: $1^{\circ}$ )por aumentar a prevalência de doenças cardiovasculares nesta população, particularmente doença coronariana obstrutiva, acidente vascularcerebral e arteriopatia periférica; $2^{\circ}$ ) por acelerar o curso de algumas doenças renais, favorecendo a evoluçãoparainsuficiência renal terminal.

\section{Recomendação}

É recomendável que todo indivíduo portador de nefropatia seja avaliado quanto à presença de alterações lipídicas ${ }^{182}$.

Grau de recomendação: $B$. Nível de evidência: 4 .
A avaliação inicial mínima deve incluir a determinação, em jejum, do perfil lipídico completo. É importante frisarque algumas doenças renais, particularmente nefropatia diabética, exercem grande influência sobre o grau e gravidade da dislipidemia. Outros fatores, como drogas imunossupressoras e o tipo de membrana utilizada em dialisadores podem também afetar os níveis de lípides na circulação. O tratamento da dislipidemia associada a nefropatia deve sempre incluir intervenção dietética, em geral associada a aumento da atividade física. No entanto, na maioria dos casos, tratamento medicamentoso é também necessário.

\section{Epidemiologia}

1) Síndrome nefrótico

Algum tipo de dislipidemia encontra-se presente em praticamente todos os portadores de síndrome nefrótico ${ }^{182-184}$. A prevalência de hipercolesterolemia e de aumento de LDLé de cerca de $90 \%$ em vários estudos; $\mathrm{HDL}<35 \mathrm{mg} / \mathrm{dL}$ ocorre em $60 \%$ dos casos; hipertrigliceridemia e $\mathrm{Lp}$ (a) $>30 \mathrm{mg} / \mathrm{dL} \mathrm{em}$ $60 \%$ dos pacientes. A intensidade das alterações lipídicas são diretamente proporcional ao grau de proteinúria e inversamente proporcional à taxa de albumina plasmática. Pacientes com síndrome nefrótico secundário a nefropatia diabética tendem a ter um perfil lipídico mais alterado.

\section{2) Insuficiência renal crônica não dialítica}

Em geral, uma prevalência menor de dislipidemia. Estima-se que hipercolesterolemia, redução do HDL, hipertrigliceridemia e elevação da Lp(a) ocorrem em 30 a 40\% dos pacientes ${ }^{185}$.

\section{3) Hemodiálise}

O perfil lipídico dos renais crônicos tende a mudar após o início da hemodiálise periódica ${ }^{186}$. Assim, enquanto que a prevalência de hipercolesterolemia e de elevação de LDL permanecem estáveis, próximos a $40 \%$, a prevalência de HDL reduzido aumenta para $50 \%$ a $60 \%$. Hipertrigliceridemia também tende a ser mais elevada que na insuficiência renal não dialítica. A freqüência de elevação de Lp(a)é semelhante à observada antes da instituição da diálise.

\section{4) Diálise peritonial}

A prevalência de dislipidemia em pacientes tratados por diálise peritoneal aproxima-se daquela observada na hemodiálise. No entanto, hipertrigliceridemia tende a ser mais freqüente e intensa, possivelmente devido à maior oferta calórica proporcionada pela solução de diálise peritoneal que contém glicose.

\section{5) Transplante renal}

A principal modificação do perfil lipídico de renais crônicos, ocorrida após o transplante renal, é a normalização dos níveis de HDL e de Lp(a) ${ }^{182,183}$. Por outro lado, tanto o colesterol total como a LDL permanecem elevados, e estas anormalidades são observadas em $70 \%$ dos pacientes. Hipertrigliceridemia tende a ser menos freqüente em comparação com hemodiálise e diálise peritoneal. 


\section{Dislipidemia e doença cardiovascular em doentes renais}

A prevalência de doenças cardiovasculares é elevada em portadores de nefropatia crônica e são a principal causa de mortalidade nesta população em seus vários estádios ${ }^{182,186}$.Em pacientes com síndrome nefrótico, os riscos relativos de morte coronariana e de infarto do miocárdio são, respectivamente, 2,8 e 5,5 vezes maior que na população controle. Em portadores de insuficiência renal não dialítica, o risco de infarto do miocárdio é 2,5 vezes maior. Nesses dois grupos, os níveis de colesterol, triglicérides e HDL (relação inversa) correlacionam-se com doença cardiovascular. Pacientes tratados por hemodiálise ou diálise peritoneal estão entre os renais crônicos com maior morbidade e mortalidade cardiovascular. Cerca de 50\% das mortes nessa população são atribuídas à morte súbita, acidente vascular cerebral, infarto do miocárdio e insuficiência cardíaca. Nesse grupo de renais crônicos, níveis reduzidos de HDL-C, hipertrigliceridemia e elevação da Lp(a) parecem se correlacionar melhor com eventos cardiovasculares que colesterol total e LDL-C. Em transplantados, colesterol total, LDL-C e níveis reduzidos de HDL-C são os melhores preditores de doença cardiovascular.

\section{Dislipidemia e progressão da doença renal ${ }^{187}$}

Vários estudos indicam que a velocidade de progressão da doença renal é acelerada pela dislipidemia em pacientes com ou sem síndrome nefrótica. Esta conclusão é baseada tanto em evidências clínicas como histopatológicas. Os melhores preditores de declínio da função renal foram os níveis de colesterol total, LDL-C e apolipoproteína B. Existem resultados conflitantes quanto à relação com polimorfismo apolipoproteína E (genótipo E2). Em transplantados renais, hipercolesterolemia parece acelerar a perda de enxertos em portadores de rejeição crônica.

\section{Recomendações para o tratamento ${ }^{187}$}

Além de atividade física e dieta, recomenda-se o uso de medicamentos para a maioria dos pacientes renais portadores de dislipidemia. As vastatinas são consideradas as drogas mais eficazes para promover a redução do LDL-C. Fibratos são recomendados para o controle da hipertrigliceridemia. A doses destes últimos medicamentos precisam ser ajustadas para o nível de função renal.

Grau de recomendação: $B$. Nível de evidência: 2.

Miosite e rabdomiólise podem ocorrer em pacientes renais tratados com fibratos. Medicamentos capazes de elevar os níveis do HDL-C são em geral pouco eficazes e ainda não foram avaliados em renais crônicos.

\section{B) SIDA e inibidores de protease}

Pacientes com SIDA (síndrome da imunodeficiência adquirida) apresentam aumento nos TG e redução do HDL$\mathrm{C}^{188}$. A dislipidemia é agravada pelos inibidores de protease (IP). Alguns autores sugerem que exista uma homologia entre o sitio catalítico da protease do HIV1 onde se liga o IP e regiões de duas proteínas envolvidas no metabolismo lipídico: CRABP-1 (cytoplasmic retinoic-acid binding protein type 1) e LRP (low density lipoprotein-receptor- related protein). De acordo com essa hipótese, os IP inibem a CRABP-1 e se ligam a LRP, resultando na hiperlipidemia. Ocupando o sítio da CRABP-1, os IPs inibem a ligação do ácido retinóico, anulando seu papel e com isto reduzindo a diferenciação e aumentando a apoptose de adipócitos periféricos. Esses fenômenos levam a hiperlipidemia por redução do armazenamento periférico e aumento da liberação de lípides na circulação.

\section{Recomendação ${ }^{188}$}

Os lípides devem ser dosados no início do acompanhamento. Para pacientes com valores iniciais nos limites desejáveis e sem terapia anti retroviral (TAR), a dosagem deve ser repetida a cada dois anos. Para pacientes com indicação de TAR, realizar dosagem antes do tratamento, um mês após o início e a cada três meses a partir daí. Na ausência de estudos específicos, optamos por adotar valores de referência recomendados por esta diretriz. Os fibratos e os ômega-3 podem ser utilizados nesses pacientes. As vastatinas podem modificar os níveis séricos e eficácia dos IP por compartilharem os mesmos sítios de metabolização hepática por isso devem ser usadas com cuidado ${ }^{188}$. Uma outra possibilidade é a toxicidade muscular desses fármacos. Deve se dar preferência a fibratos de $3^{\text {a }}$ geração (fenofibrato micronisado e ciprofibrato) devido a sua capacidade de reduzir o LDL-C além dos triglicérides. A associação com vastatinas pode ser realizada mas com cuidado.

Grau de recomendação: $B$. Nível de evidência: 4.

\section{C) Síndromes isquêmicas agudas (SIA)}

Após uma SIA ocorre diminuição do LDL-C, HDL-Ce, geralmente, há aumento dos triglicérides. Entretanto, o perfil lipídico até $24 \mathrm{~h}$ corresponde aos valores usuais dos pacientes (ver grupo de laboratório). Existem evidências clínico-epidemiológicas comprovando que o uso precoce das vastatinas normaliza os níveis séricos de LDL-C e estabiliza a função endotelial ${ }^{189}$. Alguns registros de pacientes com eventos coronarianos agudos também mostraram uma redução dos principais eventos cardiovasculares e, ainda, uma redução global de mortalidade no primeiro ano para os que fizeram uso de vastatina desde a alta hospitalar ${ }^{190,191}$.

O estudo MIRACL ${ }^{34}$ incluiu 3.086 pacientes com angina do peito instável ou infarto agudo do miocárdio não Q e níveis séricos de colesterol $<270 \mathrm{mg} / \mathrm{dL}$. O objetivo primário - a combinação de morte, infarto não fatal, reanimação pós parada cardíaca, piora da isquemia e necessidade de hospitalização por isquemia foi reduzida em $16 \%$ após quatro meses de tratamento com atorvastatina $80 \mathrm{mg} /$ dia ( $\mathrm{p}<0,05)$. O benefício foi decorrente da diminuição de $26 \%$ da isquemia grave, necessitando hospitalização ( $p<0,05)$. É de opinião desse grupo que embora não haja diminuição dos eventos coronarianos maiores (morte, reinfarto) com o uso precoce de vastatinas, o benefício dos estudos que avaliaram os pacientes a longo prazo (4S,CARE e LIPID) ${ }^{76-78}$ no mínimo será obtido mais precocemente. Existe evidência também de que o uso precoce das vastatinas aumenta a aderência ao tratamento ${ }^{192}$. 


\section{Recomendação}

Pacientes com SIA devem dosar o perfil lipídico, de preferência nas primeiras $24 \mathrm{~h}$ dos eventos e intervenção, tendo como meta um valor de LDL-Cinferior a $100 \mathrm{mg} / \mathrm{dL}$. As vastatinas estão indicadas para os indivíduos no IAM ou angina instável, se o LDL-C $\geq 130 \mathrm{mg} / \mathrm{dL}$. As doses preconizadas são aquelas para se atingir a meta de LDL-C. Para os pacientes com LDL-C $100-129 \mathrm{mg} / \mathrm{dL}$, o uso fica a critério do médico, lembrando que após $24 \mathrm{~h}$ do evento esses níveis correspondem a níveis mais baixos do que o usual. Se o LDL-Cé $<100 \mathrm{mg} / \mathrm{dL}$ não há indicação de tratamento farmacológico hipolipemiante nesse situação. O LDL-C deverá ser reavaliado dois meses após o evento agudo e seguidas as recomendações gerais para prevenção secundária.

Grau de recomendação: $B$. Nível de evidência: 2 .

\section{D) Idosos (>70 anos)}

Nessa faixa etária, deve ser dada especial atenção ao afastamento de causas secundárias de dislipidemias, principalmente hipotireoidismo, diabetes mellitus e IRC. Os estudos de prevenção secundária com vastatinas mostram alta eficácia nessa faixa etária ${ }^{193}$. Em prevenção secundária, nos estudos 4S (incluídos 1.021 pacientes com idades entre $65 \mathrm{e}$ 70 anos), CARE (incluídos 1.283 pacientes com mais de 65 anos) e LIPID (3.514 pacientes com idades entre 65 e 70 anos), foi demonstrada significativa redução de eventos clínicos e mortalidade com sinvastatina ou pravastatina. Baseado nesses estudos é necessário tratar entre 10 e 24 pacientes (NNT) para reduzir um evento clínico num período de cinco anos, ou seja, um número relativamente baixo de indivíduos deve ser tratado para se verificar benefício significativo. Recentes evidências demonstram que o tratamento com vastatinas pode ser benéfico na prevenção de acidentes vasculares cerebrais e preservação da função cognitiva ${ }^{194}$. Na prevenção primária, os dados disponíveis são ainda limitados, com benefício sugerido no estudo AFCAPS/TexCAPS ${ }^{75}$.

\section{Recomendação ${ }^{193}$}

Nessa faixa etária, deve ser dada especial atenção ao afastamento de causas secundárias de dislipidemias. Os estudos de prevenção secundária com vastatinas mostram alta eficácia nessa faixa etária logo devem ser seguidas as mesmas recomendações para indivíduos mais novos. $\mathrm{Na}$ prevenção primária os dados disponíveis ainda são limitados devendo os casos ser avaliados de forma individual.

Grau de recomendação: $B$. Nível de evidência: 2 .

\section{E) Mulheres no período climatérico pós-menopausal}

Prevenção primária - A TRH pode melhorar o perfil lipídico das mulheres após a menopausa (pode diminuir o LDL-C em até 20-25\%) e pode aumentar o HDL-C (em até $20 \%)^{22,195}$.É importante considerar que não se sabe se essas alterações possam ser benéficas do ponto de vista de redução de risco cardiovascular. Os efeitos sobre o perfil lipídico dependem do tipo, da via, dose e duração do uso do estrogênio/progestogênio. A via oral propicia aumento dos níveis séricos de TG, diferentemente da via transdérmica: por isso, pacientes com hipertrigliceridemia $(>400 \mathrm{mg} / \mathrm{dl})$ devem preferencialmente usar a via transdérmica. A maioria dos estudos observacionais revela que a TRH pode estar associada a uma menor morbimortalidade por doença cardiovascular ${ }^{195}$. Entretanto, resultados de estudos prospectivos e controlados como o Women's Health Initiave ou WISDOM ainda não estão disponíveis. Em pacientes usuárias de TRH por indicações ginecológicas (por exemplo: controle de sintomas vasomotores, osteoporose, etc), atualmente, não existe indicação cardiológica de suspensão da terapêutica ${ }^{196}$.

\section{Recomendação}

Não há indicação da TRH com a finalidade de prevenir eventos clínicos decorrentes da aterosclerose ${ }^{196}$. Em pacientes usuárias de TRH por indicações ginecológicas (por exemplo: controle de sintomas vasomotores, osteoporose), atualmente, não existe indicação cardiológica de suspensão da terapêutica. A utilização de vastatinas é eficaz em mulheres com HDL-C baixo ${ }^{75}$ eé o tratamento de escolha em mulheres sob risco.

\section{Grau de recomendação para a TRH: $C$. Nivel de evidência: 4.}

Prevenção secundária - Apesar da evidência de estudos observacionais ${ }^{195}$, não há evidência de estudos prospectivos controlados de que a TRH traga benefício na prevenção secundária da aterosclerose ${ }^{196,197}$. No momento, há evidências de que a TRH na prevenção secundária possa aumentar o risco de tromboembolismo e o risco cardiovascular das usuárias, no primeiro ano de uso ${ }^{197}$.

\section{Recomendação}

Não se recomenda o uso de terapia de reposição hormonal na prevenção secundária da aterosclerose ${ }^{196}$. As vastatinas diminuem a morbi-mortalidade em mulheres portadoras de aterosclerose e após a menopausa, sendo os medicamentos de escolha para a prevenção de eventos clínicos ${ }^{76-78}$.

Grau de recomendação para a TRH:D.

Nivel de evidência: 2.

\section{F) Gestação}

Mulheres dislipidêmicas em idade fértil e sem contracepção adequada devem seguir orientação dietética e, se necessário, utilizar a colestiramina. Os fibratos devem ser considerados em casos de hipertrigliceridemia muito grave $(\mathrm{TG}>1000 \mathrm{mg} / \mathrm{dL})^{38}$.

\section{G) Mulheres 20-45 anos e homens 20-35 anos}

Nessas faixas etárias a doença aterosclerótica é rara exceto para os portadores de síndromes genéticas, fumantes importantes ou diabéticos.

\section{Recomendação}

As MEV devem ser enfatizadas em adultos jovens com LDL $\geq 130$. Entretanto, deve se considerar terapia hipolipemiante para indivíduos com LDL-C entre 160mg/dL- 
$189 \mathrm{mg} / \mathrm{dL}$, principalmente em fumantes. Aqueles com LDLC >190mg/dL devem receber terapia hipolipemiante, como os adultos mais velhos ${ }^{38}$.

Grau de recomendação: $B$. Nível de evidência: 2.

\section{H) Crianças e adolescentes}

Os valores de referência para o perfil lipídico em crianças e adolescentes encontram-se na tabela XXVII:

\section{Recomendação}

Os lípides devem ser dosados em crianças com parentes de $1^{\circ}$ grau com aterosclerose precoce, parentes de $1^{\circ}$ grau com dislipidemias graves $(\mathrm{CT} \geq 300 \mathrm{mg} / \mathrm{dL}$ ou $\mathrm{TG}$ $\geq 400 \mathrm{mg} / \mathrm{dL}$ ); presença de pancreatite aguda, xantomatose, obesidade ou outros FR ${ }^{198}$.

\section{Grau de recomendação: $B$. Nível de evidência: 4 .}

Tratamento da dislipidemia em crianças e adolescentes

Dieta - Confirmada a dislipidemia, o tratamento dietético deverá ser iniciado após dois anos de idade, priorizando as necessidades energéticas e vitamínicas próprias da idade. Deve-se encorajar a ingestão de fibras e desestimular a de alimentos ricos em colesterol e gordura saturada.

Terapia farmacológica - Havendo refratariedade à dieta, o uso de drogas hipolipemiantes para crianças acima de 10 anos pode ser considerado, nas seguintes situações: dislipidemia familiar com LDL-C>190mg/dL; antecedentes familiares de doença aterosclerótica prematura; 2 ou mais FR com LDL-C>160mg/dL; na vigência de aterosclerose manifesta, com LDL-C>130mg/dL ${ }^{198}$.

A colestiramina é a droga recomendável, por não apresentar efeitos sistêmicos na dose de $2 \mathrm{mg}$ /dia com dose máxima de $8 \mathrm{mg} /$ dia. As vastatinas, devido à pequena experiência atual, podem ser usados em casos de HF grave (CT $>300 \mathrm{mg} / \mathrm{dL}$ ) e/ou aterosclerose manifesta, nos quais o uso das resinas foi insatisfatório. A quilomicronemia requer somente tratamento dietético.

Em situações excepcionais, considerações sobre outras formas de tratamento incluem a plasmaférese, LDL aférese, anastomose ileal parcial e transplante hepático.

\section{I) - Dislipidemias graves}

Para os portadores de formas graves de dislipidemia e que apresentam pequena ou mesmo nenhuma resposta a

\begin{tabular}{|lcccc|}
\hline \multicolumn{4}{|c|}{ Tabela XXVII - Valores de referência para os lípides entre 2 e } \\
$\mathbf{1 9}$ anos
\end{tabular}

modificações do estilo de vida associadas ao uso de hipolipemiantes em doses habituais, em centro de referência, podem ser tomadas as seguintes medidas:

1) Utilização de doses muito elevadas de hipolipemiantes, como, por exemplo, 80mg de atorvastatina ou sinvastatina para o tratamento da hipercolesterolemia familiar ${ }^{199,200 .}$ Esse tratamento exige monitorização laboratorial e seguimento clínico mais frequiente, essas doses têm sido empregadas em raríssimos casos.

2) Associação de medicamentos com diferentes mecanismos de ação. São possíveis as seguintes associações: a) para a hipercolesterolemia: vastatinas + resinas, vastatinas + acipimox, resinas + acipimox, vastatinas + resinas + acipimox; b) para a hipertrigliceridemia: fibratos + acipimox, fibratos + ômega-3, fibratos + acipimox + ômega-3; c) para as dislipidemias mistas: vastatinas + fibratos, vastatinas + acipimox. vastatinas + fibratos + acipimox.

A associação de medicamentos também exige a monitorização laboratorial e seguimento clínico mais freqüente, tendo em vista a possibilidade de efeitos indesejáveis. A associação permite a administração de menores doses a fim de diminuir os efeitos indesejáveis. Entretanto, em casos muito graves, doses não habituais podem ser administradas.

3) Medidas alternativas ${ }^{201}$ - Aféreses, anastomose ileal parcial, transplante de fígado e terapêutica genética.

A) Aféreses - São processos que permitem a filtração das lipoproteínas reduzindo acentuadamente seus níveis circulantes (LDL-C-70\%. VLDL-C-50\%, HDL-C-8\%), mas que devem ser executados a cada 7-15 dias em sessões com duração de 3h. Em nosso meio, considerando as dificuldades técnicas e o alto custo, a plasmaférese é indicada para a hipercolesterolemia familiar (heterozigótica grave ou homozigótica)e, excepcionalmente, para a quilomicronemia grave com risco de pancreatite.

B) Anastomose ileal parcial ${ }^{202}$ - Trata-se de procedimento cirúrgico, proposto por Buchwald, reversível: cerca de $200 \mathrm{~cm}$ ou 2/3 do intestino delgado na sua porção distal são excluídos em alça cega, sendo feita anastomose término-lateral do seguimento proximal na região da válvula ileocecal. Esse procedimento diminui significativamente a absorção de colesterol proveniente da alimentação e interfere no cicloêntero-hepático levando a reduções de CT (25\%) e de LDL-C (30 a 35\%). Como efeitos indesejáveis, citam-se a diarréia (desaparece com a administração de colestiramina), calculose renal e biliar, perda de peso e obstrução intestinal. Éindicada para o tratamento da hipercolesterolemia familiar heterozigótica grave, mantendo-se na evolução os hipolipemiantes.

C) Transplante hepático - É excepcionalmente indicado para a hipercolesterolemia familiar homozigótica ${ }^{203}$. Introduz no organismo células hepáticas com receptores funcionastes.

D) Terapia genética ${ }^{204}$ - Ainda experimental não tem indicação.

\section{J) Transplante cardíaco (TC)}

A presença de dislipidemia após TC está associada a maior incidência de doença vascular do enxerto. Por outro 


\begin{tabular}{|c|c|c|c|c|c|c|}
\hline $\begin{array}{l}\text { Fenótipo } \\
\text { Lipídico }\end{array}$ & $\begin{array}{l}\text { Alteração } \\
\text { Genética }\end{array}$ & $\begin{array}{c}\text { Genes } \\
\text { Associados }\end{array}$ & $\begin{array}{l}\text { Modo de } \\
\text { herança }\end{array}$ & $\begin{array}{c}\text { Requência } \\
\text { Populacional }\end{array}$ & $\begin{array}{c}\text { Características clínicas } \\
\text { marcantes }\end{array}$ & $\begin{array}{l}\text { Associação com } \\
\text { aterosclerose prematura }\end{array}$ \\
\hline $\begin{array}{l}\mathrm{Qm} \uparrow \uparrow \uparrow \\
(\mathrm{TG} \uparrow \uparrow \uparrow)\end{array}$ & $\begin{array}{c}\text { Hiper- } \\
\text { Quilomicronemia }\end{array}$ & $\begin{array}{l}\text { Apo CII } \downarrow \downarrow \\
\text { LLP } \downarrow \downarrow\end{array}$ & co-dominante\# & $1: 1000.000$ & $\begin{array}{c}\text { Pancreatite } \\
\text { xantomas eruptivos } \\
\text { lipemia retinal }\end{array}$ & + \\
\hline $\begin{array}{l}\text { VLDL } \uparrow \text { ou } \uparrow \uparrow \\
\text { (TG } \uparrow \text { ou } \uparrow \uparrow)\end{array}$ & $\begin{array}{l}\text { Hipertrigliceridemia } \\
\text { familiar }\end{array}$ & Vários & $\begin{array}{c}\text { Segregação } \\
\text { autossômica } \\
\text { dominante }\end{array}$ & $1: 300$ & - & - \\
\hline $\begin{array}{l}\text { VLDL } \uparrow \uparrow \mathrm{e} / \mathrm{ou} \\
\mathrm{LDL} \uparrow \uparrow \\
\text { (TG e/ou CT*) }\end{array}$ & $\begin{array}{l}\text { Hiperlipidemia } \\
\text { familiar } \\
\text { combinada }\end{array}$ & $\begin{array}{l}\text { Apo AI-CIII-AIV? } \\
\text { LLP e outros? }\end{array}$ & $\begin{array}{c}\text { Segregação } \\
\text { autossômica } \\
\text { dominante }\end{array}$ & 0,5 a $1: 100$ & - & H \\
\hline 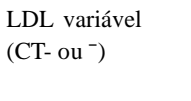 & - & Apo E2, E3, E4 & Co-dominante & $\begin{array}{c}\text { Até } 5 \% \text { da } \\
\text { variação do CT } \\
\text { na população }\end{array}$ & - & + quando for $\uparrow$ \\
\hline $\begin{array}{l}\mathrm{LDL} \uparrow \uparrow \uparrow \\
(\mathrm{CT} \uparrow \uparrow \uparrow)\end{array}$ & $\begin{array}{l}\text { Hipercolesterolemia } \\
\text { familiar- }\end{array}$ & $\begin{array}{l}\text { Apo B100 } \\
\text { receptor LDL }\end{array}$ & $\begin{array}{l}\text { Dominante } \\
\text { co-dominante }\end{array}$ & $\begin{array}{c}1: 500 \\
\text { (heterozigoto) } \\
1: 1.000 .000 \\
\text { (homozigoto) }\end{array}$ & $\begin{array}{c}\text { Xantomas tendinosos } \\
\text { xantelasma e arco } \\
\text { corneal precoces }\end{array}$ & +++ \\
\hline $\begin{array}{l}\text { IDL } \uparrow \uparrow \uparrow \\
(\mathrm{CT} \uparrow \uparrow \mathrm{e} T \mathrm{TG} \uparrow \uparrow)\end{array}$ & $\begin{array}{l}\text { Disbetalipoproteinemia } \\
\text { (tipo III) }\end{array}$ & $\begin{array}{c}\text { Apo E (E2) } \\
\text { outros defeitos } \\
\text { genéticos apo E }\end{array}$ & $\begin{array}{c}\text { Co-dominante } \\
\text { não mendeliana }\end{array}$ & $\begin{array}{c}\text { Frequência de } \\
\text { E2/E2 = 1:100 } \\
\text { Mas da lipemia } \\
1: 5000\end{array}$ & $\begin{array}{c}\text { Xantoma } \\
\text { tuberoeruptivo } \\
\text { tardio }\end{array}$ & + \\
\hline $\mathrm{HDL}^{-}$ & - & Apo A & Recessivo & & - & + ou? \\
\hline $\mathrm{HDL}^{-}$ & - & $\begin{array}{l}\text { LLP hepática } \uparrow \\
\text { HDL } \downarrow \\
\text { apo AI-CIII-AIV } \\
\text { LLP periférica } \downarrow\end{array}$ & $\begin{array}{c}\text { Recessivo } \\
\text { Polimorfismos }\end{array}$ & $?$ & - & \\
\hline $\mathrm{HDL}^{---}$; TG- & Tangier & $\mathrm{ABC} 1$ & co-dominante & muito raro & infiltração linfóide & + \\
\hline Lp (a) $\uparrow$ ou « & - & Apo (a) polimórfica & Co-dominante & $?$ & - & + ou? \\
\hline $\begin{array}{l}\mathrm{LDL} \uparrow \text { ou } \uparrow \uparrow \\
\mathrm{CT} \uparrow \text { ou } \uparrow \uparrow\end{array}$ & $\begin{array}{l}\text { Hipercolesterolemia } \\
\text { poligenética }\end{array}$ & $1 / 100$ ou $5 / 100 ?$ & Múltiplos genes & $?$ & - & + \\
\hline $\begin{array}{l}\text { VLDL } \uparrow \text { e } \mathrm{HDL}^{-} \\
\mathrm{LDL} \text { pequenas } \\
\mathrm{CT} \uparrow \uparrow \text { Nou } \uparrow ; \mathrm{TG} \uparrow\end{array}$ & $\begin{array}{l}\text { Resistência à insulina } \\
\text { (síndrome X) }\end{array}$ & $?$ & $?$ & $?$ & $\begin{array}{c}\text { Insulina } \uparrow ; \\
\text { intolerância à glicose; } \\
\text { HAS; obesidade } \\
\text { microalbuminúria, } \\
\text { fibrinogênio } \uparrow ; \text { PAI-1 } \uparrow \\
\text { microalbuminúria; } \\
\text { ácido úrico } \uparrow\end{array}$ & H \\
\hline
\end{tabular}

lado o uso de vastatinas pode reduzir a progressão da vasculopatia, independente de redução do colesterol e também parece reduzir a incidência de rejeição ${ }^{205}$.

\section{Recomendação}

O uso de pravastatina está indicado nos pacientes submetidos ao TC. Deve ser tomado cuidado com a toxicidade muscular devido a interação das vastatinas com a ciclosporina ${ }^{205}$.

Grau de recomendação: $B$. Nível de evidência: 2 .

\section{X-Genética e Dislipidemias}

Avanços no conhecimento do metabolismo lipídico têm permitido uma compreensão cada vez maior das influências genéticas na interação entre lipoproteínas e receptores, na expressão de muitas enzimas, de componentes estruturais dessas partículas e ainda da complexa interação genegene e gene-ambiente. Do outro lado, a biologia molecular tem incorporado novos procedimentos, tornando-se mais acessível à prática clínica, não apenas ao diagnóstico, mas também, em futuro próximo, como uma forma de terapia.

Neste complexo e vastíssimo campo da ciência priorizamos nosso enfoque nas principais dislipidemias associadas a forte influência genética.

Todo o espectro das doenças cardiovasculares envolve fatores genéticos, que podem contribuir de forma causal ou na sua patogênese. Diferenças nas seqüências de nucleotídeos entre dois indivíduos ou entre todos os indivíduos em uma população constitui variação genética. As diferenças nas sequiências de nucleotídeos são sempre devidas a mutações, sendo algumas vantajosas e outras prejudiciais. Algumas variações na seqüência de nucleotídeos são bastante comuns, sendo denominadas polimorfismos. De forma simples, os alelos específicos em um ou mais loci representam o genótipo para aqueles genes, sendo o fenótipo o efeito da ação do gene. Na tabela XXVIII estão assinaladas as principais dislipidemias de forte componente genético. 


\section{XI - Referências}

1. Cooper AD. Hepatic uptake of chylomicron remnants. J Lipid Res 1997; 38: 2173-92.

2. Goldberg IJ. Lipoprotein lipase and lipolysis: central roles in lipoprotein metabolism and atherogenesis. J Lipid Res 1996; 37: 693-707.

3. Tall AR. Plasma cholesteryl ester transfer protein. J Lipid Res 1993; 34: 1255-74.

4. Brown MS, Goldstein J. A receptor-mediated pathway for cholesterol homeostasis. Science 1986; 232: 34-7.

5. 5-Pease RJ, Leiper JM. Regulation of hepatic apolipoprotein-B-containing lipoprotein secretion. Curr Opin Lipidol 1996; 7: 132-8.

6. Fielding CJ, Fielding PE. Molecular physiology of reverse cholesterol transport. J Lipid Res 1995; 36: 211-28.

7. Austin MA, Breslow JL, Hennekens $\mathrm{CH}$, et al. Oow density lipoprotein subclass pattersns and risk of myocardial infarction. JAMA 1988; 260: 1971-21.

8. Packard CJ. Understanding coronary heart disease as a consequence of defective regulation of apolipoprotein B metabolism. Curr Op Lipidol 1999; 10: 237-44.

9. Colvin PL. Parks JS. Metabolism of high density lipoprotein subfractions. Curr Op Lipidol 1999; 10: 309-14.

10. Santos RD, Maranhão RC. Importância da lipoproteína (a) na aterosclerose. Rev Soc Cardiol do Estado de São Paulo 2000; 10: 723-7.

11. Klausen IC, Sjol A, Hansen OS, etal. Apolipoprotein (a) isoforms and coronary heart disease in men. A nested case-control study. Atherosclerosis 1997; 132: 77-84.

12. Brown MS, Goldstein JL. Lipoprotein metabolism in the macrophage: implications for cholesterol deposition in atherosclerosis. Ann Rev Biochem 1983; 52: 223-61.

13. Sobenin IA, Tertov VV, Orekhov AN. Atherogenic modified LDL in diabetes. Diabetes 1996; 45: S35-S9.

14. McIntyre N, Harry DS. Clinical disorders of palsma lipid and lipoprotein metabolism. In: McIntyre N, Harry DS, eds. Lipids and Lipoproteins in Clinical Practice. London: Wolfe Publishing, 1991: 93-139.

15. Goldstein JL, Hobbs HH, Brown MS. Familial hyperecholesterolemia. In: ScriverCR, Beaudet AL, Sly WS, Valle D, eds. The metabolic and Molecular Basis of Inherited Disease. New York: McGraw-Hill, 1995: 1981-2030.

16. Defesche JC, Pricker KL, Hayden MR, Van den Ende AE, Kastelein JJP. Familial defective apolipoprotein B100 is clinically indistinguishable from familial hypercholesterolemia. Arch Intern Med 1993; 153: 2349-56.

17. Davignon J, Gregg RE, Sing CF. Apolipoprotein E polymorphism and atherosclerosis. Arteriosclerosis 1988; 8: 1-21.

18. Ross R. Atherosclerosis: an inflammatory disease. NEngl J Med 1999; 340: 115.

19. Falk E, Shah PK, Fuster V. Coronary plaque disruption. Circulation 1995; 92: 657-71.

20. Zaman AG, Helft G, Worthley SG, Badimon JJ. The role of plaque rupture and thrombosis in coronary artery disease. Atherosclerosis 2000; 149: 251-66.

21. Higuchi ML, Sambiase N, Palomino S, et al. Detection of Mycoplasma pneumoniae and Chlamydia pneumoniae in ruptured atherosclerotic plaques. Braz $\mathrm{J}$ Med Biol Res 2000; 9: 1023-6.

22. Sociedade Brasileira de Cardiologia $-2^{\circ}$ Consenso Brasileiro Sobre Dislipidemias. Arq Bras Cardiol 1996; 67: 1-16.

23. Marcovina SM, Gaur VP, Albers JJ. Biological variability of cholesterol, triglyceride, low- and high-density lipoprotein cholesterol, lipoprotein (a), and apolipoproteins A-I and B. Clin Chem 1994; 40: 574-8.

24. Smith SJ, Cooper GR, Myers GL, Sampson EJ. Biological variability in concentrations of serum lipids: sources of variation among results from published studies and composite predicted values. Clin Chem 1993; 39: 1012-22.

25. Report from the Laboratory Standardization Panel of the National Cholesterol Education Program - Current status of Blood Cholesterol Measurement in clinical Laboratories in the United States. Clin Chem 1988; 34: 193-201.

26. Report from the Laboratory Standardization Panel of the National Cholesterol Education Program - Recommendations for Improving Cholesterol Measurement. NIH Publication Nº 93-2964, January 1993

27. Bachorik PS, Ross JW. National cholesterol education program recommendations for measurement of low-density lipoprotein cholesterol: executive summary. Clin Chem 1995; 41: 1414-20.

28. Stein EA, Myers GL. National cholesterol education program recommendations for measurement of triglyceride: executive summary. Clin Chem 1995; 41: 1421-26.

29. Warnick GR, Wood PD. National cholesterol education program recommendations for measurement of high-density lipoprotein cholesterol: executive summary. Clin Chem 1995; 41: 1427-33.

30. Pichet G, Lopes LM, Cotrim FLS, Scartezini M,Lima JCC, Martinez TLR. Lípides e lipoproteínas: interpretação dos resultados laboratoriais e metodologias. In: Martinez TLR (ed). Condutas Clínicas nas Dislipidemias. Belo Horizonte: Health, 1997: 85-115.

31. Cooper GR, Smith SJ, Meyers GL, Sampson EJ, MagidE. Estimating and minimizing effects of biologic sources of variation by relative range when measuring the mean of serum lipids and lipoproteins. Clin Chem 1994; 40: 227-32.
32. Young DS. Effects of Drugs on Clinical Laboratory Tests. Washington: AACC Press, 1990.

33. Nygard O, Nordrehaug JE, Fefsum H, et al. Plasma homocysteine levels and mortality in patients with coronary artery disease. N Engl J Med 1997; 337: 230-6.

34. Yarnell JW, Baker IA, Sweetnam PM, et al. Fibrinogen, viscosity, and white blood cell count are major risk factors for ischemic heart disease. The Caerphilly and Speedwell Collaborative Heart Disease Studies. Circulation 1991; 83: 836-44.

35. Thompson SG, Kienast J, Pyke SD, Haverkate F, van de Loo JC. Hemostatic factors and the risk of myocardial infarction or sudden death in patients with angina pectoris. European concerted action on thrombosis and disabilities Angina Pectoris Study Group. N Engl J Med 1995; 332: 635-41.

36. Danesh J, WhincupP, Walker M, Lennon L, et al. Low grade inflammation and coronary heart disease: prospective study and updated meta-analysis. Br Med J 2000; 321: 199-204.

37. Ridker PM. High-Sensitivity C-Reactive Protein: Potential Adjunct for Global Risk Assessment in the Primary Prevention of Cardiovascular Disease. Circulation 2001; 103: 1813-18.

38. Executive Summary of the Third Report of the National Cholesterol Education Program (NCEP) Expert Panel on Detection, Evaluation, and Treatment of High Blood Cholesterol in Adults (Adults Treatment Panel III). JAMA 2001; 285 : 2486-97.

39. Betteridge DJ. Diabetic dyslipidaemia. Diabetes Obes Metab 2000; Suppl 1: S31-6.

40. Thompson GR, Soutar AK, Spengel FA, et al. Defects of receptor mediated low density lipoprotein catabolism in homozygous familial hypercholesterolemia and hypothyroidism. Proc Natl Acad Sci USA 1981; 78: 2591-5.

41. Wiseman SA, Powell JT, Humphries SE, et al. The magnitude of the hypercholesterolemia of hypothyroidism is associated with variation in the low density lipoprotein receptor gene. J Clin Endocrinol Metab 1993; 77: 108-12.

42. Bruckert E, De Gennes JL, Dairou F, et al. Frequence des hypothyroidies dans une population de sujets hyperlipidemiques. La Presse Medicale 1993; 22: 57-60.

43. Wheeler DC, Bernard DB. Lipid abnormalities in the nephrotic syndrome: Causes, consequences, and treatment. Am J Kidney Dis 1994; 23: 331-46.

44. Joven J, Villabona C, Vilella E, et al. Abnormalities of lipoprotein metabolism in patients with the nephrotic syndrome. N Engl J Med 1990; 323: 579-84.

45. Yamaguchi A, Fukuhara Y, Yamamoto S, et al. Oncotic pressure regulates gene transcription of albumin and apolipoprotein B in cultured rat hepatoma cells. Am J Physiol 1992; 263: C397-00.

46. Demant T, Mathes C, Gutlich K, et al. A simultaneous study of the metabolism of apolipoprotein B and albumin in nephrotic patients. Kidney Int 1998; 54: 2064-80.

47. Vega GL, Toto RD, Grundy SM. Metabolism of low density lipoproteins in nephrotic dyslipidemia: Comparison of hypercholesterolemia alone and combined hyperlipidemia. Kidney Int 1995; 47: 579-86.

48. Warwick GL, Packard CJ, Demant T. Metabolism of apolipoprotein B-containing lipoproteins in subjects with nephrotic-range proteinuria. Kidney Int 1991; 40: 129-38.

49. Senti M, Romero R, Pedro-Botet J, et al. Lipoprotein abnormalities in hyperlipidemic and normolipidemic men on hemodialysis with chronic renal failure. Kidney Int 1992; 41: 1394-9.

50. Attman PO, Samuelsson O, Alaupovic P, et al. Lipoprotein metabolism and renal failure. Am J Kidney Dis 1993; 21: 573-92.

51. Crippin J, Lindor K, Jorgensen R, et al. Hypercholesterolemia and atherosclerosis in primary biliary cirrhosis: What is the risk? Hepatology 1992; 15: 858-62.

52. Rosenson RS, Baker AL, Chow M, et al. Hyperviscosity syndrome in a hypercholesterolemic patient with primary biliary cirrhosis. Gastroenterology 1990 98: $1351-7$.

53. Hubert HB, Feinleib M, McNamara PM, et al. Obesity as an independent risk factor for cardiovascular disease: A 26-year follow-up of participants in the Framingham Heart. Circulation 1983; 67: 968-77.

54. Stankusheva T, Popova D, Krusteva A, Naumova R, Boiadzhieva P. Study of anorexia nervosa and bulimia nervosa. Vutr Boles 1988; 27: 102-6.

55. Knopp RH. Drug treatment of lipid disorders. N Eng J Med 1999; 341: 498-511.

56. Facchini FS, Hollenbeck CB, Jeppesen J, et al. Insulin resistance and cigarette smoking. Lancet 1992; 339: 1128-30.

57. The Bezafibrate Infarction Prevention Study Group. Lipids and lipoproteins in symptomatic coronary heart disease: Distribution, intercorrelation and significance for risk classification in 6700 men and 1500 women. Circulation 1992; 86: 839-48.

58. Stone NJ. Secondary causes of hyperlipidemia. MedClin North Am 1994; 78: 117-41.

59. Fredrickson DS, Levy RI, Lees RS. Fat transport in lipoproteins - an integrated approach to mechanisms and disorders. N Engl J Med 1967; 276: 32, 94, 148 , 215 e 273.

60. Guimarães AC,Lima M, MotaE, et al. The cholesterol level of a selected Brazilian salaried population. CVD Prevention 1998; 1: 306-17.

61. Rouquayrol MZ. Epidemiologia e Saúde. $4^{a}$ Edição. São Paulo: Medsi, 1994; 157-83 
62. RH Fletcher, SW Fletcher, EH Wagner. Epidemiologia clínica: elementos essenciais. $3^{\text {a }}$ edição. São Paulo: Artes Médicas 1996, 217-35.

63. Kannel WB. The Framingham study: Its 50 years legacy and future promise. J Atheroscler Thromb 2000; 6: 60-6.

64. The Multiple Risk Factor Intervention Trial Research Group. Mortality rates after 10,5 years for participants in the MRFIT. Findings related to a priori hypotheses of the trial. JAMA 1990; 263: 1795-801.

65. Schulte H, Cullen P, Assmann G. Obesity, mortality and cardiovascular disease in the Munster Heart Study (PROCAM) Atherosclerosis 1999; 144: 199-209.

66. Menotti A, Lanti M, Puddu PE, Kromhout D. Coronary heart disease incidence in northerm and southhern European populations: a reanalysis of the seven countries study for a European coronary risk chart. Heart 2000; 84: 238-44.

67. Lipid Research Clinic Program. The Lipid Research Clinic Coronary Primary Prevention trial results II. The relationship of reduction in incidence of coronary heart disease to cholesterol lowering. JAMA 1984; 251: 365-74.

68. Helsinki Heart Study: Primary prevention trial with gemfibrozil in midlle-aged men with dyslipidemia; safety of treatment, changes in risk factors, and incidence of coronary heart disease. N Engl J Med 1987; 317: 1237-45.

69. Malinka DJ, Baron JA. Cholesterol and coronary heart disease. The importance of patient-specific a thributable risc. Arch Intern Med 1988; 148: 2247-52.

70. Halme I, Hyermann I, Helgeland A, Leven P. The Oslo Study: diet and and smoking advice: additional results from a 5-years primary preventative trial in middle-aged men. Prev Med 1985; 14: 279-92.

71. Committee of Principal Investigators. A cooperative trial in the primary prevention of ischaemic heart disease using clofibrate. Br Heart J 1978; 40: 106918.

72. Derr AE, Jenderson KK, Schneider JC Jr, et al. Colestipol hydrochloride in hypercholesterolemic patients - effect on serum cholesterol and mortality. JChon Dis 1978; $31: 5-17$

73. Coronary Drug Project Research Group. Clofibrate and niacin in coronary heart disease. JAMA 1975; 231: 360-81.

74. Shepherd J, Cobbe SM, Ford I, et al. Prevention of coronary heart disease with pravastatin in men with hypercholesterolemia. NEngl J Med 1995; 333: 1301-07.

75. Downs JR, Clearfield M, Weis S, et al. Primary prevention of acute coronary events with lovastatin in men and women with average cholesterol levels Results of AFCAPS/TEXCAPS. JAMA 1998; 279: 1615-22.

76. Scandinavian Sinvastatin Survival Study Group. Randomized Trial of cholesterol lowering in 4444 patints with coronary heart disease: The Scandinavian Sinvastatin Survival Study (4S). Lancet 1994; 344: 1383-5.

77. SacksFM,PfefferMA, Moye LA, et al. The effect of pravastatin on coronary events after myocardial infarction in patients with average cholesterol level. N Engl J Med 1996; 335: 1001-09.

78. The Long-term Intervention with Pravastatin in Ischaemic Disease (LIPID) Study Group. N Engl J Med 1998; 339: 1349-57.

79. EUROASPIRE Study Group. A European Society of Cardiology survey on secondary prevention of coronary heart disease: principal results. Eur Heart J 1997; 18: 1569-82.

80. Sirtori CR, Calabresi L, Marchioli R, Rubins HB. Cardiovascular risk changes after lipid lowering medications: are they predictable? Atherosclerosis. 2000; 152: $1-8$.

81. Ministério da Saúde. Informações hospitalares do DataSus. http:Iwww.datasus.gov.br, acessado em 30/01/2001.

82. Lessa I, Mendonça GAS, Teixeira MTB. Noncommunicable chronic diseases in Brazil: from risk factors to social impact. Bol OficinaSanitPanam 1996; 120:389-413.

83. Wittels EH, Hay JW, Gotto AM Jr. Medical costs of coronary artery disease in the United States. Am J Cardiol 1990; 65: 432-40.

84. Lolio CA, Lotufo PA, Lira AC. Tendência da mortalidade por doenças isquêmica do coração nas capitais de regiões metropolitanas do Brasil, 1979-1989. Arq Bras Cardiol 1995; 64: 195-9.

85. Duncan BB, Schmidt MI, Polanczyk CA, Mengue SS. Altas taxas de mortalidade por doenças não transmissíveis em populações brasileiras. Rev Assoc Med Bras 1992; 38: 138-44

86. Jacobson TA, Schein JR, Williamson A, Ballantyne CM. Maximizing the costeffectiveness of lipid-lowering therapy. Arch Intern Med 1998; 158: 1977-89.

87. Pharoah PDP, Hollingworth W. Cost effectiveness of lowering cholesterol concentration with statins in patients with and without pre-existing coronary heart disease: life table method applied to health authority population. Br Med J 1996; 312: 1443-8.

88. Weinstein MC, Siegel JE, Gold MR, Kamlet MS, Russell LB. Recommendations of the panel on cost-effectiveness in health and medicine. JAMA 1996; 276 : 1253-8.

89. Russell LB, Gold MR, Siegel JE, Daniels N, Weinstein MC. The role of costeffectiveness analysis in health and medicine. JAMA 1996; 276: 1172-7.

90. Gold MR, Siegel JE, Russell LB, Weinstein MC. Cost-effectiveness in Health and Medicine. New York: Oxford Univerity Press, 1996.

91. Goldman L, Weinstein MC, Goldman PA, Williams LW. Cost-effectiveness of
HMG-CoA reductase inhibition for primary and secondary prevention of coronary heart disease. JAMA 1991; 265: 1145-51.

92. Hamilton VH, Racicot FE, Zowall H, Coupal L, Grover SA. The cost-effectiveness of HMG-CoA reductase inhibitors to prevent coronary heat disease. Estimating the benefits of increasing HDL-C. JAMA 1995; 273: 1032-8.

93. Pedersen TR, Kjekshus J, Berg K, for the Scandinavian Simvastatin Survival Study Group. Cholesterol lowering and the use of healthcare resources: results of the Scandinavian Simvastatin Survival Study. Circulation 1996; 93: 1796-802.

94. Ashraf T, Hay JW, Pitt B, et al. Cost-effectiveness of pravastatin in secondary prevention of coronary artery disease. Am J Cardiol 1996; 78: 409-14.

95. Prosser LA, Stinnett AA, Goldman PA, et al. Cost-effectiveness of cholesterollowering therapies according to selected patient characteristics. Ann Intern Med 2000; 132: 769-79.

96. Tsevat J, Kuntz KM, Orav J, Weinstein MC, Frank S, Goldman L. Costeffectiveness of pravastatin therapy for survivors of myocardial infarction wih average cholesterol levels. Am Heart J 2001; 141: 727-34.

97. Grundy SM, Balady GJ, Criqui MH, et al. Primary prevention of coronary heart disease: guidance from Framingham. Circulation 1998; 97: 1876-87.

98. Danesh J, Collins R, Peto R. Lipoprotein(a) and coronary heart disease. Metaanalysis of prospective studies. Circulation 2000; 102: 1082-5.

99. Castelli WP. Cholesterol and lipids in the risk of coronary artery disease. The Framingham Heart Study. Can J Cardiol 1988; 4A-5A.

100. Gould AL, Rossouw JE, Santanello NC, Heyse JF, Furberg CD. Cholesterol Reduction Yields Clinical Benefit: Impact of Statin Trials. Circulation 1998; 97 : 946-52.

101. Wilson PW, D'Agostino RB, Levy D, Kannel WB. Prediction of coronary heart disease using risk factor categories. Circulation 1998; 97: 1837-47.

102. D'Agostino RB, Grundy S, Sullivan LM, et al. Validation of the Framingham heart disease prediction scores: Results of a multiple ethnic groups investigation. JAMA 2001; 286: 180-7.

103. Recommendations of the Second Joint Task Force of the European and other Societies on Coronary Prevention. Prevention of coronary heart disease in clinical practice. Eur Heart J 1998; 19: 1434-503.

104. West of Scotland Coronary Prevention Study: identification of high-risk groups and comparison with other cardiovascular intervention trials. Lancet 1996; 348: 1339-42.

105. Haffner SM, Lehto S, Rönnemaa T, Pyörälä K, Laakso M. Mortality from coronary heart disease in subjects with type 2 diabetes and in non diabetic subjects with and without prior myocardial infarction. N Engl J Med 1998; 339: 229-34.

106. Goldstein JL, Brown MS. Familial hypercholesterolemia. In: Scriver B, Sly V, eds. The Metabolic Basis of Inherited Disease. $6^{\text {th }}$ ed. New York; McGraw Hill, 1989: $1215-50$.

107. Voors-Pette C, de Bruin TW. Excess coronary heart disease in Familial Combined Hyperlipidemia, in relation to genetic factors and central obesity. Atherosclerosis 2001: 157: 481-9.

108. Gross JL, Ferreira SG, Franco LJ, et al. Diagnóstico e classificação do diabetes melito e tratamento do diabetes melito tipo 2. Arq Bras Endocrinol Metabol 2000; 44(supl.1): 1-32.

109. National Heart, Lung, and Blood Institute/National Institutes of Diabetes and Digestive and Kidney Diseases. Clinical guidelines on the identification, evaluation and treatment of overweight and obesity in adults. The evidence report. Bethesda: National Institutes of Health, 1998: 1-228.

110. Han TS, van Leer EM, Seidell JC, Lean ME. Waist circumference action levels in the identification of cardiovascular risk factors: prevalence study in a random sample. Br Med J 1995; 311: 1401-05.

111. Krauss RM, Eckel RH, Howard B. AHA Dietary Guidelines: revision 2000: A statement for healthcare professionals from the Nutrition Committee of the American Heart Association. Circulation 2000; 102: 2284-99.

112. Beynen AC, Katan MB. Reproducibility of the variations between humans in response of serum cholesterol to cessation of egg consuption. Atherosclerosis 1985; $57:$ 19-31.

113. USDA - United States Department of Agriculture, Composition of Foods. Handbooks number 8-5 (1979), 8-10 (1983), 8-13 (1986) - adaptado.

114. Von Schacky C, Angerer P, Kothny W, et al. The effect of dietary omega-3 fatty acids coronary atherosclerosis: a randomized, double-blind, placebo-contolled trial. Ann Int Med 1999; 130: 554-62.

115. KromhoutD, Feskens EJ, Bowles $\mathrm{CH}$, et al. The protective effect of a small amount of fish on coronary heart mortality in an elderly population. Intl J Epidemiol 1995; 24: 340-5.

116. Lichtenstein AH, Ausman LM, Jalbert SM, et al. Effects of different forms of dietary hydrogenated fats on serum cholesterol levels. N Engl J Med 1999; 340 : 1933-40.

117. Neves MN. Os Elementos da dieta no tratamento da doença cardiovascular. Nutrição e doença cardiovascular. 1997; 4: 56.

118. Miettinen TA, Gylling H. Regulation of cholesterol metabolism by dietary plant sterols. Curr Opin Lipidol 1999; 10: 9-14. 
119. Anderson JW, et al. Meta-analysis of the effects of soy protein intake on serum lipids. N Engl J Med 1995; 333: 276-82.

120. Katan MB. Effects of cafestol and kahweol from coffee grounds on serun lipids and serun liver enzymes in humans. Am J Clin Nutr 1995; 61: 149-54.

121. Steinberg D. Is there a potential therapeutic role for vitamin $\mathrm{E}$ and other antioxidants in atherosclerosis? Curr Op Lipidol 2000; 11; 603-07.

122. Hertog MG, et al. Dietary antioxidants flavonoids and risk of coronary heart disease. Lancet 1993; 342: 1007-11.

123. da Luz PL, Laurindo FR. Radicais livres e antioxidantes em doenças cardiovasculares. Farmacol Terap Cardiovasc 1999; 31: 551-66.

124. Alpha-Tocopherol, Beta-Carotene Cancer Prevention Study Group. The effect of vitamin $E$ and beta-carotene on the incidence of lung cancer and other cancers in male smokers. N Engl J Med 1994; 330: 1029-35.

125. Omenn GS, Goodman GE, Thornquist MD, et al. Effects of a combination of beta carotene and vitamin A on lung cancer and cardiovascular disease. N Engl J Med 1996; 334: 1150-5.

126. Hennekens CH, Buring JE, Manson JE, et al. Lack of effect of long term supplementation with beta carotene on the incidence of malignant neoplasms and cardiovascular disease. N Engl J Med 1996; 334: 1145-9.

127. Stephens NG, Parsons A, Schofield PM, et al. Randomised controlled trial of vitamin $\mathrm{E}$ in patients with coronary disease: Cambridge Heart Antioxidant Study (CHAOS). Lancet 1996; 347: 781-6.

128. Yusuf S, Dagenais G, Pogue J, et al. Vitamin E supplementation and cardiovascular events in high-risk patients. Heart Outcomes Prevention Evaluation Study Investigators. N Engl J Med 2000; 342: 154-60.

129. GISSI-Prevenzione Investigators (Gruppo Italiano per lo Studio della Sopravvivenza nell' Infarto miocardico): Dietary supplementation with n-3 polyunsaturated fatty acids and vitamin $\mathrm{E}$ after myocardial infarction: results of the GISSI-Prevenzione trial. Lancet 1999; 354: 447-55.

130. Collaborative Group of the Primary Prevention Project (PPP). Low-dose aspirin and vitamin $\mathrm{E}$ in people at cardiovascular risk: a randomised trial in general practice. Lancet 2001; 357: 89-95.

131. Pearson TA. Alcohol and heart disease. Circulation. 1996; 94: 3023-5.

132. Rimm EB, Klatsky A, Grobbee D, et al. Review of moderate alcohol consumption and reduced risk of coronary heart disease: is the effect due to beer, wine or spirits? Br Med J 1996; 312: 731-6.

133. Gaziano JM, Hennekens CH, Godfried SL, et al. Type of alcoholic beverage and risk of myocardial infarction. Am J Cardiol 1999; 83: 52-7.

134. Pancharuniti N, Lewis CA, Sauberlich HE. Plasma homocysteine, folate and vitamin B12 concentration and risk for early-onset coronary artery disease. Am J Clin Nutr 1994; 59: 940-8.

135. Kannel WB, Belanger A, D'Agostino R, Israel I. Physical activity and physical demand on the job and risk of cardiovascular disease and death: the Framingham Study. Am Heart J 1986; 112: 820-5.

136. Ornish D, Scherwitz LW, Billings JH, et al. Intensive lifestyle changes for reversal of coronary heart disease. JAMA 1998; 280: 2001-7.

137. De Lorgeril M, Salen P, Martin J, Monjaud I, Delaye J, Mamelle N. Mediterranean diet, traditional risk factors, and the rate of cardiovascular complicatios after myocardial infarction. Circulation 1999; 99: 779-85.

138. Steffen-Batey L, Nichaman MZ, GoffCL, et al. Change in level of physical activity and risk of all-cause mortality of reinfarction. The Corpus Christi heart project. Circulation 2000; 102: 2004-9.

139. Hambrecht R, Nieubauer J, Marburger C, et al. Various intensities of leisure time physical activity in patients with coronary artery disease: effects on cardiorespiratory fitness and progression of coronary atherosclerotic lesions. J Am Coll Cardiol 1993; 22: 468-77.

140. Stefanick ML, et al.Effects of diet and exercise in men and posmenopausal women with low levels of HDL cholesterol and high levels of LDL cholesterol. N Engl J Med 1998; 339: 12-20.

141. Stubbe I, Hansson P, Gustafson A, Nilsson-Ehle P. Plasma Lipoproteins and lipolytic enzyme activities during endurance training in sedentary men: changes in high-density lipoprotein subfractions and composition. Metabolism 1983; 12: $1120-8$.

142. Kokkinos PF, Holland JC, Narayan P, Colleran JA, Dotson CO, Papademetriou V. Miles run per week and high-density lipoprotein cholesterol levels in healthy, middleaged men. A dose-response relationship. Arch Intern Med 1995; 155: 415-20.

143. Kokkinos PF, Fernhall B. Physical Activity and high density lipoprotein cholesterol levels: what is the relationship? Sports Med 1999; 28: 307-14.

144. Nicklas BJ, Katzel LI, Busby-Whitehead J, Goldberg AP. Increases in highdensity lipoprotein cholesterol with endurance exercise training are blunted in obese compared with lean men. Metabolism 1997; 46: 556-61.

145. Stefanick ML. Physical activity for preventing and treating obesity-related dyslipoproteinemias. Med Sci Sports Exerc 1999; 31(Suppl): S609-18.

146. Williams PT, Krauss RM, Vranizan KM, Wood PD. Changes in lipoprotein subfractions during diet-induced and exercise-induced weight loss in moderately overweight Men. Circulation 1990; 81: 1293-304
147. Couillard C, Després J-P, Lamarche B, et al. Effects of endurance exercise training on plasma HDL-cholesterol levels depend on levels of triglycerides. Evidence from men of the health, risk factors, exercise training and genetics (HERITAGE) family study. Arterioscler Thromb Vasc Biol 2001; 21: 1226-32.

148. Després JP, Lamarche B. Low-intensity endurance exercise training, plasma lipoproteins and risk of coronary Heart disease. J Intern Med 1994; 236: 7-22.

149. Documento de Consenso do Ministério da Saúde sobre a Abordagem e Tratamento do Fumante - Ministério da Saúde/Instituto Nacional do Câncer, 2001.

150. Fiore MC, Bailey WC, Cohen SJ, et al. Treating Tobacco Use and Dependence. Clinical Practice Guideline. US Department of Health and Human Services, Public Health Service, 2000.

151. Jorenby DE, Leischow SJ, Nides MA, et al. A controlled trial of sustained-release bupropion, a nicotine patch, or both for smoking cessation. N Engl J Med 1999; 340: 685-91.

152. Prochazka AV. New developments in smoking cessation. Chest 2000; 117 : 169S-175S.

153. Vaughan CJ, Murphy MB, Buckley BM. Statins do more than just lower cholesterol. Lancet 1996; 348: 1079-82.

154. Schwartz GG, Olsson AG, Ezakowitz MD, et al. Effects of atorvastatin on early recurrent ischemic events in acute coronary syndromes. The MIRACL study: a randomized controlled trial. JAMA 2001; 285: 1711-18.

155. Gianini SD, Forti N, Diament J. Hipolipemiantes I. Ação Predominante na Hipercolesterolemia. In: Batlouni M, Ramires JAF (ed). Farmacologia e Terapêutica Cardiovascular. São Paulo: Atheneu, 1999: 513-34.

156. The Lipid Research Clinics Coronary Primary Prevention Trial results. I. Reduction in incidence of coronary heart disease. JAMA 1984; 251: 351-64.

157. Diament J, Forti N, Giannini SD. Fibratos: semelhanças e diferenças. Rev Soc Cardiol Estado de São Paulo 1999; 1: 83-91.

158. Tikkanen MJ. Fibric acid derivatives. Curr Opin Lipidol 1992; 3: 29-33.

159. Auwerx J, Schoonjans K, Fruchart JC. Transcriptional control of triglyceride metabolism: fibrates and fatty acids change the expression of the LPL and apo C-III genes by activating the nuclear receptor PPAR. Atherosclerosis 1996: 124(suppl): S29-S37.

160. Dujovne CA. New lipid lowering drugs and new effects of old drugs. Curr Opin Lipidol 1997; 8: 362-68.

161. Rubins HB, Robins SJ, Collins D, et al. Gemfibrozil for the secondary prevention of coronary heart disease in men with low levels of high-density lipoprotein cholesterol. Veterans Affairs High-Density Lipoprotein Cholesterol Intervention Trial Study Group. N Engl J Med 1999; 341: 410-18.

162. Jin FY, Kamanna VS, Kashyap ML. Niacin accelerates intracellular apo B degradation by inhibiting triacylglycerol synthesis in human hepatoblastoma (HepG2) cells. Arterioscler Thromb Vasc Biol 1999; 19: 1051-9.

163. Sposito AC, Caramelli B, Mansur AP, Serrano CV, Ramires JAF. Effect of niacin and etofibrate association on subjects with coronary artery disease and serum high-density lipoprotein cholesterol <35mg/dl. Am J Cardiol 1999; 83: 98-100

164. Mori TA, Beilin LJ, Burke V, et al. Interactions between dietary fat, fish, and fish oils and their effects on platelet function in men at risk of cardiovascular disease. Arterioscler Thomb Vasc Biol 1997; 17: 279-86.

165. Ros E. Intestinal absorption of triglyceride and cholesterol: dietary and pharmacological inhibition to reduce cardiovascular risk. Atherosclerosis 2000; 151 357-79.

166. Fruchart JC, Duriez P. Potential role of drug combinations in the prevention of cardiovascular disease. Eur Heart J 2000; Suppl. 2: D-54-D-6.

167. Gylling H, Radhakrishnan R, Miettinen TA. Reduction of serum cholesterol in postmenopausal women with previous myocardial infarction and cholestero malabsorption induced by dietary sitostanol ester margarine: women and dietary sitostanol. Circulation 1997; 96: 4226-31.

168. Bottorff M. "Fire and forget?" Pharmacological considerations in coronary care. Atherosclerosis 1999; 147(suppl 1): S23-S30.

169. Tomlinson B, Lan IW. Combination therapy with cerivastatin and gemfibrozil causing rhabdomyolysis: is the interaction predictable? Am J Med 2001; 110: 669

170. Farmer JA, Gotto AM. Anti hyperlipidemic agents. Drug interactions of clinical significance. Drug Safety 1994; 11: 301-9.

171. Christians U, Jacobson W, Floren LC. Metabolism and drug interactions of HMG-CoA reductase inhibitors in transplant patients. Pharmacol Ther 1998 80: 1-34.

172. Bays HE, Dujovne CA. Drug interactions with lipid altering drugs. Drug Safety 1998; 19: 355-71.

173. Opie LH. Interactions with cardiovascular drugs. Curr Probl Cardiol 1993; 18: 529

174. Johnson MD, Newkirk G, White Jr. Clinically significant drug interactions. Postgrad Med 1999; 105: 193-222.

175. Meade TW, Brennan PJ. Determination of who may derive most benefit from aspirin in primary prevention: subgroup results from a randomised controlled trial. Br Med J 2000; 321: 13-17.

176. Hansson L, Zanchetti A, Carruthers G, et al. Effects of intensive blood-pressure lowering and low dose aspirin in patients with hypertension: principal results 
of the Hypertension Optimal Treatment (HOT) randomised trial. Lancet 1998; 351: 1755-62.

177. Heart Outcomes Prevention Evaluation (HOPE) Study Investigators. Effects of ramipril on cardiovascular and microvascular outcomes in people with Diabetes Melito: results of the HOPE study and MICRO-HOPE substudy. Lancet 2000; 355: 253-59.

178. Yusuf S, Sleight P, Pogue J. Effects of an angiotensin-converting-enzyme inhibitor, ramipril, on cardiovascular events in high-risk patients. The Heart Outcomes Prevention Evaluation Study Investigators N Engl J Med 2000; 342 : 145-53.

179. Pfeffer M., Braunwald E, Moye L, et al. Effect of captopril on mortality and morbidity in patients with left ventricular dysfunction after myocardial infarction. Results of the survival and ventricular enlargement trial. The SAVE Investigators. N Engl J Med 1992; 327: 669-77.

180. The SOLVD Investigattors. Effect of enalapril on mortality and the development of heart failure in asymptomatic patients with reduced left ventricular ejection fractions. N Engl J Med 1992; 327: 685-91.

181. Yusuf S, Peto R, Lewis J, et al. Beta blockade during and after myocardial infarction: an overview of the randomized trials. Prog Cardiovasc Dis 1985; 27: 335-71.

182. Kasiske BL. Hyperlipidemia in patients with chronic renal disease. Am J Kidney Dis 1998; 32(suppl 3): S142-S56.

183. Wissing KM, Abramowicz D, Broeders N, Vereerstraeten P. Hypercholesterolemia is associated with increased kidney graft loss caused by chronic rejection in male patients with previous acute rejection. Transplantation 2000; 70: 464-72.

184. De Lima JJG, Diament J, Gianini SD, Horta PE, Krieger EM, Pileggi F. Plasma lipid profile and coronary artery disease in Brazilian hemodialysis patients. Intern J Cardiol 1995; 48: 163-6.

185. De Lima JJG, Maranhão RC, Latrilha MCM, et al. Early elevation of Lipoprotein(a) levels in renal insufficiency. Renal Fail 1997; 19: 145-54.

186. Cheung AK, Sarnak MJ, Yan G, et al. Atherosclerotic vascular disease risks in chronic hemodialysis patients. Kidney Int 2000; 58: 353-62.

187. Yang WQ, Song NG, Ying SS, et al. Serum lipid concentrations correlate with the progression of chronic renal failure. Clin Lab Sci 1999; 12: 104-08.

188. Geletko SM, ZuWallack AR. Treatment of hyperlipidemia in HIV-infected patients. Am J Health Syst Pharm 2001; 58: 607-14.

189. Dupuis J, Tardif JC, Cernacek P, et al. Cholesterol Reduction Rapidly Improves Endothelial Function After Acute Coronary Syndromes: The RECIFE (Reduction of Cholesterol in Ischemia and Function of the Endothelium) Trial. Circulation 2000; 99: 3227-33.
190. Stenestrand U, Wallentin L, for the Swedish Registry of Cardiac Intensive Care (RIKS-HIA). Early statin treatment following acute myocardial infarction and 1-year survival. JAMA 2001; 285: 430-6.

191. Aronow HD, Topol EJ, Roe MT, et al. Effect of lipid-lowering therapy on early mortality after acute coronary syndromes: an observational study. Lancet 2001; 357: $1063-8$.

192. Feely J. The therapeutic gap - compliance with medication and guidelines Atherosclerosis 1999; 147(suppl. 2): S31-S7.

193. Carlsson CM, Carnes M, McBride PE, Stein JH. Managing dyslipidemia in older adults. J Am Geriatr Soc 1999; 47: 1458-65.

194. Jick H, Zornberg GH, Jick SS S, Drachman DA. Statins and the risk of dementia. Lancet 2000; 356: 1627-31.

195. Grady D, Rubin SM, Petitti DB, et al. Hormone replacement therapy to prevent disease and prolong life in postmenopausal women. Ann Intern Med 1992; 117: 1016-37.

196. Mosca L, Collins P, Herrington DM, et al. Hormone replacement therapy and cardiovascular disease: A Statement for Healthcare Professionals From the American Heart Association. Circulation 2001; 104: 499-503.

197. Hulley S, Grady D, Bush T, et al, for the Heart and Estrogen/progestin Replacement Study (HERS) Research Group. JAMA 1998; 280: 605-13.

198. American Academy of Pediatrics. National Cholesterol Education Program: Report of the Expert Panel on Blood Cholesterol Levels in Children and Adolescents. Pediatrics 1992; 89: S495-584.

199. Raal.FJ, Pilcher GL, Ilingworth R, et al. Expanded-dose simvastatin is effective in homozygous familial hypercholesterolemia. Atherosclerosis 1997: 135: 249-56.

200. Wierzbicki AS, Lumb PJ, Semra Y, Chik G, Christ ER, Crook MA. Atorvastatin compared with simvastatin-based therapies in the management of severe familial hyperlipidaemias. QJM. 1999; 92: 387-94.

201. Issa JS, Safi Jr. J. Dislipidemias graves: medidas alternativas. Rev Bras Med $1998 ; 55: 29-34$.

202. Buchwald H, Varco R, Matts JP, et al. Effects of partial ileal bypass surgery on mortality and morbidity from coronary heart disease in patients with hypecholesterolemia. N Engl J Med 1990; 323: 946-55.

203. Bilheimer DW, Goldstein JL, Grundy SM, et al. Liver transplantation to provide low density lipoprotein receptors and lower cholesterol in a children with homozygous familial hypercholesterolemia. N Engl J Med 1984; 311: 1658-64.

204. Grossman M, Rader DJ, Muller DWM, et al. A pilot study of ex-vivo gene therapy for homozygous familial hypercholesterolemia. Nat Med 1995 1: 1148-54.

205. Kobashigawa JA, Katznelson S, Laks H, et al. Effect of pravastatin on outcomes after cardiac transplantation. N Eng J Med 1995; 333: 621-5.

206. Lusis AJ. Atherosclerosis. Nature 2000; 407: 233-41. 